\title{
WestVirginiaUniversity
}

THE RESEARCH REPOSITORY @ WVU

Graduate Theses, Dissertations, and Problem Reports

2009

\section{Improvement of the physical and nutritional quality of pelleted feed}

Curran Kenji Gehring

West Virginia University

Follow this and additional works at: https://researchrepository.wvu.edu/etd

\section{Recommended Citation}

Gehring, Curran Kenji, "Improvement of the physical and nutritional quality of pelleted feed" (2009).

Graduate Theses, Dissertations, and Problem Reports. 2794.

https://researchrepository.wvu.edu/etd/2794

This Thesis is protected by copyright and/or related rights. It has been brought to you by the The Research Repository @ WVU with permission from the rights-holder(s). You are free to use this Thesis in any way that is permitted by the copyright and related rights legislation that applies to your use. For other uses you must obtain permission from the rights-holder(s) directly, unless additional rights are indicated by a Creative Commons license in the record and/ or on the work itself. This Thesis has been accepted for inclusion in WVU Graduate Theses, Dissertations, and Problem Reports collection by an authorized administrator of The Research Repository @ WVU. For more information, please contact researchrepository@mail.wvu.edu. 
Improvement of the Physical and Nutritional Quality of Pelleted Feed

\title{
Curran Kenji Gehring
}

Thesis submitted to the Davis College of Agriculture, Forestry and Consumer Sciences at West Virginia University in partial fulfillment of the requirements for the degree of

\author{
Master of Science \\ in \\ Animal and Nutritional Sciences \\ Joseph S. Moritz, Ph.D., Chair \\ Jacek Jaczynski, Ph.D. \\ Janet M. Tou, Ph.D.
}

Division of Animal and Nutritional Sciences

Morgantown, West Virginia 2009

Keywords: Pellet Quality, Pellet Binder, Broiler Performance, Mixer-Added Fat, TMEn, TAAD, Exogenous Enzymes 


\section{ABSTRACT \\ Improvement of Physical and Nutritional Feed Quality}

\section{Curran Kenji Gehring}

Experiments were conducted to improve the physical and nutritional quality of pelleted feed. One experiment focused specifically on improvement of pellet quality using functional muscle proteins. A second experiment examined the effects of increasing mixer-added fat (MAF) on feed manufacture variables, broiler performance variables and carcass composition. In experiment 1, muscle proteins (myofibrillar and sarcoplasmic) were recovered using isoelectric/solubilization precipitation, and a functional paste (TPP) was formed by mixing recovered proteins with typical surimi additives. Trout protein paste was included in broiler diets at $0,2.5$ or $5 \%$. A tap water treatment (3.9\%) was included to match the moisture added by the 5\% TPP treatment. Pellet manufacture variables, nitrogen-corrected true metabolizable energy (TMEn) and true amino acid digestibility were evaluated. Muscle protein inclusion improved pellet quality considerably, however 5\% TPP decreased pellet mill throughput and increased relative electrical energy usage (REEU). Protein paste may be included in broiler diets below $2.5 \%$ to improve pellet quality without negative effects on pellet mill throughput and digestibility. Improving pellet quality is important because industry pellet quality is often low and our lab has demonstrated positive effects of feeding high quality pellets to broilers. Further experimentation revealed that nutrient availability may be reduced by adjusting feed manufacture strategies to improve pellet quality. Experiment 2 was conducted in order to determine if increasing mixer-added fat would improve broiler performance by maintaining nutrient availability in broiler diets pelleted at high temperature. . Increasing MAF reduced the electrical energy usage required to manufacture broiler feed. Feed intake and live weight gain were increased with enzyme addition. Enzyme addition, conditioning temperature and MAF interacted in their effects on feed conversion ratio. Overall, enzyme addition decreased feed conversion ratio, but the effect was greatest with $1 \% \mathrm{MAF}$ and $82^{\circ} \mathrm{C}$ or $4 \% \mathrm{MAF}$ and $85^{\circ} \mathrm{C}$. Increasing MAF and conditioning temperature reduced abdominal fat pad yield. There was no difference in carcass, breast or leg yield due to any of the factors. It is likely that increased MAF improved exogenous enzyme retention and nutrient utilization by broilers. While striving to achieve high pellet quality, nutritionists should consider increasing mixer-added fat to increase profitability because of improved nutrient and exogenous enzyme retention. 


\section{Acknowledgements}

This work has been made possible by the tremendous support and encouragement of my colleagues, family and friends. First and foremost, I would like to express my gratitude to my major professor and friend, Dr. Joe Moritz. He believed in me when others did not and gave me a chance to be involved in research. Additionally, Dr. Moritz has inspired me to push myself continually and strive to do my best even with many impediments along the way. I would also like to thank my other committee members, Dr. Jacek Jaczynski and Dr. Janet Tou. I could not have gotten to this point without their patience, guidance and encouragement since I was an undergraduate. I would also like to thank the faculty, staff and fellow graduate students of the Division of Animal and Nutritional Sciences who were always willing to offer advice or encouragement throughout my undergraduate and graduate careers. The nature of my research is very labor intensive and thus it would have been impossible to complete without the help of my good friends in Dr. Moritz's lab. The friendship and assistance of Dr. Nancy Buchanan, Sarah Cutlip, John Hott, Amanda Rack, Kelley Lilly, Kala Beaman, Staci Loop and Laurel Worley are appreciated beyond words. My research was also made easier by the assistance of research technicians Rick Wood and Sarah Beamer. Last but not least, I would like to thank my family for their continued love, support and patience throughout my high school and college career. 
TABLE OF CONTENTS

PAGE

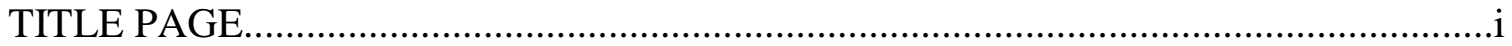

ABSTRACT

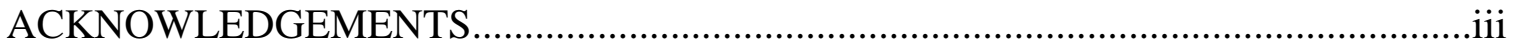

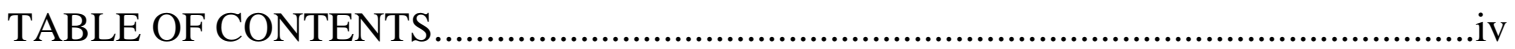

LIST OF TABLES............................................................................................

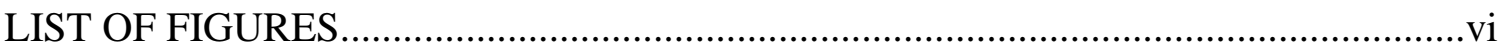

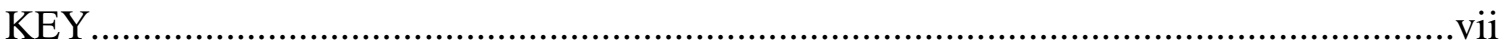

CHAPTER ONE

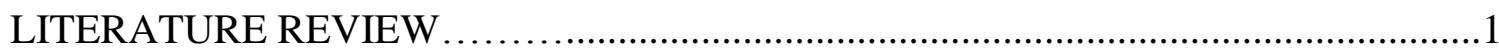

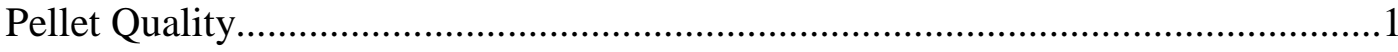

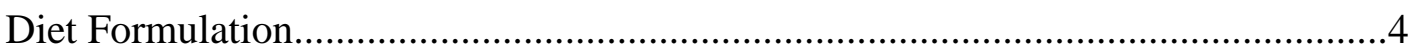

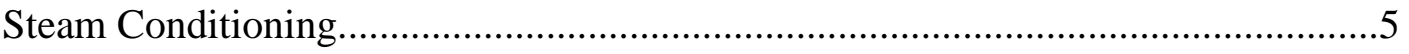

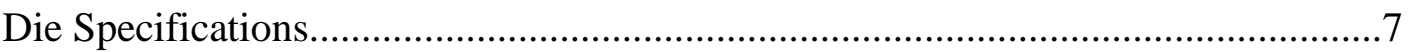

Mash Moisture

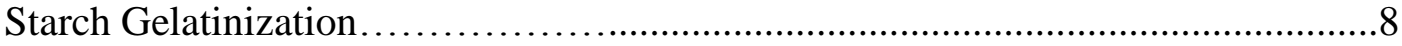

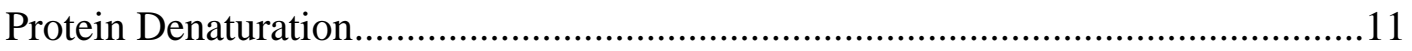

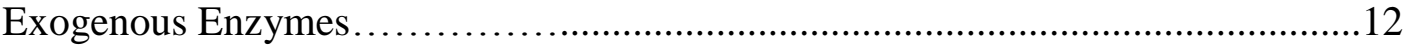

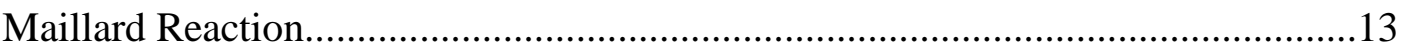

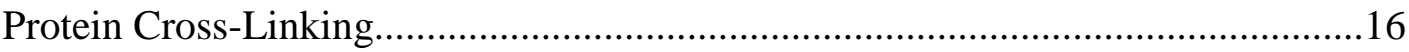

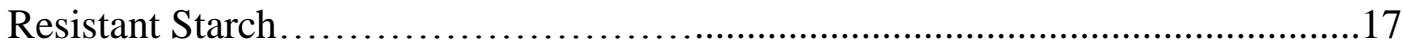

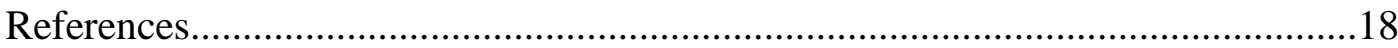




\section{CHAPTER TWO}

IMPROVEMENT OF PELLET QUALITY WITH PROTEINS RECOVERED FROM

WHOLE FISH USING ISOELECTRIC SOLUBILIZATION-PRECIPITATION..........32

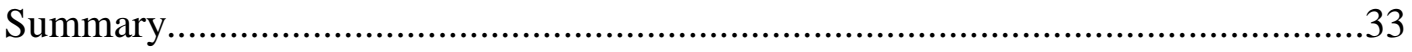

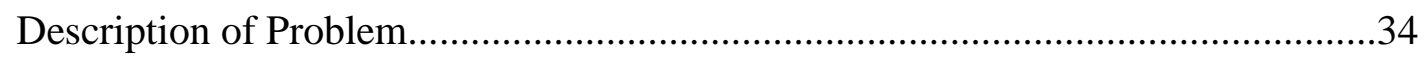

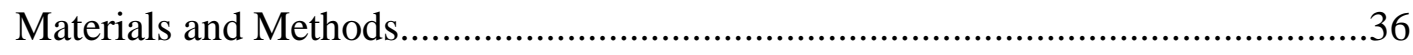

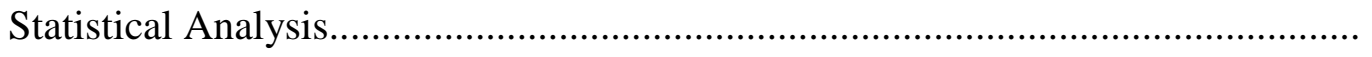

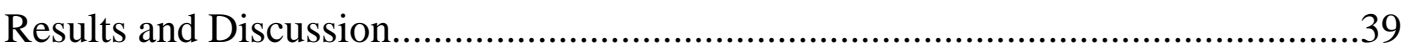

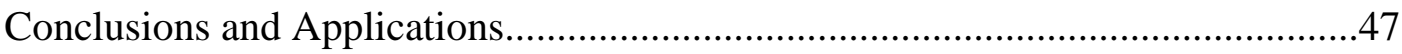

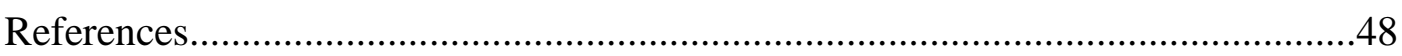

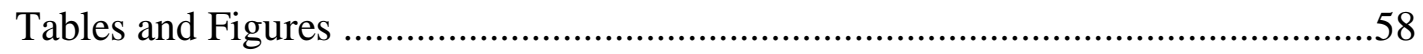

\section{CHAPTER THREE}

\section{INCREASING MIXER-ADDED FAT IMPROVES EXOGENOUS ENZYME}

EFFICACY AND BROILER PERFORMANCE....................................................66

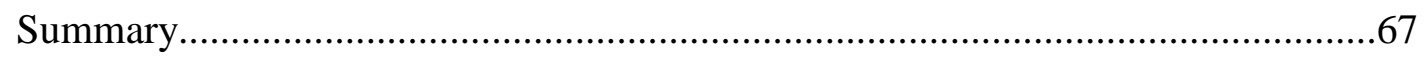

Description of Problem...................................................................................68

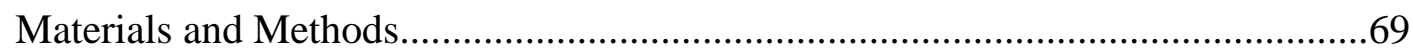

Statistical Analysis.

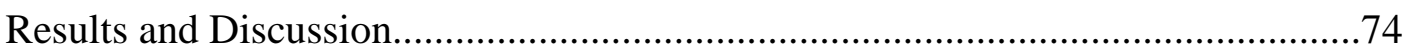

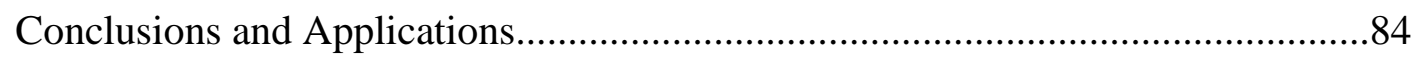

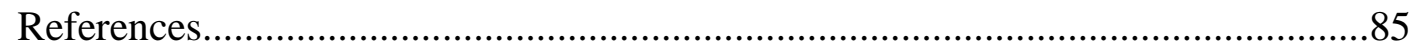

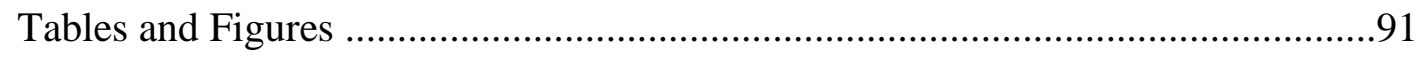




\section{LIST OF FIGURES}

CHAPTER ONE

Figure 1. Starch granule organization................................9

\section{CHAPTER TWO}

Figure 1. Flowchart for recovery of muscle proteins from whole trout using isoelectric solubilization/precipitation..............................62

Figure 2. Protective effect of TPP against pellet degradation..............64

\section{LIST OF TABLES}

CHAPTER TWO

Figure 1. Dietary treatment formulations and composition .......................58

Table 2. Proximate composition and ME of trout protein isolate and trout

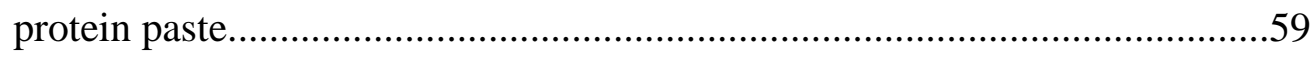

Table 3. Amino acid profile of trout protein isolate and trout protein paste..60

Table 4. Effect of trout protein paste on manufacturing variables................62

Table 5. Pellet and Mash Moisture...........................................................64

Table 6. True amino acid digestibility of pelleted diets and isoelectrically

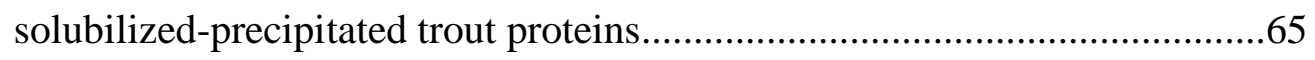

\section{CHAPTER THREE}

Table 1. Grower diet formulations and composition.............................91

Table 2. Finisher diet formulations and composition.............................93

Table 3. Feed manufacture variables..................................................95

Table 4. Effect of fat and sand on pellet manufacture variables................97

Table 5. Broiler performance variables...............................................98 
Table 6. 38-d broiler processing variables

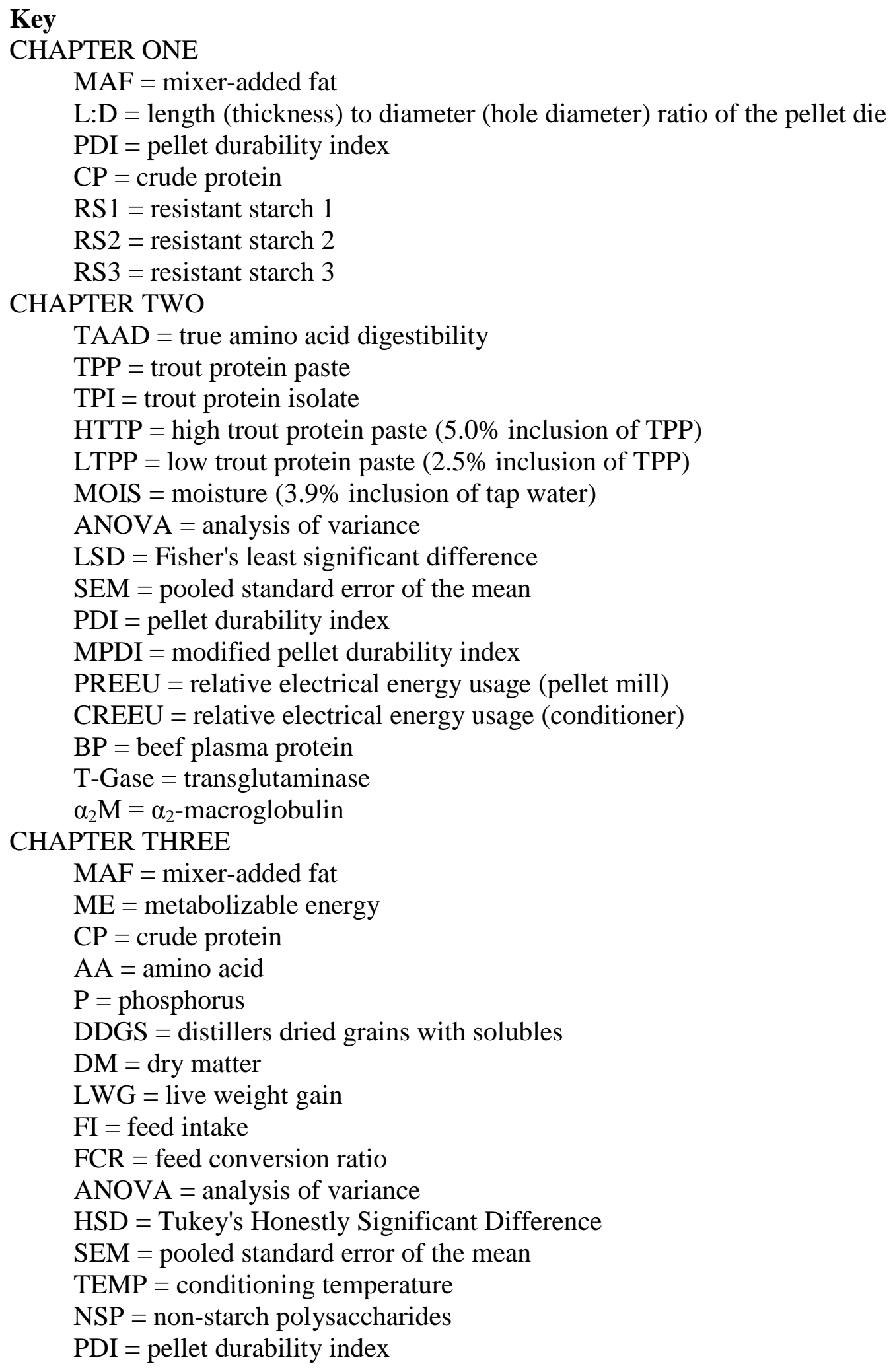


MPDI = modified pellet durability index

$\mathrm{ENZ}=$ exogenous enzyme addition

$\mathrm{PC}=$ positive control 


\section{LITERATURE REVIEW}

\section{Pellet Quality}

Although pelleting is an energy-intensive process, it is well understood that the ensuing physical and nutritional benefits more than justify the cost of production (Behnke, 1996). Consequently, more than 80 percent of all non-ruminant feed in the U.S. is pelleted (Behnke, 2001). Behnke (1994) attributed the benefits of pelleting to: 1) decreased feed wastage; 2) reduced selective feeding; 3) decreased ingredient segregation; 4) less time and energy expended for prehension; 5) destruction of pathogenic organisms; 6) thermal modification of starch and protein; 7) increased digestibility; and 8) improved palatability. Additionally, pelleting improves feed handling characteristics and may reduce feed formulation cost by allowing the use of alternative feed ingredients (Fairfield, 2003); likely due to densification of light, fibrous materials.

Several studies have revealed that pelleted diets improve broiler and swine performance over mash diets (Hussar and Robblee, 1962; Baird, 1973; Wondra et al., 1995; Medel et al., 2003). Performance and carcass composition may be further improved by increasing pellet quality. Pellet quality has been defined as the ability of a feed pellet to maintain post-manufacturing integrity throughout the mechanical agitations produced by conveying, shipping and handling by birds (Cramer et al., 2003). In the broiler industry, due to sheer manufacture volume, pellet quality is often neglected in favor of least-cost diet formulation and high feed throughput. Because of production challenges associated with increased demand for larger broilers, low pellet quality may be exacerbated in older feed mills with capacities designed to accommodate production 
of smaller birds (Dozier et al., 2006). As a result, feed in the industry may contain an excessive amount of fines in relation to intact pellets. Scheideler (1991) reported that in some instances, 70 percent or more of feed pellets may be reduced to fines by the time they are consumed. Broilers provided high quality pellets spend less time eating and sit more than broilers fed mash or a mixture of low quality pellets and mash (Nir et al., 1994). Additionally, when feed is pelleted, less time and energy are used for prehension (Jensen et al., 1962; Behnke, 1994). When broilers consume mash or pelleted feed containing a high proportion of fines, fine particles spill from the sides of the beak and a reduced volume of feed is consumed per peck (Jensen et al., 1962). Spilled feed represents squandered productive energy and increased feed wastage.

Feed form effects on broiler performance and carcass composition are well established. Feeding high quality pellets (94 pellet durability index, 5\% fines) decreased broiler feed intake and feed conversion ratio compared to broilers fed slightly lower quality pellets (90 pellet durability index, 9\% fines) (Cutlip et al., 2008). Lilly et al.(2009) conducted a study to directly examine the effect of pellet quality on broiler performance, using the same diet formulation as in the previous study (3.09\% soybean oil), and determined that increasing pellet quality from 60 to $90 \%$ pellets in the feed pan, improves carcass weight of broilers by nearly 2 fold. Previous experimentation by the same authors, used diets formulated at a reduced energy density (1.26\% soybean oil), and no feed form effects on broiler performance were detected (Gehring et al., 2009). Thus, it is likely that feed form effects may be masked by reduced nutrient quality in low fat formulations if significant nutrient loss occurs during pelleting. 
Pellet quality is affected by several factors, namely diet formulation, ingredient particle size, mash moisture, mixer uniformity, steam conditioning parameters (temperature, pressure, retention time), die speed, die specifications, and cooling. Reimer (1992) deemed diet formulation the most influential factor (40\%), followed by conditioning (20\%) and particle size (20\%) and to a lesser extent, die specification (15\%) and drying/cooling (5\%).

Although Reimer's theory has been repeated widely, there is little peer-reviewed evidence to support it. According to Thomas et al.(1997), with respect to modern conditioning systems, pellet quality may be influenced more by equipment than by diet formulation. Furthermore, it is known that die length to diameter ratio plays a substantial role in determining pellet quality (Buchanan et al., 2008) and ambient temperature may greatly influence the amount of moisture that is added to mash in the conditioner.

Gehring et al. (2009) reported that all factors are important and that interactions among factors may exist.

Factors that affect pellet quality by increasing feed temperature may also negativelyaffect broiler performance by reducing nutrient availability and exogenous enzyme retention. The pelleting process involves raising temperature and moisture by injecting steam into mash feed and further increasing feed temperature during pellet formation due to mechanical friction at the mash-die interface. Lubrication of the die ports by increasing the amount of fat added in the mixer (mixer-added fat; MAF) may reduce the extent of exogenous enzyme denaturation, loss of amino acids, and resistant starch formation during processing. 


\section{Diet Formulation}

Diet formulation is one of the most apparent factors that influences pellet formation and quality. Because broiler diets are formulated to be least-cost, a wide variety of feedstuffs may be used to meet nutritional requirements. Depending on the ingredients used, pellet quality may vary widely. Additionally, the processing history and location of origin may influence the physicochemical properties of feedstuffs and their effect on the pelleting process (Thomas et al., 1998). Ingredient selection should be determined with respect to price, bioavailability and the effect on physical and nutritional pellet quality.

Feed ingredients are comprised of primary constituents including starch, protein, sugar, non-starch polysaccharides, lipids, inorganic matter and water (Thomas et al., 1998). Although corn is the major ingredient in broiler diets in the United States and starch gelatinization is often afforded primary importance, protein has been shown to affect pellet quality markedly (Winowiski, 1988; Thomas et al., 1997; Briggs et al., 1999). Briggs et al. (1999) increased crude protein from 16.3 to $21 \%$ and subsequently increased pellet durability from 75.8 to $88.8 \%$, respectively. This finding corroborates work by Winowiski (1988) who reported increased pellet durability when crude protein was increased by using wheat at the expense of corn. Recently, Buchanan et al. (2009) reported improved pellet quality with diets containing added moisture (2\% and $4 \%$ ) and added soybean meal (2\%) compared to least-cost diet formulations.

Feed ingredient costs have increased substantially, especially in terms of corn and fat prices. Current industry practice is to reduce the amount of added fat in broiler diets to reduce diet cost and improve pellet quality (Gehring et al., 2009). This reduction due 
to least-cost diet formulation may be exacerbated by the use of exogenous enzymes that have substantial metabolizable energy matrix values. Formulation to a reduced metabolizable energy target may reduce the amount of added fat in broiler diets to 0.5 or $1 \%$ of the diet (Blair, 2009). Additionally, post-pellet spray application of supplemental fat is prevalent in the industry and consequently, very little fat may be added in the mixer. Skoch et al. (1983) reported reduced protein digestibility of steam-conditioned diets compared to mash diets in weanling pigs. The effect of pelleting on nutrient integrity is dependent on processing conditions and may significantly affect product quality even among pelleted feeds. Mounting evidence suggests that the nutritional quality of pelleted broiler diets may be compromised if the amount of fat added in the mixer is below a critical value (Gehring et al., 2009).

Though increasing dietary calories from fat reduces pellet quality (Salmon, 1987; Cavalcanti and Behnke, 2005a; 2005b), industry pellet quality is sufficiently low such that performance responses associated with feed form effects are not likely to overshadow effects of nutrient availability. Fat added in the mixer may contribute to improved nutrient utilization and enzyme efficacy by coating feed particles (Eliasson et al., 1981; Zimonja et al., 2007) and lubricating the pellet die (Jones et al., 1995; Cutlip et al., 2008). Die lubrication may also provide further benefits associated with reduced electrical energy usage required to pellet broiler feed.

\section{Steam Conditioning}

Steam conditioning is a major part of the pelleting process. Moisture and temperature of mash feed are increased by steam injection into conditioner barrel, prior to extrusion through the pellet die. The addition of moist heat is essential for feed particle 
agglomeration and formation of a durable pellet (Froetschner, 2005). Other benefits are apparent as well, such as improved throughput (Skoch et al., 1981) and die lubrication (Skoch et al., 1981; Skoch et al., 1983) resulting in reduced electrical energy usage.

The ability to form high quality pellets by steam conditioning increases broiler performance compared to mash as previously described. Bayley et al. (1968) determined that steam conditioning at $70^{\circ} \mathrm{C}$ improved subsequent broiler performance compared to mash. Despite the benefits of steam conditioning, nutrient availability (Cutlip et al., 2008) and broiler performance may be compromised above a specific temperature. The upper threshold for steam conditioning temperature appears to be approximately 80 $95^{\circ} \mathrm{C}$, as indicated by several broiler studies (Bayley et al., 1968; Nissinen, 1994; Nir et al., 1995; Silversides and Bedford, 1999). Estimation of the maximum steam conditioning temperature for a particular diet is not likely to be undertaken with further precision because of the multitude of factors that affect nutrient retention.

Further complication arises when comparing diets formulated with or without exogenous enzymes. Increasing steam conditioning temperature above $80^{\circ} \mathrm{C}$ improves broiler weight gain and feed conversion with exogenous xylanase addition but reduces broiler performance without xylanase, in wheat-based diets (Cowieson, et al., 2005). Wheat- or barley-based diets may exhibit this effect because of the release of previously encapsulated non-starch polysaccharides (Cowieson et al., 2005) that are a substrate for various carbohydrases.

The difficulty in estimating the effect of steam conditioning temperature on nutrient availability in broiler diets is potentially a serious problem in the industry. The amount of moisture that is added to mash feed depends on the diet composition as well as 
ambient temperature (Cutlip et al., 2008, Briggs et al., 1999). Nutrient and enzyme retention may be particularly compromised in the winter months because more steam is required to reach conditioning temperature (Wyatt, 2009).

\section{Die Specifications}

Pellets are formed by extrusion of conditioned mash through a pellet die. Within the die ports, frictional heat, compression force and shear significantly affect the structure and availability of feed polymers (Stevens, 1987; Briggs et al., 1999). Pellet dies are typically characterized by their length (thickness) to diameter (hole diameter) ratio (L:D). An L:D ratio of 10 has been suggested as optimal for high grain poultry rations (CPM). Increasing the L:D ratio is associated with increased residence time in the die and subsequent improvement of pellet quality (Gehring et al., 2009) by increasing the portion of dietary starch and protein that may participate in agglomeration reactions. However, increasing the L:D ratio may be detrimental to nutrient availability and subsequent broiler performance, especially if the conditioning temperature is within the $80-90^{\circ} \mathrm{C}$ range.

\section{Mash Moisture}

Mash moisture affects pellet manufacture in numerous ways by improving pelleting performance, electrical energy usage, pellet quality and feed stability (Skoch, 1981; Skoch,1983; Cutlip et al, 2008). Thus, feed ingredient and mash moisture should be monitored closely in order to predict feed production costs and benefits reliably. The magnitude of the aforementioned effects cannot be predicted accurately based upon moisture concentration per se, because water activity is arguably more important than total moisture with regard to pellet manufacture. The amount of moisture added to mash via steam conditioning is affected by numerous factors, including the moisture diffusivity 
of the feed ingredients, steam quantity and quality, the degree of mixing during conditioning and conditioning chamber dimensions (residence time), as expressed by Briggs et al. (1999).

Pelleting parameters may also be affected by the location of moisture addition. Greer and Fairchild (1999) and Muirhead (1999) determined that control of cold mash moisture in the mixer could be utilized to maximize pellet durability and pelleting efficiency. Subsequently, Moritz et al. determined that moisture addition in the mixer (up to 5\%) improves broiler feed efficiency (2001) and significantly reduces electrical energy usage $(\sim 17 \%)$, while maintaining or improving pellet quality and broiler performance, in diets formulated with decreased energy density $(2002,2003)$.

Increasing mash moisture either through moisture addition in the mixer or steam conditioning is beneficial only if there is sufficient frictional force in the pellet die to extrude mash. When mash moisture exceeds approximately $18 \%$, frictional force may be reduced to the point that mash cannot be effectively extruded through the die ports and mash feed accumulates between the rolls and die (Gilpin et al., 2002). Electrical energy usage is significantly increased as the ability to push conditioned feed through the die is reduced (Gilpin et al., 2002). Additionally, if the problem is not corrected immediately, the die may become plugged and "slip", requiring an interruption of feed production and extensive time and labor to clear the machinery.

\section{Starch Gelatinization}

Starch comprises the majority of commercial broiler diets and plays a role in feed particle agglomeration and pellet formation. Starches are homopolymers of $\alpha$-D-glucose consisting of $\alpha$-D-(1,4) and/or $\alpha$-D-(1,6) linkages. The two main structural 
polysaccharides in starch are amylose and amylopectin. Amylose comprises $18-33 \%$ of starch (Buleon et al., 1998) and is essentially a linear polymer of glucose with few branch points. The majority of starch consists of amylopectin, a much larger molecule comprised of regular branch chains every 20-25 glucose residues (Sajilata et al., 2006).

Higher order plants store energy in the form of starch that is packaged into distinct granules. Within the granule, adjacent amylopectin short chains form double helices that associate into clusters. The clusters pack into ordered arrays of alternating crystalline and amorphous lamellae (Smith et al., 2001). Together the crystalline and amorphous lamellae create semi-crystalline regions that alternate with amorphous regions

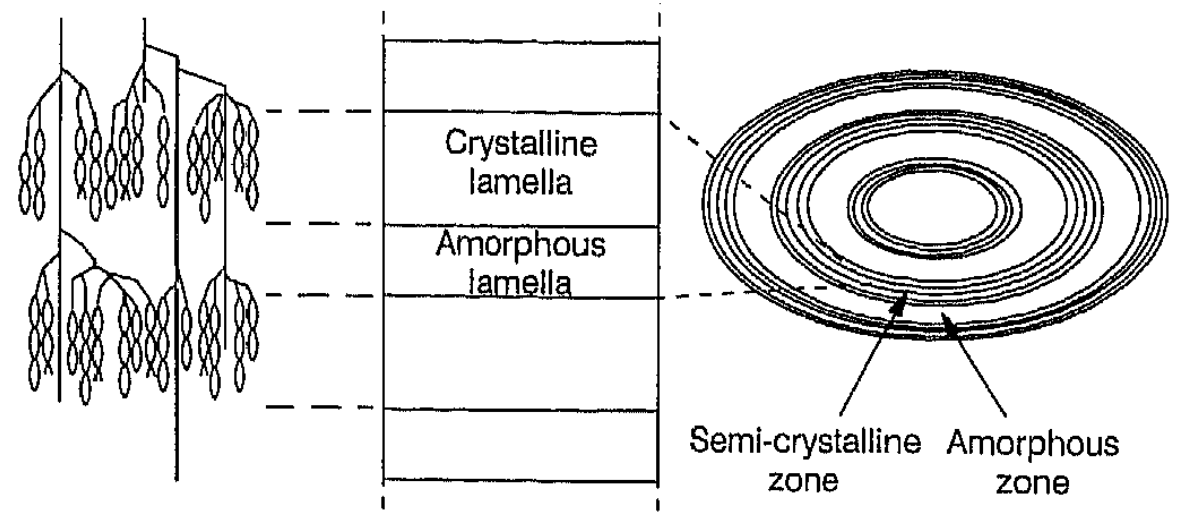

Figure 1. Starch granule organization. Adapted from Smith et al., 2001.

that contain amylose interspersed with amylopectin (Jane et al., 1992). Amylopectin is much less organized in the amorphous regions because amylose disrupts the structural order of the amylopectin crystallites (Jenkins and Donald, 1995).

Cooking or other thermal processing with sufficient water may cause starch granules to gelatinize (Karim et al. 2000; Zaritzky, 2000). Gelatinization is characterized by water diffusion into the granule, granule swelling, loss of crystallinity, amylose 
leaching and formation of a paste-like gel (Olkku and Rha, 1978; Hoover, 1995). The starch gel consists of gelatinized granules embedded within a continuous amylose network (Zaritzky, 2000) and may act as an adhesive to bind feed ingredients (Lund, 1984). The degree of starch gelatinization and subsequent particle binding are dependent on several factors, including granule size, amylose:amylopectin ratio (Madsen and Christensen, 1996), amylopectin branch chain length (Jane and Chen, 1992), diet composition (Bean and Osman, 1959; Ghiasi et al., 1982), mash moisture (Moritz et al., 2002, 2003), steam conditioning (Heffner and Pfost, 1973; Skoch et al., 1981), and die specifications.

Dietary starch gelatinization does not typically exceed 25-30\% (Moritz et al., 2003; Moritz et al., 2005) due to the pelleting process. Moisture is a limiting factor for starch gelatinization in broiler diets. Moisture addition to the mixer was reported to decrease the peak temperature of starch gelatinization, as well as overall starch gelatinization (Moritz et al., 2003). In a previous study, starch gelatinization was increased significantly by increasing mash moisture (Moritz et al., 2001). Water acts a plasticizer that decreases the glass transition temperature of starch (Zaritzky, 2000), as demonstrated by Moritz et al. (2003). However, water also acts as a lubricant (Moritz et al., 2003) and reduces frictional and compression forces (Cavalcanti and Behnke, 2005a; 2005b) in the pellet die. Moritz et al. (2001) observed increased starch gelatinization when moisture was added to low moisture diets $(\sim 8 \%)$ possibly due to water being deficient for appreciable gelatinization at that level.

The extent that starch gelatinization affects pellet quality has been brought into question (Wood, 1987), although in practical broiler diets, gelatinization may play a 
larger role in determining pellet quality than in the past. Wood (1987) pelleted diets with different types of starch (native and pregelatinized) and protein (native and predenatured). The pellet durability index (PDI) of pellets that contained $40 \%$ native starch and $60 \%$ native protein was 85 . Replacing the starch fraction with pregelatinized starch only increased pellet durability by $11 \%$. Starch gelatinization had a much greater affect when the protein fraction was predenatured, improving PDI from 19 to 70, with native vs. pregelatinized starch, respectively. Modern broiler diets are much more complex than those used in much of the research evaluating the relative effects of starch and protein on pellet quality. Therefore, the contribution of starch gelatinization on pellet quality remains equivocal, although it is likely that protein affects pellet quality to a greater extent.

\section{Protein Denaturation}

Dietary protein has been regarded as the primary dietary factor that affects pellet formation and quality (Briggs et al., 1999). This is despite protein comprising only 18$20 \%$ of most broiler diets compared to a $60-70 \%$ inclusion of starch. Moisture addition in the mixer decreased starch gelatinization but increased pellet durability index (Moritz, 2003), and modified pellet durability index increased with small increases ( 2 and $4 \%$ ) of $48 \% \mathrm{CP}$ soybean meal that were accompanied by reductions in total starch content (Buchanan and Moritz, 2009), indicating a greater contribution of dietary protein to feed ingredient agglomeration and subsequent pellet quality.

The major source of protein in United States broiler diets is solvent-extracted soybean meal. Approximately $90 \%$ of the protein fraction of soybeans is comprised of 7S ( $\beta$-conglycinin) and $11 \mathrm{~S}$ (glycinin) storage globulins (Kinsella, 1979). Thermal 
denaturation is a prerequisite for gel formation of globular proteins (Kinsella, 1976; Renkema et al., 2002). At typical feed pH ( 7.0), gelation coincides with glycinin denaturation (Renkema et al., 2000). The amount of soy and animal protein denaturation that occurs during the pelleting process remains ambiguous. Aqueous dispersions of glycinin and soy protein isolate do not thermally denature below $85^{\circ} \mathrm{C}$, as indicated by differential scanning calorimetry (Renkema et al., 2000, Lakemond et al., 2000). Broiler diets are low moisture systems ( 10-15\% moisture) and pelleting temperatures are typically below $85^{\circ} \mathrm{C}$, so it is likely that much of the protein denaturation responsible for pellet formation is caused by frictional heat, as well as shear and compression forces in the pellet die.

The functionality of dietary proteins significantly affects pellet quality (Wood, 1987; Gehring et al., 2009). Gehring et al. (2009) improved pellet quality with muscle proteins recovered from trout using a $\mathrm{pH}$-shift process. Recovery of muscle proteins by solubilization at low or high $\mathrm{pH}$ and precipitation at their isoelectric point, yields partially-refolded proteins with increased gelation capacity compared to whole muscle (Gehring et al., 2009). Pellet durability was increased by 33\% compared to a cornsoybean meal-based control by addition of $5 \%$ trout protein paste.

\section{Exogenous Enzymes}

Broiler diets are commonly supplemented with exogenous enzymes in order to increase nutrient digestibility, decrease digesta viscosity, decrease diet cost and decrease nutrient excretion (Bedford, 2000, 2002). Although the benefits of exogenous enzyme addition are numerous and well-established, enzymes may be denatured during the pelleting process. Broiler diets are typically formulated below the intended nutrient 
values, with the assumption that exogenous enzymes, such as phytase, protease, or carbohydrases, will improve nutrient utilization and make up the difference (Bedford, 2002). Thus, if a significant portion of the added enzyme preparation is denatured during pelleting, the diet will be nutrient deficient and may lead to poor broiler performance. Some research has focused on exogenous enzyme retention after pelleting (Inborr and Bedford, 1994; Spring et al., 1996; Silversides and Bedford, 1999; Cowieson, et al., 2005; Stark et al., 2009), although the applicability of the data is questionable. Intrinsic enzyme stability is determined by several factors such as amino acid sequence, three-dimensional structure and the sum of many non-covalent interactions such as hydrogen bonds, Van der Waals forces, hydrophobic interactions, and ion-pair networks (Yip et al., 1995; Daniel et al., 1996). Thermostable enzymes may be recovered from naturally-occurring thermophiles or thermostability may be conferred by targeted amino acid substitution or enzyme coating (Wyatt, 2009). Because there may be many different isoforms grouped under a single enzyme commission number, and commercial enzyme preparations differ greatly in terms of origin, production, and stability, it is not likely that retention data from one study can be applied to other enzymes, even of the same class. Care should be taken by feed mill managers to maintain pelleting temperatures below the published denaturation temperature for a particular enzyme. Additionally, lubrication of the pellet die by addition of fat in the mixer may improve enzyme retention and efficacy.

\section{Maillard Reaction}

The Maillard reaction refers to a complex series of reactions occurring during food processing or storage, as well as in vivo in the tissues of birds, mammals, fish, and 
reptiles (Panigrahy et al., 1976; Cannon and Davison, 1978; Iqbal et al., 1999; Fayle and Gerrard, 2002). Maillard reaction products are utilized to provide desirable flavors, aromas and colors to human foods (Ames, 1998; Martins et al., 2001), although they are also associated with reduced nutritional quality (Martins et al., 2001), especially with regard to production animal feed and thermally processed feed ingredients (Parsons et al, 1992, Anderson-Haferman et al, 1993; Zhang and Parsons, 1994). Various processing and storage variables influence the Maillard reaction (Ames, 1990), including diet formulation (nature and amount of reactants), cold mash moisture (water activity), steam conditioning (temperature and time) and die specification (retention time and pressure). Maillard reactions occur in three stages, described by Mauron (1981) as the initial Maillard reaction, the advanced Maillard reaction, and the final Maillard reaction. The initial reaction involves the condensation of an amine and a carbonyl compound to form a Schiff base, and subsequent isomerization to form Amadori or Heyns products (Dills, 1993). The reaction typically occurs between a protein and a reducing sugar and primarily involves the $\varepsilon$-amino group of lysine (Dills, 1993), but may also involve the $\alpha$-amino groups of terminal amino acids (Dills, 1993; Martin et al., 2001) or crystalline amino acids used in broiler diets. The Schiff base cyclizes to form an $\mathrm{N}$-substituted glycosylamine that undergoes subsequent Amadori or Heyns rearrangement (Dills, 1993).

The advanced Maillard reaction refers to the production of reactive intermediates and some of the initial flavor and aroma compounds (Mauron, 1981; Hodge, 1953). Amadori and Heyns products decompose to form a variety of highly reactive dicarbonyl degradation products that can further react with other reducing sugars or amino acids 
(Hodge, 1953; Martins et al., 2001). Further decomposition reactions yield heterocyclic compounds associated with flavor and aroma (Mauron, 1981; Hodge, 1953). The most apparent nutritional consequence of the Maillard reaction is the loss of sugars and amino acids (Dills, 1993). Glycosylamines are readily hydrolysable to yield the free amino acid and sugar but Amadori and Heyns products are not (Dills, 1993). Although the secondary Maillard reaction products do not yield available sugar or amino acids, many are absorbed as isopeptide moieties and are subsequently excreted in the urine (ValleRiestra and Barnes, 1969; Ford and Shorrock, 1971; Hurrel and Carpenter, 1981), presenting problems with the interpretation of ileal and total tract digestibility assays (Wang and Parsons, 1998). Fernandez and Parsons (1996a) and Wang and Parsons (1998) expressed that most of the true digestible lysine determined using the precisionfed cecectomized rooster assay is available for protein synthesis and growth. In contrast, Batterham et al., (1990; 1993), reported that ileal digestible Lys and Met in meat and bone meal were not totally bioavailable. According to Wang and Parsons (1998), most of the early Maillard reaction products would be determined to be digestible using the ileal digestibility assay but not in the precision fed rooster assay, because in the latter assay both urine and feces are collected.

Deoxysones and Strecker degradation products formed during the advanced Maillard reaction stage are precursors for high molecular weight brown polymers and copolymers known as Melanoidins (Ames, 1998; Kitts, 2007). Increased non-enzymatic browning has been associated with reduced nutritional quality of thermally-processed feed ingredients such as dried distillers grains with solubles (Fastinger et al, 2006) and canola meal (Newkirk and Classen, 2002). Fastinger et al. (2006) reported that the 
apparent and true amino acid digestibility of corn dried distillers grains with solubles decreased as the degree of lightness $\left(\mathrm{L}^{*}\right)$ and yellowness $\left(\mathrm{b}^{*}\right)$ reached values of 28-32 and $15-20$, respectively.

Soluble non-starch polysaccharides reduce nutritional quality of poultry diets by increasing digesta viscosity (Antoniou et al., 1981; Choct and Annison, 1990; Bedford, 2000) and reducing luminal nutrient and enzyme diffusion. It could be expected that melanoidins would increase digesta viscosity in a similar manner; however, the plasticization effect of water molecules released during the initial condensation reaction, apparently offsets the effect of the melanoidins, such that there is only a slight increase in viscosity (Manzocco and Maltini, 1999). Therefore, product darkening by melanoidins indicates decreased nutrient availability due to advanced Maillard reaction product formation rather than the final Maillard reaction products themselves.

\section{Protein Cross-linking}

Thermomechanical feed processing can also reduce amino acid digestibility by cross-linking reactions other than the Maillard reaction. Some of these reactions may hinder the interpretation of amino acid digestibility data because amino acids that are not released in vivo may be freed by acid hydrolysis (Evans and Butts, 1948; Moughan and

Rutherford, 1996). One of the primary cross-linking reactions that may occur in soybean meal is the formation of an isopeptide linkage between the side-chain carboxyl groups of Asp or Glu and the $\varepsilon$-amino group of Lys (Block et al., 1946). Such isopeptides are resistant to enzymic digestion but not to acid hydrolysis (Evans and Butts, 1948). Protein denaturation that occurs during thermomechanical processing may also be favorable for the formation of intra- and intermolecular cross-links involving other amino acids (Valle- 
Riestra and Barnes, 1970). The resultant aggregated and cross-linked proteins are less accessible to digestive enzymes (Moughan and Rutherford, 2008) and thus, may reduce the utilization of amino acids that are not involved in the cross-links directly.

\section{Resistant Starch}

A significant fraction (15-20\%) of dietary starch may be recovered in the terminal ileum undigested ( Noy and Sklan, 1995; Bedford, 2002). This fraction is termed resistant starch and consists of three general classes (Brown, 1996). Resistant starch 1 (RS1) is the portion of dietary starch that is unutilized by the bird because of encapsulation within plant material, such as cell wall components (Annison and Topping, 1994). The RS1 component may be highly available in terms of structure; however, the encapsulation retards the access of $\alpha$-amylase to the substrate. Many cereal endosperm cells remain intact even after grinding and pelleting (Bedford, 2002) and thus, an appreciable amount of the RS1 starch may escape digestion.

Resistant starch 2 (RS2) refers to the portion of dietary starch that is undigested due to the size and structure of the native granule. Structural and chemical factors that may affect digestibility of starches include size (Franco et al., 1992), protein encapsulation (Colonna and Mercier, 1985), crystalline structure (Brown, 1996) and amylose-lipid complexing (Holm et al., 1983; Zimonja et al., 2007). Starches that exhibit a B crystalline pattern are digested poorly and are found in potatoes, bananas and other tuber or high amylose starch sources (Annison and Topping, 1994; Brown, 1996). Conversely, cereal starches exhibit an A crystalline pattern and are more thoroughly digested than B pattern starches or legume starches, that exhibit a combination of $\mathrm{A}$ and B type structure (Annison and Topping, 1994). Native or ungelatinized starch is also 
classified as RS2 (Englyst et al., 1992) and is less accessible to pancreatic $\alpha$-amylase than gelatinized starch.

The final class of resistant starch is RS3 or retrograded starch. Retrogradation occurs following thermal processing and is characterized by reassociation amylose molecules and stabilization of the structure by hydrogen bonding (Haralampu, 2000). When starch granules gelatinize, amylose is leached from the granules in the form of random coil polymers (Roos, 1995; Haralampu, 2000). Cooling initiates the formation of double helices and subsequent reassociation and hydrogen bonding to form indigestible crystalline (Wu and Sarko, 1978) complexes with proteins and cell wall structures (Bedford, 2002).

\section{REFERENCES AND NOTES}

Ames, J. M. 1990. Control of the Maillard reaction in food systems. Trends Food Sci. Technol. 1:150-154.

Ames, J. M. 1998. Applications of the Maillard reaction in the food industry. Food Chem. 62:431-439.

Anderson-Haferman, J. C., Y. Zhang and C.M. Parsons. 1993. Effects of processing on the nutritional qualityof canola meal. Poult. Sci. 72:326-333.I

Annison,G., and D. L. Topping. 1994. Nutritional role of resistant starch: chemical structure vs physiological function. Annu. Rev. Nutr. 14:297-320.

Antoniou, T., R. R. Marquardt, and E. Cansfield. 1981. Isolation, partial characterization, and antinutritional activity of a factor (pentosans) in rye grain. J. Agric. Food Chem. 28:1240-1247.

Baird, D. M. 1973. Influence of pelleting swine diets on metabolizable 
energy, growth and carcass characteristics. J. Anim. Sci. 36:516-521.

Batterham, E. S., L. M. Andersen, D. R. Baigent, S. A. Beech, and R. Elliott, 1990. Utilization of ileal digestible amino acids by pigs: lysine. Br. J. Nutr. 64:679-690.

Batterham, E. S., L. M. Andersen, and D. R. Baigent. 1993.Utilization of ileal digestible amino acids by growing pigs: methionine. Br. J. Nutr. 70:711-720.

Bayley, H.S., J.D. Summers, and S.J. Slinger. 1968. The effect of steam pelleting feed ingredients on chick performance: effect on phosphorous availability, metabolizable energy value and carcass composition. Poult. Sci. 47:1140-1148.

Bean, M. L., and E. M. Osman. 1959. Behavior of starch during preparation. II. Effects of different sugars on the viscosity and gel strength of starch pastes. J. Food Sci. 24:655-671.

Bedford, M. R. 2000. Exogenous enzymes in monogastric nutrition - their current value and future benefits. Anim. Feed Sci. Tech. 86:1-13.

Bedford, M. R. 2002. The role of carbohydrases in feedstuff digestion. Pages 319-336 in Poultry Feedstuffs - Supply, Composition and Nutritive Value. J. M. McNab and K. N. Boorman, ed. CABI Publ., England.

Behnke, K. C. 1994. Factors affecting pellet quality. Maryland Nutr. Conf. Dept. of Poultry Science and Animal Science, College of Agriculture, University of Maryland, College Park.

Behnke, K. C. 1996. Feed manufacturing technology: Current issues and challenges. Anim. Feed Sci. Technol. 62:49-57. 
Behnke, K. C. 2001. Factors influencing pellet quality. FeedTech. Volume 5 Number 4. Reed Business Information, International Agri-\&Horticulture, Doetinchem, The Netherlands.

Blair, M. 2009. Maintaining poultry feed quality. May 19-21, Indianapolis, IN.

Block, R. J., P. R. Cannon, R. W. Wissler, C. H. Steffee, Jr., R. L. Straube, L. E. Frazier, and R. L. Woolridge. 1946. The effect of baking and toasting on the nutritional value of proteins. Arch. Biochem. 10:295-301.

Briggs, J. L., D. E. Maier, B. A. Watkins, and K. C. Behnke. 1999. Effect of ingredients and processing parameters on pellet quality. Poult. Sci. 78:1464-1471.

Brown, I. 1996. Complex carbohydrates and resistant starch. Nutr. Rev. 54:S115S119.

Buchanan, N. P., K. G. S. Lilly, C. K. Gehring, and J. S. Moritz. 2008. The effect of diet formulation and manufacturing technique on pellet processing variables and quality. Poult. Sci. 87(Suppl. 1):166.(Abstr.)

Buchanan, N. P., and J. S. Moritz. 2009. Main effects and interactions of varying formulation, protein, fiber, and moisture on feed manufacture and pellet quality. J. Appl. Poult. Res. 18:274-283.

Buléon, A., P. Colonna, V. Planchot, and S. Ball. 1998. Starch granules: structure and biosynthesis. Inter. J. Biol. Macromol. 23:85-112.

Cannon, D.J., and P. F. Davison. 1978. The crosslinking of skin collagen in annual fish. Exp. Gerontol. 13:101 - 106.

Cavalcanti, W. B., and K. C. Behnke. 2005a. Effect of composition of feed model systems on pellet quality: A mixture experimental approach I. Cereal Chem. 82:455-461. 
Cavalcanti, W. B., and K. C. Behnke. 2005b. Effect of composition of feed model systems on pellet quality: A mixture experimental approach II. Cereal Chem. 82:462-467.

Choct, M., and G. Annison. 1990. Anti-nutritive activity of wheat pentosans in broiler diets. Br. Poult. Sci. 31:811-821.

Colonna, P., and C. Mercier. 1985. Gelatinization and melting of maize and pea starches with normal and high amylose genotypes. Phytochemistry. 24:1667-1674.

Cowieson, A. J., M. Hruby, and M. Faurschou Isaksen. 2005. The effect of conditioning temperature and exogenous xylanase addition on the viscosity of wheatbased diets and the performance of broiler chickens. Br. Poult. Sci. 46:717-724.

Cramer, K. R., K. J. Wilson, J. S. Moritz, and R. S. Beyer. 2003. Effect of sorghum-based diets subjected to various manufacturing procedures on broiler performance. J. Appl. Poult. Res. 12:404-410.

Cutlip, S. E., J. M. Hott, N. P. Buchanan, A. L. Rack, J. D. Latshaw and J. S. Moritz. 2008. The effect of steam conditioning practices on pellet quality and growing broiler nutritional value. J. App. Poult. Res. 17: 249-261.

Daniel, R. M., M. Dines, and H. H. Petach. 1996. The denaturation and degradation of stable enzymes at high temperatures. Biochem. J. 317:1-11.

Dills, W. L. Jr, 1993. Protein fructosylation: fructose and the Maillard reaction. Am. J. Clin. Nutr. 58(suppl):779S-783S.

Dozier, W. A., III., K. Behnke, M. T. Kidd, and S. L. Branton. 2006. Effects of addition of roller mill ground corn to pelleted feed on pelleting parameters, broiler performance, and intestinal strength. J. Appl. Poult. Res. 15:236-244. 
Eliasson, A. -C., K. Larsson, and Y. Miezis. 1981. On the possibility of modifying the gelatinization properties of starch by lipid surface coating. Starch/Stärke. 33:231-235.

Englyst, H. N., S. M. Kingman, and J. H. Cummings. 1992.Classification and measurement of nutritionally important starch fractions. Eur. J. Clin. Nutr. 46(Suppl 2): S33-S50.

Evans, R. J., and H. A. Butts. 1948. Studies on the heat activation of lysine in soy bean oil meal. J. Biol. Chem. 175:15-20.

Fairfield, D. A. 2003. Pelleting for profit-part 1. Feed and Feeding Digest. 54(6):1-5.

Fastinger, N.D., J.D. Latshaw, and D.C. Mahan. 2006. Amino acid availability and true metabolizable energy content of corn distillers dried grains with solubles in adult cecectomized roosters. Poul. Sci. 85:1212-1216.

Fayle, S. E., and J. A. Gerrard. 2002. What is the Maillard reaction? Pages 1-8 in The Maillard Reaction. P. S. Belton, ed. The Royal Society of Chemistry., Cambridge, England.

Fernandez, S. R., and C. M. Parsons. 1996. Bioavailability of the digestible lysine and valine in cottonseed and soybean meals for chicks. Poultry Sci. 75:216-223.

Ford, J. E., and C. Shorrock. 1971. Metabolism of heat-damaged proteins in the rat: Influence of heat damage on the excretion of amino acids and peptides in the urine. Br. J. Nutr. 26:311-322.

Franco, C. M. L., S. J. do Rio Preto, C. F. Ciacco. 1992. Factors that affect the enzymatic degradation of natural starch granules-effect of the size of the granules. Starch/Stärke. 44:422-426. 
Froetschner, J.R. 2005. Current issues in feed manufacturing. DSM.

Gehring, C. K., K. G. S. Lilly, and J. S. Moritz. 2009a. Maximizing the performance of broilers fed pelleted diets. Multi-State Poultry Feeding and Nutrition Conference. May 19-21, Indianapolis, IN.

Gehring, C. K., J. Jaczynski and J. S. Moritz. 2009b. Improvement of pellet quality with proteins recovered from whole fish using isoelectric solubilization/precipitation. J. Appl. Poult. Res. (Accepted Manuscript).

Ghiasi, K., R. C. Hoseney, and E. Varriano-Marston. 1982. Effects of flour components and dough ingredients on starch gelatinization. Cereal Chem. 60:58-61.

Gilpin, A. S., T. J. Herrman, K. C. Behnke, and F. J. Fairchild. 2002. Feed moisture, retention time and steam as quality and energy utilization determinants in the pelleting process. Appl. Eng. Agric. 18:331-338.

Greer, D., and F. Fairchild. 1999. Cold mash moisture control boosts pellet quality. Feed Manage. 50: 20-21.

Haralampu, S. G. 2000. Resistant starch—a review of the physical properties and biological impact of RS3. Carbohydr. Polym. 41:285-292.

Heffner, L. E., and H. B. Pfost, 1973. Gelatinization during pelleting. Feedstuffs 45:32.

Hodge, J. E. 1953. Dehydrated foods: Chemistry of browning reactions in model systems. J. Agric. Food Chem. 1:928-943.

Holm J, I. Björck, S. Ostrowska, A.-C. Eliasson, N.-G. Asp, K. Larsson, and I. Lundquist. 1983. Digestibilityof amylose lipid complexes in vitro and in vivo. Starch/Stärke. 35:294-297. 
Hoover, R. 1995. Starch retrogradation. Food Rev. Int. 11:331-346.

Hurrell, R. F., and K. J. Carpenter. 1981. The estimation of available lysine in foodstuffs after Maillard reactions. Prog. Food Nutr. Sci. 5:159-176.

Hussar, N., and A. R. Robblee, 1962. Effects of pelleting on theutilization of feed by the growing chicken. Poultry Sci. 41:1489-1493.

Inborr, J., and M. R. Bedford. 1994. Stability of feed enzymes to steam pelleting during feed processing. Anim. Feed Sci.Technol. 46:176-196.

Iqbal, M., L. L. Probert, N. H. Al-humadi, and H. Klandorf. 1999. Protein glycosylation and advanced glycosylation end products (AGEs): an avian solution. J. Gerontol. Biol. Sci. 54: B171-B176.

Jane, J. -L., and J. -F. Chen. 1992. Effect of amylose molecular size and amylopectin branch chain length on paste properties of starch. Cereal Chem. 69:60-65.

Jane, J. -L., A. Xu, M. Radosavljevic, and P. A. Seib. 1992. Location of amylose in normal starch granules. I. Susceptibility of amylose and amylopectin to cross-linking reagents. Cereal Chem. 69:405-409.

Jenkins, P. J., and A. M. Donald. 1995. The influence of amylose on starch granule structure. Int. J. Biol. Macromol. 17:315-321.

Jensen, L. S., L. H. Merril, C. V. Reddy, and J. McGinnis. 1962. Observations on eating patterns and rate of food passage of birds fed pelleted and unpelleted feed. Poult. Sci. 41:1414-1419.

Jones, F. T., K. T. Anderson, and P. R. Ferket. 1995. Effect of extrusion on feed characteristics and broiler chicken performance. J. Appl. Poult. Res. 4:300-309. 
Karim, A. A., M. H. Norziah, and C. C. Seow. 2000. Methods for the study of starch retrogradation. Food Chem. 71:9-36.

Kinsella, J. E. 1976. Functional properties of proteins in foods: a survey. Crit. Rev. Food Sci. Nutr. 23:323-395.

Kinsella, J. E. 1979. Functional properties of soy proteins. J. Am. Oil Chem. Soc. $56: 242-258$.

Bedford, M. R. 2002. The role of carbohydrases in feedstuff digestion. Pages 319-336 in Poultry Feedstuffs - Supply, Composition and Nutritive Value. J. M. McNab and K. N. Boorman, ed. CABI Publ., Wallingford, UK.

Kitts, D. D. 2007. Carbohydrates and mineral metabolism. Pages 413-434 in Functional Food Carbohydrates. C. G. Biliaderis and M. S. Izydorczyk, ed. CRC Press. Boca Raton, FL.

Lakemond, C. M. M., H. H. J. de Jongh, M. Hessing, H. Gruppen, and A. G. J. Voragen. 2000. Heat denaturation of soy glycinin: Influence of $\mathrm{pH}$ and ionic strength on molecular structure. J. Agric. Food Chem. 48:1991-1995.

Lilly, K. G. S., C. K. Gehring, K. R. Beaman, and J. S. Moritz. 2009. Evaluating the effects of pellet quality on broiler performance and carcass yield. Poult. Sci. 88(Suppl. 1):(Accepted Abstract).

Lund, D. 1984. Influence of time, temperature, moisture, ingredients and processing conditions on starch gelatinization. Crit. Rev. Food Sci. Nutr. 20:249-273. Madsen, M. H., and D. H. Christensen. 1996. Changes in viscosity properties of potato starch during growth. Starch-Stärke. 48:245-249. 
Manzocco, L., and E. Maltini. 1999. Physical changes induced by the Maillard reaction in a glucose-glycine solution. Food. Res. Int. 32:299-304.

Moughan, P. J., and S. M. Rutherfurd. 1996. A new method for determining digestible reactive lysine in foods. J. Agric. Food Chem. 44:2202-2209.

Moughan, P. J., and S. M. Rutherford. 2008. Available lysine in foods: A brief historical overview. J. AOAC Int. 91:901-906.

Martins, S. I. F. S., W. M. F. Jongen, M. A. J. S. van Boekel. 2001. A review of Maillard reaction in food and implications to kinetic modeling. Trends Food. Sci. Tech. 11:364-373.

Master Model Pellet Mill, California Pellet Mill Company (CPM). Crawfordsville, IN.

Mauron, J. 1981. The Maillard reaction in food: a critical review from the nutritional standpoint. Prog. Food Sci. 5:5-35.

Medel, P., M. A. Latorre, C. de Blas, R. Lazaro, and G. G. Mateos. 2003. Heat processing of cereals in mash or pellet diets for young pigs. Anim. Feed Sci. and Tech. 113:127-140.

Moritz, J. S., R. S. Beyer, K. J. Wilson, K. R. Cramer, L. J. McKinney, and F. J. Fairchild. 2001. Effect of moisture addition at the mixer to a corn-soybean based diet on broiler performance. J. Appl. Poult. Res. 10:347-353.

Moritz, J .S., K. J. Wilson, K. R. Cramer, R. S. Beyer, L. J. McKinney, W. B. Cavalcanti, and X. Mo. 2002. Effect of formulation density, moisture, and surfactant on feed manufacturing, pellet quality, and broiler performance. J. Appl. Poult. Res. 11:155163. 
Moritz, J.S., K. R. Cramer, K. J. Wilson, and R. S. Beyer. 2003. Feed manufacture and feeding of rations with graded levels of added moisture formulated at different energy densities. J. Appl. Poult. Res. 12:371-381.

Moritz, J. S., A. S. Parsons, N. P. Buchanan, W. B. Cavalcanti, K. R. Cramer, and R. S. Beyer. 2005. Effect of gelatinizing dietary starch through feed processing on zeroto three-week old broiler performance and metabolism. J. Appl. Poult. Res. 14:47-54.

Morrison, W. R., R. F. Tester, C. E. Snape, R. Law, and M. J. Gidley. 1993. Swelling and gelatinization of cereal starches. IV. Some effects of lipid-complexed amylose and free amylose in waxy and normal barley starches. Cereal Chem. 70: 385391.

Muirhead, S. 1999. Precision in mash moisture management improves pellets. Feedstuffs. 71: 16 .

Newkirk, R.W., and H. L. Classen. 2002. The effects of toasting canola meal on body weight, feed conversion efficiency, and mortality in broilers chickens. Poult. Sci. $81: 815-825$

Nir, I., Y. Twina, E. Grossman, and Z. Nitsan. 1994. Quantitative effects of pelleting on performance, gastrointestinal tract and behavior of meat-type chickens. Br. Poult. Sci. 33:589-602.

Nir, I., R. Hillel, I. Ptichi, and G. Shefet. 1995. Effect of particle size on performance. 3. Grinding pelleting interactions. Poult. Sci. 74: 771-783.

Nissinen, V. 1994. The effects and interactions of enzymes and hydrothermal preteatments and their contribution tofeeding value. Inter. Mill. Flour Feed. May: $21-22$. 
Noy, Y., and D. Sklan, 1995. Digestion and absorption in the young chick. Poultry Sci. 74:366-373.

Olkku, J., and C. Rha. 1978. Gelatinization of starch and wheat flour starch. A Review. Food Chem. 3:293-317.

Panigrahy, G.K., and B. K. Patnaik. 1976. Change in the stability of tendon collagen during ageing in the reptile Calotes ersicolor : a brief note. Mech. Ageing Dev. $5: 443-446$.

Parsons, C.M., K. Hashimoto, K. J. Wedekond, Y. Han, D. H. Baker. 1992. Effect of overprocessing of availability of amino acids and energy in soybean meal. Poult. Sci. 71:133-140.

Reimer, L. 1992. Conditioning. In: Proc. Northern Crops Institute Feed Mill Management and Feed Manufacturing Technol. Short Course. p. 7. California Pellet Mill Co. Crawfordsville, IN.

Renkema, J. M. S., C. M. M. Lakemond, H. H. J. de Jongh, H. Gruppen, and T. van Vliet. 2000. The effect of $\mathrm{pH}$ on heat denaturation and gel performing properties of soy proteins. J. Biotech. 79:223-230.

Renkema, J. M. S., H. Gruppen, and T. van Vliet. 2002. Influence of pH and ionic strength on heat-induced formation and rheological properties of soy protein gels in relation to denaturation and their protein compositions. 50:6064-6071.

Sajilata, M. G., R. S. Singhal, and P. R. Kulkarni. 2006. Resistant starch - A review. Compr. Rev. Food Sci. Food Saf. 5:1-17.

Salmon, R. E. 1985. Effects of pelleting, added sodium bentonite and fat in a 
wheat-based diet on performance and carcass characteristics of small white turkeys. Anim. Feed Sci. Technol. 12:223-232.

Scheideler, S. E. 1991. Pelleting is important for broilers. Pages 1-7 in Proc. $18^{\text {th }}$ Annu. Carolina Poult. Nutr. Conf., Charlotte, NC. North Carolina State Univ., Raleigh.

Silversides, F. G., and M. R. Bedford. 1999. Effect of pelleting temperature on the recovery and efficacy of a xylanase enzyme in wheat-based diets. Poult. Sci. 78:11841190.

Skoch, E. R., S. F. Binder, C. W. Deyoe, G. L. Allee, and K. C. Behnke. 1983. Effects of steam pelleting conditions on performance of pigs fed a corn-soybean meal diet. J. Anim. Sci. 57:922-928.

Skoch, E.R., K.C. Behnke, C.W. Deyoe, and S.F. Binder. 1981. The effect of steam-conditioning rate on the pelleting process. Anim. Feed Sci. Tech. 6:83.

Smith, A. M. 2001. The biosynthesis of starch granules. Biomacromolecules. $2: 335-341$

Spring, P., K. E. Newman, C. Wenk, R. Messikommer, and M. Vukić Vranjkeš. 1994. Influence of pelleting temperature on the activity of different enzymes. Poult. Sci. 75:357-361.

Stark, C.R. 1994. Pellet Quality. Ph.D Dissertation. Kansas State University. Manhattan, Kansas.

Stark, C. R., B. E. Spencer, J. C. H. Shih, C. G. Chewning, and J. J. Wang. 2009. Evaluation of keratinase stability in pelleted broiler diets. J. Appl. Poult. Res. 18:30-33. 
Stevens, C. A., 1987. Starch gelatinization and the influence of particle size, steam pressure and die speed on the pelleting process. Ph.D.Dissertation. Kansas State University, Manhattan, KS.

Thomas, M., D. J. van Zuilichem, and A. F. B. Van der Poel. 1997. Physical quality of pelleted animal feed. 2. Contribution of processes and its conditions. Anim. Feed Sci. Tech. 64:173-192.

Thomas, M., T. van Vliet, and A. F. B. Van der Poel. 1998. Physical quality of pelleted animal feed. 1. Contribution of feedstuff components. Anim. Feed Sci. Tech. 70:59-78.

Valle-Riestra, J., and R. H. Barnes. 1970. Digestion of heat-damaged egg albumen by the rat. J. Nutr. 100:873-882.

Wang, X., and C. M. Parsons, 1998. Effect of raw material source, processing system, and processing temperatures on amino acid digestibility of meat and bone meals. Poultry Sci. 77:834-841.

Winowiski, T. 1988. Wheat and pellet quality. Feed Manage. 39(9):58-64.

Wondra, K. J., J. D. Hancock, K. C. Behnke, and C. R. Stark. 1995. Effects of mill type and particle size uniformity on growth performance, nutrient digestibility, and stomach morphology in finishing pigs. J. Anim. Sci. 73:2564-2573.

Wood, J. F. 1987. The functional properties of feed raw materials and their effect on the production and quality of feed pellets. Anim. Feed Sci. Technol. 18:1-17.

Wu, H.-C. H., and A. Sarko. 1978. The double-helical molecular structure of crystalline B-amylose. Carb. Res. 61:7-25. 
Wyatt, C. L. 2009. Technical tools for supporting next generation thermo-tolerant enzymes in poultry diets. Multi-State Poultry Feeding and Nutrition Conference. May 1921, Indianapolis, IN.

Yip, K. S. P., T. J. Stillman, K. L. Britton, P. J. Artymiuk, P. J. Baker, S. E. Sedelnikova, P. C. Engel, A. Pasquo, R. Chiaraluce, V. Consalvi, R. Scandurra, and D. W. Rice. 1995. The structure of Pyrococcus furiosus glutamate dehydrogenase eveals a key role for ion-pair networks in maintaining enzyme stability at extreme temperatures. Structure. 3:1147-1158.

Zaritzky, N. E. 2000. Physical and microstructural properties of frozen gelatinized starch suspensions. Pages 15-28 in Trends in Food Engineering. Lozano, J. E., C. Añón, E. Parada-Arias, and G. V. Barbosa-Cánovas, eds. CRC press, Boca Raton, FL.

Zatari, I. M., P. R. Ferket, and S. E. Scheideler. 1990. Effect of pellet integrity, calcium lignosulfonate, and dietary energy on the performance of summer-raised broiler chickens. Poult. Sci. 69(Suppl.1):198. (Abstr.)

Zhang, Y., and C. M. Parsons, 1994. Effects of overprocessing on the nutritional quality of sunflower meal. Poultry Sci.73:436-442.

Zimonja, O., A. Stevnebø, and B. Svihus. 2007. Nutritional value of diets for broiler chickens as affected by fat source, amylose level and diet processing. Can. J. Anim. Sci. 87:553-562. 


\title{
Improvement of pellet quality with proteins recovered from whole fish using isoelectric solubilization-precipitation
}

\author{
C.K. Gehring, J. Jaczynski, and J.S. Moritz ${ }^{1}$ \\ Division of Animal and Nutritional Sciences \\ West Virginia University, Morgantown 26506 \\ Keywords: Pellet Quality, Pellet Binder, TAAD, Muscle Proteins, Gelation, Isoelectric \\ Solubilization/Precipitation \\ Running Title: Improvement of Pellet Quality \\ Primary Audience: feed manufacturers, broiler producers, nutritionists, researchers
}

${ }^{1}$ Corresponding Author: Joe.Moritz@mail.wvu.edu 


\section{SUMMARY}

Muscle proteins are known to form thermally induced gel networks and may bind particles such as feed constituents. Dietary incorporation of functional proteins may improve pellet quality. Muscle proteins were recovered from rainbow trout by using isoelectric solubilization-precipitation. The objectives of this study were 1) to determine the proximate composition and amino acid content, AMEn, TMEn and true amino acid digestibility of trout protein isolate and paste (TPP), and 2) to determine the effects of TPP on feed manufacturing, pellet quality and true amino acid digestibility of broiler diets formulated to include TPP. Four treatments, consisting of 1) a control, 2) 5\% TPP (HTPP), 3) 2.5\% TPP (LTPP), and 4) 3.9\% added moisture (MOIS) were manufactured at the West Virginia University pilot feed mill using a Latin square design. Five percent TPP resulted in the highest pellet quality, followed by LTPP, MOIS and the control. The improvement in pellet quality could be attributed to gelation of the recovered proteins. Addition of TPP reduced pellet mill production rate. Relative electrical energy usage decreased with MOIS but increased with HTPP relative to the control and LTPP treatments. Negative effects of increased viscosity likely associated with TPP, were absent with LTPP. Digestibility of Asp, Glu, Pro, Ile and Leu were lower for HTPP than the control. However, Ala digestibility was decreased in LTPP compared to with the control. Therefore, fish muscle proteins incorporated at less than $5 \%$ of the diet may be beneficial to the broiler industry as a pellet binder and nutritive feed additive. 


\section{DESCRIPTION OF PROBLEM}

Pelleted diets improve broiler feed conversion and decrease overall broiler production costs compared to mash diets. However, feed in the broiler industry often contains mostly fines, instead of whole pellets. It is apparent that production cost benefits are more likely to be realized with high-quality pellets. Feed costs represent the majority of the total cost of broiler production [1]; consequently, substantial economic losses may be incurred by feeding diets with low pellet quality. Factors that may reduce pellet quality include a fast production rate, ingredients that inhibit pellet binding, and attrition stresses associated with transportation and handling [2]. Several strategies have been explored to improve the physical quality of pelleted feed, including moisture addition at the mixer [3-5], ingredient selection [6,7], and the use of specific pellet binders, as reviewed by Thomas et al. [7]. Although various commercial pellet binders have demonstrated efficacy, increased pellet quality may be somewhat offset by nutrient dilution. Currently, very few nutritive pellet binders are available to the poultry industry. Proteins affect pellet formation by binding feed particulates [7]. However, binding capability is inherently dependent upon protein functionality. To possess optimum functionality, proteins must be in a native or undenatured state. Wood reported that pellets had a harder texture in feeds containing raw soybean meal than in feeds using denatured soybean meal [8]. The ability of native, functional proteins to immobilize water and particulates within a stable gel network [9] may be applied to improve the physical quality of pelleted feeds.

A novel method for recovery of muscle proteins, known as isoelectric solubilization-precipitation, has been developed as an alternative to conventional surimi 
processing [10-13], resulting in increased yield. Additionally, functionality may be improved, compared with surimi, after frozen storage or with addition of functional additives, or both [14]. Isoelectric solubilization-precipitation results in a 3-phase fractionation of fish raw materials (Figure 1): 1) a top phase (neutral lipids); 2) a middle phase (a soluble protein solution from which proteins are subsequently precipitated at their isoelectric point to yield a protein isolate); and 3) a bottom phase (bone, skin, stromal proteins, and membrane lipids). To curtail production expenses, functional muscle proteins may be recovered from fish processing by-products, low-value pelagic species or alternative underutilized species such as Antarctic krill [15]. Isoelectric solubilization-precipitation may be used to make novel and cost-effective fish-based feed additives for the poultry industry.

Muscle proteins recovered using isoelectric solubilization-precipitation retain functionality and their gel-forming ability is well documented [14-16]. Gelation of recovered muscle proteins may lead to improved pellet durability and resilience to postpellet stresses. Pellet quality must be taken into account when developing strategies to optimize broiler performance. Thus, functional feed additives that lead to pellets better suited to withstand the rigors of transportation and handling will be beneficial to the poultry industry. The potential to support dietary amino acid requirements may also be advantageous. The objectives of this study were 1) to determine the proximate and amino acid compositions, AMEn, TMEn and true amino acid digestibility (TAAD) of proteins recovered from whole eviscerated fish using isoelectric solubilizationprecipitation, and 2) to determine the effects of trout protein paste (TPP) on feed manufacturing, pellet quality, and the TAAD of broiler diets formulated to include TPP. 


\section{MATERIALS AND METHODS}

\section{Recovery of Trout Muscle Protein}

Rainbow trout (Onchorynchus mykiss) were obtained from a West Virginia University aquaculture research facility. Trout were eviscerated, minced [17], and immediately vacuum packaged [18], blast frozen, and stored at $-20^{\circ} \mathrm{C}$. Trout protein isolate (TPI) was obtained using isoelectric solubilization-precipitation (Figure 1) [19]. Cryoprotectants [20], at a concentration of $8.3 \%$, were added to the TPI before vacuum packaging and freezing at $-20^{\circ} \mathrm{C}$. After isolation of a sufficient volume of TPI to proceed with the experiment, $10.43 \mathrm{~kg}$ of TPI (with cryoprotectants) was thawed prior to each day of feed manufacture. Proteins in thawed TPI were extracted with $2.5 \% \mathrm{NaCl}$ and mixed with protease-inhibiting and gel-enhancing additives [21]. The $\mathrm{pH}$ and moisture content were adjusted to 7.5 and $78 \%$, respectively, to yield TPP. Care was taken throughout the process to maintain a temperature of 1 to $4^{\circ} \mathrm{C}$ to minimize autoproteolysis.

Before diet formulation, TPI was analyzed for amino acid content [22]. Concentrations of individual amino acids were calculated and corrected for moisture and content of additives. The AMEn of TPP was determined by precision feeding intact Single Comb White Leghorn roosters [23]. Proximate compositions of TPI and TPP also were determined [24].

\section{Diet Formulation and Feed Manufacture}

Experimental broiler grower diets were formulated to meet or exceed CobbVantress specifications [25]. Diets were formulated to be isocaloric and similar in concentrations of amino acids and added fat. Sand was included in order to facilitate a high soybean oil inclusion and retain a similar nutrient profile. Accordingly, CP was 
allowed to fluctuate to meet the aforementioned criteria. The concentration of soybean oil in each diet was formulated to be approximately equal, because pellet quality is known to decrease with increasing fat inclusion [26, 27]. Dietary treatments consisted of 1) the control; 2) 5\% TPP (high TPP, HTPP); 3) 2.5\% TPP (low TPP, LTPP); and 4) $3.9 \%$ added moisture (MOIS; Table 1). The addition of $3.9 \%$ moisture at the mixer is equivalent to the moisture added by a 5\% inclusion of TPP. Moritz et al. [3-5] have demonstrated a substantial increase in pellet durability with addition of moisture at the mixer. Thus, it was imperative that a moisture treatment be incorporated to differentiate moisture and protein effects. Mash for all treatments was mixed for 20 min and batched before commencing with the experiment. Allotments of mash for each treatment were set aside in four batches to equal $300 \mathrm{lb}(136 \mathrm{~kg})$ after TPP or moisture addition. On each day of manufacture, TPP and moisture were added to their respective treatments. Diets were manufactured at the West Virginia University pilot feed mill [28] over four d, using a Latin square design. Trout protein paste was added to approximately $60 \mathrm{lb}(27 \mathrm{~kg})$ of mash in a horizontal ribbon mixer [28] and mixed for $5 \mathrm{~min}$ prior to addition to the LTPP or HTPP treatment. Moisture was added at the mixer in the form of a fine mist [29]. Mash containing TPP or added moisture was mixed for $20 \mathrm{~min}$, and control mash was mixed for 5 min. After mixing, mash was conveyed to the conditioner-pellet mill. Mash was conditioned [30] to a steady-state temperature of $82^{\circ} \mathrm{C}\left(180^{\circ} \mathrm{F}\right)$. Steam pressure at the guage was $262 \mathrm{kPa}$ (38 psig). Feed temperature was monitored with a digital thermometer inserted directly into the stream of conditioned mash and was controlled by manual adjustment of steam flow rate into the conditioner. Feeder rate of mash into the conditioner was constant among all treatments. Pellets were formed with a California 
Pellet Mill [28] and cooled in a horizontal belt cooler. The time from pellet formation until exiting the cooler was approximately $2 \mathrm{~min}$. Relative electrical energy usage of the pellet mill and conditioner were determined [31], as well as pellet mill production rate, bulk density, and percentage of fines.

One representative bag from each manufacturing run was reserved for determination of pellet durability. Pellet durability index (PDI) and modified pellet durability index (MPDI) [32] were determined on the day of manufacture.

\section{TAAD and TME $_{n}$}

True amino acid digestibility of pelleted treatments, TPI, TPP, and $\mathrm{TME}_{\mathrm{n}}$ for TPI and TPP were determined by precision feeding cecectomized [33] Single Comb White Leghorn roosters (Hy-Line W-36). Digestibility assays were performed according to a modification of the procedure described by McNab and Blair [23]. Roosters were placed in individual raised wire cages equipped with cup drinkers, and feed was withheld for 24 $\mathrm{h}$ to evacuate their gastrointestinal tracts. Seven treatments were assigned to roosters in a randomized complete block design: 1) cornstarch, 2) TPI, 3) TPP, 4) control pellets, 5) LTPP pellets, 6) HTPP pellets, and 7) MOIS pellets. Four replications were conducted for each treatment. Cornstarch was used as a nitrogen-free control to account for endogenous losses. Wet samples (TPI and TPP) were lyophilized and ground to facilitate precision feeding. Aliquots of $25 \mathrm{~g}$ each were precision-fed using a 0.5 -in $(1.27-\mathrm{cm})$ tube inserted into the crop. Excreta were collected on plastic trays placed directly beneath each bird during a 24-h fasting period. Samples were weighed, air-dried and ground [34] prior to analysis. All treatments were evaluated for TAAD, and TPI and TPP samples were evaluated for $\mathrm{TME}_{\mathrm{n}}$. Excreta samples for TAAD determination were analyzed for 
amino acid content [22], and excreta samples for $\mathrm{TME}_{\mathrm{n}}$ determination were analyzed for gross energy [35] and $\mathrm{N}$ content [24]. $\mathrm{TME}_{\mathrm{n}}$ was calculated according to the method of Parsons et al. [36], and TAAD was calculated according to the method of Sibbald [37]. Roosters used in the assays were handled in accordance with West Virginia University Animal Care and Use Committee guidelines.

\section{Statistical Analysis}

Data were analyzed using the GLM procedure of SAS [38] to determine the effect of TPP inclusion on manufacturing variables and TAAD. Multiple comparisons of means were made using Fisher's LSD test. Values were considered significant at $\alpha=$ 0.05 .

\section{RESULTS AND DISCUSSION}

\section{Trout Protein Nutritional Value}

Proximate composition and ME values for TPI and TPP are presented in Table 2. The TPI ( $\%$ of DM) contained greater than $90 \%$ protein, as indicated by amino acid analysis (Table 3) [22]. Concentrations of CP, lipids, and ash in rainbow trout filet (\% of DM) have been reported as 74.4-81.4, 12.9-13.4 and 5.1-5.6\%, respectively [39, 40]. Comparatively, TPI contained $85.8,5.1$, and $3.1 \%$, the latter two values becoming negligible on a wet (as-fed) basis. Isoelectric solubilization-precipitation likely resulted in removal of nonmuscle protein constituents and thus concentration the protein. Similar results were obtained by Chen et al. [45] using trout processing by-products.

Trout protein paste contained $2.9 \%$ fat (\% of DM; Table 2) compared to 12.9 13.4\% for trout filet. Hence, there would be little concern for reduction of sensory quality (i.e., off-flavors, odors, or both) of poultry meat caused by inclusion of fish- 
derived muscle protein paste. Although some researchers have speculated that membrane lipids are sedimented with the bottom phase [15], it is possible that membrane lipids (phospholipids) are retained with the recovered proteins. Fish phospholipids are generally highly unsaturated and therefore readily oxidizable; however, at such a small inclusion of the total diet, their presence may not be a negative factor. Inclusion of fish meal is usually limited in commercial broiler diets because of product taint associated with highly oxidizable polyunsaturated fatty acids and trimethylamine [42], as well as the possibility of gizzard erosion or ulceration caused by gizzerosine formed through thermal processing [43]. The presence of prooxidants, such as heme proteins, also may contribute to product quality issues. Dietary fish meal has been associated with offflavors and odors in broiler meat $[44,45]$. Therefore, the isoelectric solubilizationprecipitation product may be of interest to nutritionists, because muscle protein isolates retain only a small percentage of lipids and heme proteins, and the aforementioned concerns may be alleviated.

Nitrogen-corrected AME and TME (\% as is; Table 2) of TPI and TPP are lower than that of most common feed additives [46]. The addition of functional additives to create TPP decreased the ME of TPI by approximately $350 \mathrm{kcal} / \mathrm{kg}$, presumably because of decreased fat (5.1 vs $2.9 \%)$ and increased ash (.1 vs. 15.4\%).

Acidic amino acids and lysine were found in the highest concentrations in recovered trout protein (Table 3). Trout protein paste had a similar amino acid composition to NRC [46] values for yellow dent corn. The concentration of each amino acid, with the exception of Cys, Leu, Phe, and Ser, was higher in TPP than in corn. 
Concentrations of the first limiting amino acids in corn- and soybean-based diets, Met,

Lys and Thr, were higher in TPP compared to corn by 11, 223 and 41\%, respectively.

\section{Manufacturing Variables}

Several manufacturing variables were influenced by addition of TPP (Table 4). Pellet mill production rate was decreased with TPP addition at either 2.5 or $5 \%$ compared with the control $(P \leq 0.05)$. Unexpectedly, production rate was decreased with moisture

addition. This reduction was possibly due to pellet mill operator apprehensions of slipping or plugging the die, as the pellet mill may become plugged with excessive moisture in the mash [47]. Relative electrical energy usage by the pellet mill was decreased by MOIS but increased by HTPP (Table 4) compared with the control ( $P \leq$ 0.05). Past research has shown that moisture addition and reduction of electrical energy usage are correlated [5]. Relative electrical energy usage was not affected by LTPP. Five percent TPP likely affected production rate and relative electrical energy usage by increasing mash viscosity. Although higher viscosity may have negatively affected some manufacturing variables, higher viscosity may increase friction (i.e., frictional heat, at the mash-die interface), which may contribute to increased starch gelatinization and protein gelation, resulting in increased pellet durability.

Bulk density decreased with TPP or moisture addition compared with the control ( $P \leq 0.05$; Table 4$)$. This reduction of bulk density may be related to pellet quality. Although there were no treatment effects on production of fines $(P=0.2682)$, total fines were numerically reduced with either concentration of TPP or moisture addition. Moritz et al. [5] reported reduced feed bulk density as graded levels of moisture were added to corn- and soybean-based diets. They attributed this phenomenon to increased air space 
with a greater percentage of intact pellets in relation to fines.

\section{Pellet and Mash Moisture}

The concentration of moisture in feed samples numerically followed the expected patterns for mash and hot pellets. Cool pellets demonstrated expected patterns of moisture concentration $(P \leq 0.05$; Table 5). Cool pellet moisture was 13.4, 14.5, 16.0, and $15.7 \%$ for the control, LTPP, HTPP, and MOIS treatments, respectively. As formulated, there was no difference between HTPP and MOIS $(P \leq 0.05)$.

\section{TAAD of Trout Proteins and Corn- and Soybean-Based Diets}

The TAAD of pelleted diets and recovered trout protein (TPI and TPP) are presented in Table 6. Digestibility of TPI was greater than $95 \%$ for the majority of amino acids assayed. Digestibility of the majority of TPI amino acids decreased $(P \leq 0.05)$ after addition of salt and functional additives (TPP). The cause of this phenomenon is unknown; however, the component responsible may be related to protein-based functional additives, specifically beef plasma protein (BPP) or transglutaminase (TGase).

Spray-dried BPP is known as an effective protease inhibitor and therefore as a gelation-enhancing additive for use in surimi products [48]. However, the use of BPP in the surimi seafood industry has been abandoned, largely because of fears of transmission of bovine spongiform encephalopathy [49]. Of the more than 60 different proteins [50] found in BPP, protease inhibition of BPP is attributed to kininogens and $\alpha_{2}$ macroglobulin $\left(\alpha_{2} \mathbf{M}\right)$ [51]. Kininogens are specific inhibitors of cysteine proteases [52], such as lysosomal cathepsins, responsible for weakening surimi gels [53]. $\alpha_{2}$ Macroglobulin is a nonspecific protease inhibitor able to inhibit all 4 classes of proteases 
[54]. Protease inhibition by $\alpha_{2} \mathrm{M}$ is facilitated by irreversible binding of substrate, resulting in steric hindrance to large macromolecules [54]. It is possible that a quantity of $\alpha_{2} \mathrm{M}$ would be complexed to endogenous proteases in trout muscle; thus the concentration of functional $\alpha_{2} \mathrm{M}$ available to inhibit gastric and pancreatic enzymes would be less than that added to TPI. Additionally, under certain conditions, BPP has been shown to improve performance of broilers [55] and pigs [56]. Ravindran and Morel [57] demonstrated higher ileal amino acid digestibility of spray dried BPP compared with soybean meal in broiler chickens, indicating that digestibility may not be diminished by inclusion of bovine plasma in broiler diets. Further research is required in order to determine if BPP is, in fact, responsible for decreased amino acid digestibility of TPP as compared to TPI.

The TGase (protein-glutamine $\gamma$-glutamyltransferase, E.C.

2.3.2.13), is a widely disseminated enzyme [58] commonly used in the food industry to catalyze the formation of $\varepsilon$ - $(\gamma$-glutamyl) lysine covalent cross-links [59], that are responsible for an increased "suwari" effect, or gel setting [60]. Digestibility of $\varepsilon$ - $(\gamma-$ glutamyl)lysine bonds has been disputed. Tang et al. [61] showed that in vitro digestibility of casein by pepsin or trypsin was decreased significantly following microbial TGase treatment [65]. In contrast, high bioavailability of the isopeptide moiety was reported in rats [62], chicks [62], and pigs [63].

With respect to the extremely low concentration of BPP and TGase in the LTPP and HTPP treatments, there may have been no effect on amino acid digestibility of the pelleted feed. Diets containing TPP, compared with the control, did not affect digestibility of Cys, Lys, Met, Thr or Val $(P>0.05)$ regardless of the inclusion level. At 
a concentration of $2.5 \%$, TPP decreased digestibility only for Ala $(P>0.05)$. Digestibility of Asp, Glu, Ile, Pro and Leu were lower for HTPP than the control $(P<0.05)$; however, TAAD of HTPP was not different $(\mathrm{P}>0.05)$ from that of LTTP or MOIS for all amino acids, with the exception of Ile. Reduced digestibility associated with protein paste may be a function of feed viscosity. Increased digesta viscosity has been associated with decreased performance and nutrient availability in chickens $[64,65]$. Large inclusions of TPP may decrease the availability of nutrients to digestive enzymes and reduce amino acid availability in a dose-dependent manner. However, this effect may be offset by increased pellet quality. To minimize undesirable effects on pellet mill production rate and electrical energy usage, as well as prevent decreased amino acid digestibility, it is the recommendation of the authors that TPP inclusion not exceed 5\%.

\section{TPP on Pellet Quality}

Broiler diets in the United States are comprised primarily of corn; thus, starch gelatinization is typically the major physicochemical factor that affects pellet formation and integrity. As expected, feed industry representatives may be concerned predominantly with starch gelatinization [47]; however, protein also has been shown to affect pellet quality $[47,66]$ and protein gelation may be used to enhance the quality of pelleted feeds.

Muscle proteins added to broiler diets improved pellet quality $(\mathrm{P} \leq 0.05$; Table 4$)$. Pellet durability was increased by $33 \%$ compared with the control with a $5 \%$ inclusion of TPP. High TPP increased the PDI by $15 \%$ when compared with an equal addition of moisture (MOIS treatment). There was no difference in PDI between LTPP and MOIS; however, LTPP pellets had a greater MPDI $(\mathrm{P} \leq 0.05)$, despite having only half the 
volume of moisture added to the cold mash. Inclusion of sand in the control was nearly 2-fold greater than inn HTPP to maintain similar nutrient profiles within treatments. Sand inclusion may affect pellet quality; however, because LTPP had a higher pellet quality compared with MOIS, despite having more than 2 orders of magnitude more sand and without added-moisture, it is the opinion of the authors that sand inclusion did not confound the effect of TPP on pellet quality.

Increased PDI and MPDI of the TPP treatments (HTPP and both LTPP and HTPP, respectively) compared with the control and MOIS treatments indicate that moisture addition per se, was not responsible for these results. Pellet quality is defined by Cramer et al. [67] as the ability of a pellet to withstand mechanical agitations produced through conveying, transportation, and handling by birds. Thus, quality is not determined merely by post-manufacturing durability, but more notably by the integrity of pellets at the feeder. According to a survey of broiler pellet quality, pellet integrity is exhausted rapidly between the feed mill and the farm, resulting in fewer than $30 \%$ whole pellets presented to birds [68]. Incorporation of recovered trout proteins into broiler grower diets had a protective effect on pellet integrity (Figure 2). In a commercial setting, it is likely that an increased number of whole pellets would survive transportation and handling. Despite a higher PDI, MOIS pellets had a reduction of durability (PDI minus MPDI) equal to the control. Conversely, LTPP and HTPP pellets had a reduced loss of integrity in an inclusion-dependent fashion. The immobilization of large volumes of water and other ingredients by muscle protein gels has been well established. Chen and Jaczynski [69] demonstrated formation of a strong gel with trout muscle proteins, isolated under similar conditions, using isoelectric solubilization-precipitation. 
Therefore, the data support the theory that gelation of functional recovered proteins improved pellet quality.

Inclusion of functional muscle proteins in broiler diets will likely result in a greater percentage of intact pellets in the feeder and may improve broiler performance. However, reduced digestibility observed for some amino acids is of concern and future research should elucidate the causative factor(s) affecting amino acid availability of feeds containing recovered muscle proteins. A feeding trial should be conducted to determine the effects of pelleted diets containing muscle protein paste on broiler performance.

The suitability of using isoelectric solubilization-precipitation to produce muscle protein pellet binders for production animal agriculture also must be ascertained. Laboratory batch processing would be impractical for commercial recovery of muscle proteins; however, Jaczynski [70] developed a method for continuous protein recovery using an industrial bioreactor system. Thus, recovery of muscle proteins for use in animal feeds may ultimately be economically viable, especially if used as a functional ingredient. Another concern is the amount of moisture present in the material. Muscle protein pastes are approximately $78 \%$ moisture and thus may present problems associated with transportation and handling. It may be beneficial to remove moisture (i.e., lyophilize recovered muscle protein liquid or isolate and add water at the mixer) to reduce shipping costs and ease handling. Currently, the best application for this technology would be in the US Southeast, where broiler production and aquaculture are concentrated [77]. The close proximity of catfish-processing facilities to feed mills in the region may lead to reduced transportation and handling costs. 


\section{CONCLUSIONS AND APPLICATIONS}

1. Muscle proteins recovered using isoelectric solubilization-precipitation improved pellet quality.

2. Five percent, but not $2.5 \%$, trout protein paste increased pellet mill relative electrical energy usage and decreased pellet mill production rate.

3. Digestibility of some amino acids decreased in corn- and soybean-based diets containing trout protein paste.

4. Further research should 1) attempt to elucidate the ideal concentration of protein paste to maximize pellet quality improvement while retaining the nutritional quality of the diet; 2) determine the causative factors affecting amino acid digestibility in pelleted diets containing muscle protein paste; 3 ) determine the effects of pelleted feeds containing muscle protein paste on broiler performance; and 4) identify means to reduce production and handling costs. 


\section{REFERENCES AND NOTES}

1. Behnke, K. C. 1996. Feed manufacturing technology: Current issues and challenges. Anim. Feed Sci. Technol. 62:49-57.

2. Thomas, M., and A. F. B. van der Poel. 1996. Physical quality of pelleted animal feed 1. Criteria for pellet quality. Anim. Feed. Sci. Technol. 61:89-112.

3. Moritz, J. S., R. S. Beyer, K. J. Wilson, K. R. Cramer, L. J. McKinney, and F. J. Fairchild. 2001. Effect of moisture addition at the mixer to a corn-soybean based diet on broiler performance. J. Appl. Poult. Res. 10:347-353.

4. Moritz, J. S., K. J. Wilson, K. R. Cramer, R. S. Beyer, L. J. McKinney, W. B. Cavalcanti, and X. Mo. 2002. Effect of formulation density, moisture, and surfactant on feed manufacturing, pellet quality, and broiler performance. J. Appl. Poult. Res. 11:155163.

5. Moritz, J. S., K. R. Cramer, K. J. Wilson, and R. S. Beyer. 2003. Feed manufacture and feeding of rations with graded levels of added moisture formulated at different energy densities. J. Appl. Poult. Res. 12:371-381.

6. Lilly, K. G. S., N. P. Buchanan, S. E. Cutlip, and J. S. Moritz. 2008. The effects of fiber, moisture and protein on pellet manufacture variables. Poult. Sci. 87(Suppl. 1):168. (Abstr.)

7. Thomas, M., T. van Vliet, A. F. B. van der Poel. 1998. Physical quality of pelleted animal feed 3. Contribution of feedstuff components. Anim. Feed. Sci. Technol. 70:59-78.

8. Wood, J. F. 1987. The functional properties of feed raw materials 
and their effect on the production and quality of feed pellets. Anim. Feed Sci. Technol. 18:1-17.

9. Lanier, T. C. 1986. Functional properties of surimi. Food Technol. 40:107-114.

10. Hultin, H. O., and S. D. Kelleher. 1999. Process for isolating a protein composition from a muscle source and protein composition. US Pat. No. 6,005,073. Assignee: Advanced Protein Technologies, Inc., Rockport, MA.

11. Hultin, H. O., and S. D. Kelleher. 2000. High efficiency alkaline protein extraction. US Pat. No. 6,136,959. Assignee: University of Massachusetts, Boston, MA.

12. Hultin, H. O., and S. D. Kelleher. 2001. Process for isolating a protein composition from a muscle source and protein composition. US Pat. No. 6,288,216 B1. Assignee: Advanced Protein Technologies, Inc., Ipswich, MA.

13. Hultin, H. O., and S. D. Kelleher. 2002. Protein composition and process for isolating a protein composition from a muscle source. US Pat. No. 6,451,975 B1. Assignee: Advanced Protein Technologies, Inc., Rockport, MA.

14. Kristinsson, H. G., and Y. Liang. 2006. Effect of pH-shift processing on atlantic croaker (Micropogonias undulates) muscle proteins. J. Food. Sci. 71:C304-C312.

15. Hultin, H. O., H. G. Kristinsson, T. C. Lanier, and J. W. Park. 2005. Process for recovery of functional proteins by $\mathrm{pH}$ shift. Pages 107-139 in Surimi and Surimi Seafood. $2^{\text {nd }}$ edn. J. W. Park, ed. CRC press, Boca Raton, FL.

16. Chen, Y. -C., and J. Jaczynski. 2007. Gelation of protein recovered from whole antarctic krill (Euphausia superba) by isoelectric solubilization/precipitation as affected by functional additives. J. Agric. Food Chem. 55:1814-1822.

17. Hobart meat grinder (model 4146, Hobart Corp., Troy, OH). 
18. Trout mince was vacuum packaged in polyethylene bags using a Koch vacuum-packaging machine (Ultravacâ, Model UV500; Koch, Kansas City, MO).

19. A processing flowchart for recovery of muscle protein from whole trout is shown in Figure 1. Cold $\left(1^{\circ} \mathrm{C}\right)$ distilled and deionized water $\left(\mathrm{ddH}_{2} \mathrm{O}\right)$ was added to partially frozen, ground whole trout at a 1:6 ratio (trout:water, wt/volume). Because of endogenous protease activity, the temperature during the entire processing to recover trout muscle protein was carefully controlled at $1-4{ }^{\circ} \mathrm{C}$. The homogenization-mixing was continued with a laboratory homogenizer (PowerGen 700, Fisher Scientific, Fairlawn, $\mathrm{NJ})$ set at speed three. The $\mathrm{pH}$ of the homogenate was adjusted to $11.0 \pm 0.05$ with $10 \mathrm{~N}$ $\mathrm{NaOH}$ in order to solubilize trout proteins. The $\mathrm{pH}$ meter (model AB15, Fisher Scientific, Fairlawn, NJ) was calibrated frequently to ensure accurate readings during experiments. Once the desired $\mathrm{pH}$ was obtained, the solubilization reaction was allowed to proceed for $10 \mathrm{~min}$, followed by centrifugation (Sorvall RC-5B Refrigerated Superspeed, Kendro Laboratory Products, Newton, CT) at $10000 \mathrm{x} g$ for $10 \mathrm{~min}$. The supernatant was collected, and the $\mathrm{pH}$ was adjusted to $5.50 \pm 0.05$ by $10 \mathrm{~N} \mathrm{HCl}$ in order to isoelectrically precipitate trout proteins. Once the desired $\mathrm{pH}$ was obtained, the precipitation reaction was allowed to proceed for $10 \mathrm{~min}$. The precipitated protein was centrifuged at $10000 \mathrm{x} g$ for $10 \mathrm{~min}$ to remove free water.

20. Recovered trout proteins were mixed with a cryoprotectant mixture of $4 \%$ crystalline dihydrate trehalose (Cargill Inc., Wayzata, MN), 4\% D-sorbitol (Sigma Aldrich Inc., St. Louis, MO) and 0.3\% phosphate (PP; Kena FP-28, Innophos, Cranbury, NJ) (Cryoprotectant:TPI, wt/wt) in a benchtop mixer (Sunbeam Mixmaster model 2350, Sunbeam Products Inc., Boca Raton, FL). 
21. Muscle proteins were extracted with $2.5 \% \mathrm{NaCl}(\mathrm{wt} / \mathrm{wt})$, followed by addition of functional additives, consisting of $4 \%$ potato starch (Penbind 1000 modified potato starch, Penford Food Ingredients Corp., Centennial, CO), 1\% spray-dried beef plasma protein (Proliant Inc., Ankeny, IA), 1\% microbial transglutaminase (Avtiva RM, Ajinomoto USA Inc., Teaneck, NJ) and 0.3\% PP. Functional additives were incorporated as a percentage of the final weight.

22. AOAC. 2006. Method 982. 30: Official Methods of Analysis. 17th ed. Assoc. Off. Anal. Chem., Arlington, VA. Amino acid content was determined at the Experiment Station Chemical Laboratories (Agricultural Experiment Station, University of MissouriColumbia) according to AOAC official methods.

23. McNab, J. M., and J. C. Blair. 1988. Modified assay for true and apparent metabolisable energy based on tube feeding. Br. Poult. Sci. 29:697-707.

24. AOAC. 1990. Official Methods of Analysis. 15th ed. Assoc. Off. Anal. Chem., Arlington, VA.

25. Cobb 500 Broiler Performance and Nutrition Supplement (Cobb-Vantress Inc., Siloam Springs, AR).

26. Richardson, W., and E. J. Day. 1976. Effect of varying levels of added fat in broiler diets on pellet quality. Feedstuffs 48(20):24.

27. Salmon, R. E. 1985. Effects of pelleting, added sodium bentonite and fat in a wheat-based diet on performance and carcass characteristics of small white turkeys. Anim. Feed Sci. Technol. 12:223-232. 
28. Weigh-tronix stationary feed mill SFM-2000 (integrated hammer mill, scale, micro ingredient mixer); 15-horse power horizontal shaft hammer mill (4 screens: 1/8, 3/16, 1/4, and 5/16 in.); 2,000-lb capacity single-screw vertical mixer in series with a pellet mill; 250-lb horizontal ribbon mixer; CPM 2288A master model pellet mill; 40-HP main drive motor; 12 in. diameter, $3 / 16$ in. $x 1.77$ in. die.

29. Moisture was added at a rate of $22 \mathrm{~L} / \mathrm{hr}$ (determined by adding a known volume of water to the sprayer and timing the evacuation) using a 2 gal (7.57-L) compression sprayer.

30. A $4.25 \mathrm{ft}$ length, $1.02 \mathrm{ft}$ diameter short term California Pellet Mill conditioner (3 steam inlet ports), 429 rpm shaft speed; 21 picks; 10-s feed retention time.

31. Powerlogic power meters attached to the 3-phase leads of the pellet mill main drive and conditioner motor (Square D, Palatine, IL).

32. American Society of Agricultural Engineers. 1997. ASAE S269.4: Cubes, pellets, and crumbles-Definitions and methods for determining density, durability, and moisture. ASAE Standards 1997. Am. Soc. Agric. Eng., St. Joseph, MI. Due to the use of a 3/16 in. x 1.77 in. die, pellets were sifted in a No. 6 American Society for Testing and Materials (ASTM) screen. Five hundred grams of sifted pellets were placed in a dust-tight enclosure and tumbled for $10 \mathrm{~min}$ at $50 \mathrm{rpm}$. The enclosure was of the dimensions $12 \times 12$ in., with a $2 \times 9$ in. plate affixed diagonally along one of the $12 \times 12$ in. sides. The tumbled samples were then sifted again (No. 6 ASTM) and weighed. The PDI was calculated by dividing the weight of pellets after tumbling by the weight of pellets before tumbling, and then multiplying by 100 . The MPDI was determined in a 
similar manner, with the exception of adding five $13-\mathrm{mm}$ hex nuts to the pretumbled sample to obtain added pellet agitation.

33. Parsons, C. M. 1985. Influence of caecectomy on digestibility of amino acids by roosters fed distillers' dried grains with solubles. J. Agric. Sci. Camb. 104:469-472.

34. Cyclotec 1093 sample mill, Foss Tecator, Eden Prairie, MN.

35. Isoperibol oxygen bomb calorimeter, model 1266, Parr Instrument Co., Moline, IL.

36. Parsons, C. M., L. M. Potter, and B. A. Bliss. 1982. True metabolizable energy corrected to nitrogen equilibrium. Poult. Sci. 61:2241-2246.

37. Sibbald, I. R. 1979. A bioassay for available amino acids and true metabolizable energy in feedstuffs. Poult. Sci. 58: 668-673.

38. SAS Institute. 2000. The SAS System for Windows 2000. Release 8.1. SAS Inst. Inc., Cary, NC.

39. Kinsella, J. E., J. L. Shimp, J. Mai, and J. Weihrauch. 1977. Sterol, phospholipids, mineral content and proximate composition of filets of select freshwater species. J. Food Biochem. 1:131-140.

40. Gokoglu, N., P. Yerlikaya, and E. Cengiz. 2003. Effects of cooking methods on the proximate composition and mineral contents of rainbow trout (Onchorhynchus mykiss). Food Chem. 84:19-22.

41. Chen, Y. -C., J. C. Tou, and J. Jaczynski. 2007. Amino acid, fatty acid, and mineral profiles of materials recovered from rainbow trout (Oncorhynchus mykiss) processing by-products using isoelectric solubilization/precipitation. J. Food Sci. 72:C528-C536. 
42. Leeson, S., and J. D. Summers. 1997. Ingredient evaluation and diet formulation. Pages 10-111 in Commercial Poultry Nutrition, Second Ed. University Books, Guelph, Ontario.

43. Okazaki, T., T. Noguchi, K. Igarashi, Y. Sakagami, H. Seto, K., Mori, H. Naito, T. Masumura, and M. Sugahara. 1983. Gizzerosine, a new toxic substance in fish meal, causes severe gizzard erosion in chicks. Agric. Biol. Chem. 47:2949-2952.

44. Edwards, H. M., Jr., and K. N. May. 1965. Studies with menhaden oil in practice-type broiler rations. Poult. Sci. 44:685-688.

45. Fry, J. L., P. Van Walleghem, P. W. Waldroup, and R. H. Harms. 1965. Fish meal studies. 2. Effects of levels and sources of "fishy flavor" in broiler meat. Poult. Sci. 44:1016-1019.

46. NRC, 1994. Nutrient requirements of poultry. 9 rev. ed. National Academy Press, Washington, DC.

47. Briggs, J. L., D. E. Maier, B. A. Watkins, and K. C. Behnke. 1999. Effect of ingredients and processing parameters on pellet quality. Poult. Sci. 78:1464-1471

48. Jang, I. S., and T. C. Lanier. 1999. Bovine plasma protein functions in surimi gelation compared with cysteine protease inhibitors. J. Food Sci. 64:842-846.

49. Choi, Y. J., I. S. Kang, and T. C. Lanier. 2005. Proteolytic enzymes and control in surimi. Pages 227-278 in Surimi and Surimi Seafood. $2^{\text {nd }}$ edn. J. W. Park, ed. CRC press, Boca Raton, FL.

50. Putnam, F. W. 1975. The roster of plasma proteins. Pages 57-131 in The Plasma Proteins. F. W. Putnam, ed. Academic Press, New York, NY.

51. Seymour, T. A., M. Y. Peters, M. T. Morrisey, and H. An. 1997. Surimi gel 
enhancement by bovine plasma proteins. J. Agric. Food Chem. 45:2919-2923.

52. Sasaki, M., I. Ohkubo, C. Namikawa, S. Higashiyama, H. Ishiguro, M. Kunimatsu, K. Kurachi, H. Shiokawa, and T. Takashawa. 1996. Kininogens as thiol proteinase inhibitors. Pages 393-412 in Cysteine proteinases and their inhibitors. V. Turk, ed. Walter De Gruyter and Co., Berlin, Germany.

53. An, H., V. Weerasinghe, T. A. Seymour, and M. T. Morrissey. 1994. Cathepsin degradation of Pacific whiting surimi proteins. J. Food Sci. 59:1013-1017.

54. Barrett, A. J., and P. M. Starkey. 1973. The interaction of $\alpha 2$-macroglobulin with proteinases. Characteristics and specificity of the reaction, and a hypothesis concerning its molecular mechanism. Biochem. J. 133:709-724.

55. Bregendahl, K., D. U. Ahn, D. W. Trampel, and J. M. Campbell. 2005. Effects of dietary spray-dried bovine plasma protein on broiler growth performance and breastmeat yield. J. Appl. Poult. Res. 14:560-568.

56. Pierce, J. L., G. L. Cromwell, M. D. Lindemann, L. E. Russell, and E. M. Weaver. 2005. Effects of spray-dried animal plasma and immunoglobulins on performance of early weaned pigs. J. Anim. Sci. 83:2876-2885.

57. Ravindran, V., and P. C. H. Morel. 2006. Ileal amino acid digestibility of some novel dietary protein sources for growing chickens. J. Sci. Food Agric. 86:2603 2608.

58. Kuraishi, C., K. Yamazaki, and Y. Susa. 2001. Transglutaminase: Its utilization in the food industry. Food. Rev. Int. 17:221-246.

59. Folk, J. E. 1980. Transglutaminase. Rev. Biochem. 49:517- 531. 
60. Nowsad, A. A. K. M., S. Kano, and E. Niwa. 1995. Contribution of transglutaminase on the setting of various actomyosin pastes. Fish. Sci. 61: 79-81.

61. Tang, C. H., L. Li, and X. Q. Yang. 2006. Influence of transglutaminaseinduced cross-linking on in vitro digestibility of soy protein isolate. J. Food Biochem. 30:718-731.

62. Waibel, P. E. and K. J. Carpenter. 1972. Mechanisms of heat damage in proteins. Br. J. Nutr. 27:509-515.

63. Roos, N., P. C. Lorenzen, H. Sick, J. Schrezenmeir, and E. Schlimme. 2003. Cross-linking by transglutaminase changes neither the in vitro proteolysis nor the in vivo digestibility of caseinate. Kieler Milchw. Forsch. 55:261-276.

64. Choct, M., and G. Annison. 1992. Anti-nutritive affect of wheat pentosans in broiler chickens: roles of viscosity and gut microflora. Br. Poult. Sci. 33:821-834.

65. Hughes, R. J., Choct, M., Kocher, A., and R. J. Van Barneveld. 2000. Effect of food enzymes on AME and composition of digesta from broiler chickens fed on diets containing non-starch polysaccharides isolated from lupin kernel. Br. Poult. Sci. 41:318323.

66. Winowiski, 1988. Wheat and pellet quality. Feed Manage. 39(9):58-64.

67. Cramer, K. R., K. J. Wilson, J. S. Moritz, and R. S. Beyer. 2003. Effect of sorghum-based diets subjected to various manufacturing procedures on broiler performance. J. Appl. Poult. Res. 12:404-410.

68. Scheideler, S. E. 1991. Pelleting is important for broilers. Pages 1-7 in Proc. 18th Annu. Carolina Poult. Nutr. Conf., Charlotte, NC. North Carolina State Univ., Raleigh. 
69. Chen, Y. -C., and J. Jaczynski. 2007. Protein recovery from rainbow trout (Oncorhynchus mykiss) processing by-products via isoelectric solubilization / precipitation and its gelation properties as affected by functional additives. J. Agric. Food Chem. 55:9079-9088.

70. Jaczynski, J. Industrial bioreactor and method of use in continuous protein and lipid recovery system. West Virginia Univ., assignee. U.S. Patent and Trademark Office number 20070281349, published: December 6, 2007.

71. Semmens, K. J. 2007. West Virginia Univ., Morgantown. Personal communication.

\section{Acknowledgments}

This study was partially funded by Hatch funds allocated to West Virginia University. The authors acknowledge Sara Beamer, Susan Slider and Tammy Webster for their generous assistance with laboratory analyses and providing laboratory equipment. The assistance of Nancy Buchanan, Sarah Cutlip, John Hott, Amanda Rack and Kelley Lilly with feed manufacture is appreciated greatly. Additionally, the authors thank Dr. E. Keith Inskeep for invaluable and insightful comments in regard to proofreading of the manuscript. 
Table 1. Dietary Treatment Formulations and Composition.

\begin{tabular}{|c|c|c|c|c|}
\hline \multirow[b]{2}{*}{ Item } & \multirow{2}{*}{ Control } & \multicolumn{3}{|c|}{ Dietary Treatment, ${ }^{1} \%$} \\
\hline & & LTPP & HTPP & MOIS \\
\hline \multicolumn{5}{|l|}{ Ingredient } \\
\hline Corn & 55.13 & 53.93 & 52.81 & 57.97 \\
\hline Soybean Meal & 32.89 & 31.07 & 29.13 & 28.97 \\
\hline Soybean Oil & 4.74 & 4.74 & 4.74 & 4.74 \\
\hline Sand & 3.12 & 3.54 & 3.90 & 0.01 \\
\hline Tap Water & - & - & - & 3.91 \\
\hline TPP & - & 2.50 & 5.00 & - \\
\hline Dicalcium Phosphate & 1.72 & 1.74 & 1.77 & 1.75 \\
\hline Limestone & 1.21 & 1.21 & 1.21 & 1.23 \\
\hline Salt & 0.41 & 0.41 & 0.41 & 0.41 \\
\hline DL-Methionine & 0.28 & 0.31 & 0.38 & 0.33 \\
\hline NB- $3000^{2}$ & 0.25 & 0.25 & 0.25 & 0.25 \\
\hline L-Lysine hydrochloride 3 & 0.11 & 0.17 & 0.23 & 0.26 \\
\hline Coban $60^{4}$ & 0.08 & 0.08 & 0.08 & 0.08 \\
\hline BMD $50^{5}$ & 0.05 & 0.05 & 0.05 & 0.05 \\
\hline L-Threonine & 0.01 & 0.01 & 0.04 & 0.01 \\
\hline \multicolumn{5}{|l|}{ Calculated Values } \\
\hline Crude Protein, \% & 21.00 & 21.00 & 21.00 & 19.50 \\
\hline Ether Extract, \% & 7.12 & 7.06 & 7.00 & 7.19 \\
\hline $\mathrm{AME}_{\mathrm{n}}, \mathrm{kcal} / \mathrm{kg}$ & 3172 & 3107 & 3041 & 3172 \\
\hline Lysine, \% & 1.25 & 1.25 & 1.25 & 1.25 \\
\hline Methionine, \% & 0.61 & 0.62 & 0.68 & 0.63 \\
\hline TSAA, $\%$ & 0.96 & 0.96 & 1.00 & 0.96 \\
\hline Threonine, \% & 0.83 & 0.80 & 0.80 & 0.80 \\
\hline Tryptophan, \% & 0.28 & 0.26 & 0.25 & 0.25 \\
\hline Calcium, \% & 0.88 & 0.88 & 0.88 & 0.88 \\
\hline P, Available, \% & 0.42 & 0.42 & 0.42 & 0.42 \\
\hline Sodium, \% & 0.17 & 0.17 & 0.17 & 0.17 \\
\hline \multicolumn{5}{|l|}{ Analyzed Values ${ }^{5}$} \\
\hline Crude Protein, \% & 19.24 & 18.28 & 19.40 & 16.82 \\
\hline Ether Extract, \% & 5.18 & 5.27 & 5.30 & 5.22 \\
\hline Ash, $\%$ & 9.49 & 9.57 & 10.84 & 6.19 \\
\hline \multicolumn{5}{|c|}{ 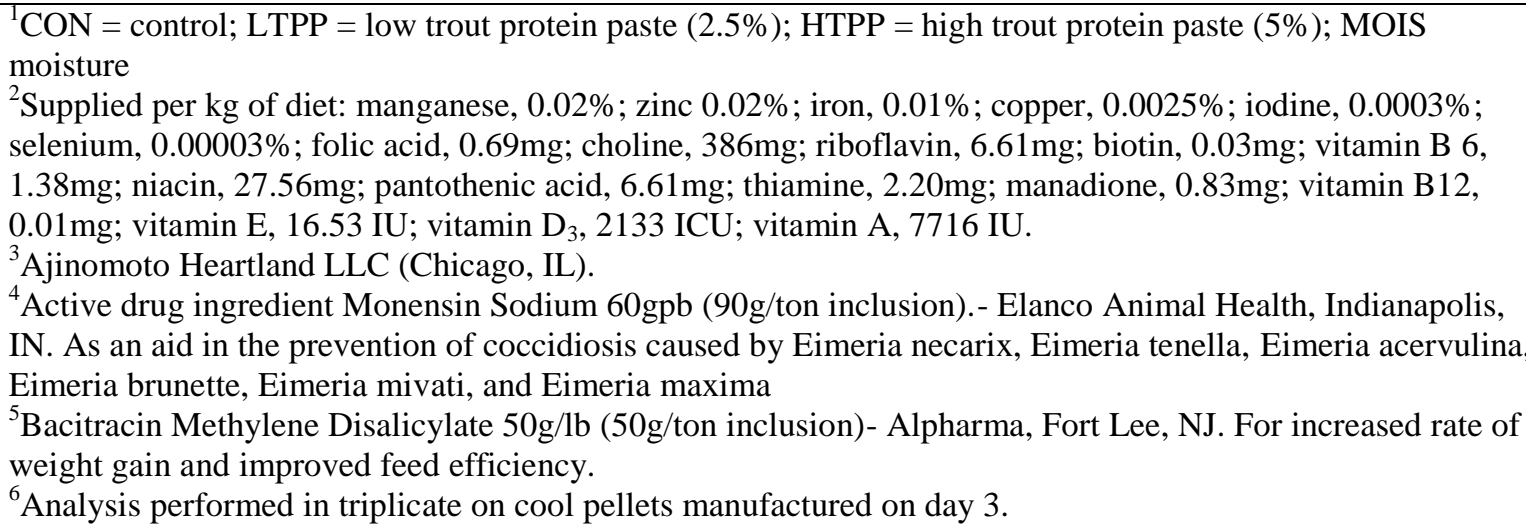 } \\
\hline
\end{tabular}


Table 2. Proximate composition and ME of trout protein isolate and trout protein paste (mean $\pm \mathrm{SD}$ ).

\begin{tabular}{lcc}
\hline Component $(\%)$ & $\begin{array}{r}\text { Trout Protein Isolate } \\
(\text { mean } \pm \text { SD })\end{array}$ & $\begin{array}{c}\text { Trout Protein Paste } \\
(\text { mean } \pm \text { SD })\end{array}$ \\
\hline Moisture & $73.27 \pm 0.02$ & $78 \pm 1$ \\
Dry Matter $^{1}$ & $26.73 \pm 0.02$ & $22 \pm 1$ \\
Ash $^{1}$ & $3.12 \pm 0.01$ & $15.40 \pm 0.08$ \\
Crude Protein $^{1}$ & $85.77 \pm 0.18$ & $36.78 \pm 0.43$ \\
Amino Acids $^{1,2}$ & $90.37 \pm 1.15$ & $40.33 \pm \mathrm{NA}^{3}$ \\
Ether Extract $^{1}$ & $5.11 \pm 0.02$ & $2.89 \pm 0.38$ \\
AME $_{n}^{4} \quad(\mathrm{kcal} / \mathrm{kg})$ & & \\
$\mathrm{TME}_{\mathrm{n}}{ }^{4}$ & $1,117 \pm 115$ & $794 \pm 53$ \\
\hline
\end{tabular}

${ }^{1}$ Calculated on a DM basis.

${ }^{2}$ The value for trout protein isolate was determined by HPLC [21]. The value for trout protein paste is estimated based on a conversion factor of 6.96, which explains the difference between CP and HPLC data.

${ }^{3} \mathrm{NA}=$ not applicable.

${ }^{4}$ Calculated on a wet (as-is) basis. 
Table 3. Amino acid profile of trout protein isolate and trout protein paste (mean $\pm \mathrm{SD})^{1}$.

\begin{tabular}{|c|c|c|c|c|}
\hline \multirow[b]{2}{*}{ Amino Acid } & \multicolumn{2}{|c|}{ Trout Protein Isolate, $\%$} & \multicolumn{2}{|c|}{ Trout Protein Paste, \% } \\
\hline & DM Basis & $\begin{array}{c}\text { As-Is Basis } \\
\text { (73.27\% Moisture) }\end{array}$ & DM Basis & $\begin{array}{c}\text { As-Is Basis } \\
\text { (78\% Moisture) }\end{array}$ \\
\hline Alanine & $5.2 \pm 0.1$ & $1.4 \pm 0.0$ & $2.2 \pm 0.0$ & $0.5 \pm 0.0$ \\
\hline Arginine $^{2}$ & $5.8 \pm 0.1$ & $1.5 \pm 0.0$ & $2.4 \pm 0.0$ & $0.5 \pm 0.0$ \\
\hline Aspartic Acid & $9.4 \pm 0.1$ & $2.5 \pm 0.0$ & $4.0 \pm 0.0$ & $0.9 \pm 0.0$ \\
\hline Cysteine & $1.0 \pm 0.0$ & $0.3 \pm 0.0$ & $0.6 \pm 0.0$ & $0.1 \pm 0.0$ \\
\hline Glutamic Acid & $13.5 \pm 0.2$ & $3.6 \pm 0.0$ & $6.0 \pm 0.0$ & $1.3 \pm 0.1$ \\
\hline Glycine & $3.9 \pm 0.1$ & $1.0 \pm 0.0$ & $1.6 \pm 0.0$ & $0.4 \pm 0.0$ \\
\hline Histidine $^{2}$ & $2.6 \pm 0.1$ & $0.7 \pm 0.0$ & $1.1 \pm 0.0$ & $0.2 \pm 0.0$ \\
\hline Hydroxylysine & $0.01 \pm 0.01$ & - & - & - \\
\hline Hydroxyproline & - & - & - & - \\
\hline Isoleucine $^{2}$ & $4.6 \pm 0.1$ & $1.2 \pm 0.0$ & $2.0 \pm 0.0$ & $0.4 \pm 0.0$ \\
\hline Lanthionine & $0.02 \pm 0.02$ & $0.01 \pm 0.00$ & $0.05 \pm 0.01$ & $0.01 \pm 0.00$ \\
\hline Leucine $^{2}$ & $8.4 \pm 0.1$ & $2.2 \pm 0.0$ & $3.5 \pm 0.0$ & $0.8 \pm 0.0$ \\
\hline Lysine $^{2}$ & $8.9 \pm 0.1$ & $2.4 \pm 0.0$ & $3.8 \pm 0.0$ & $0.8 \pm 0.0$ \\
\hline Methionine $^{2}$ & $3.1 \pm 0.0$ & $0.8 \pm 0.0$ & $0.9 \pm 0.0$ & $0.2 \pm 0.0$ \\
\hline Ornithine & $0.12 \pm 0.00$ & $0.03 \pm 0.00$ & $0.01 \pm 0.01$ & - \\
\hline Phenylalanine $^{2}$ & $4.0 \pm 0.1$ & $1.1 \pm 0.0$ & $1.8 \pm 0.0$ & $0.4 \pm 0.0$ \\
\hline Proline & $2.7 \pm 0.0$ & $0.7 \pm 0.0$ & $1.5 \pm 0.0$ & $0.3 \pm 0.0$ \\
\hline Serine & $3.0 \pm 0.1$ & $0.8 \pm 0.0$ & $1.6 \pm 0.0$ & $0.3 \pm 0.0$ \\
\hline Taurine & $0.14 \pm 0.00$ & $0.04 \pm 0.0$ & $0.09 \pm 0.01$ & $0.02 \pm 0.00$ \\
\hline Threonine $^{2}$ & $4.1 \pm 0.1$ & $1.1 \pm 0.0$ & $1.8 \pm 0.0$ & $0.4 \pm 0.0$ \\
\hline Tryptophan $^{2}$ & $1.1 \pm 0.0$ & $0.3 \pm 0.0$ & $0.7 \pm 0.0$ & $0.1 \pm 0.0$ \\
\hline Tyrosine & $3.5 \pm 0.1$ & $0.9 \pm 0.0$ & $1.5 \pm 0.0$ & $0.3 \pm 0.0$ \\
\hline Valine $^{2}$ & $5.4 \pm 0.1$ & $1.4 \pm 0.0$ & $2.4 \pm 0.0$ & $0.5 \pm 0.0$ \\
\hline TEAA $^{3}$ & 48.0 & 12.8 & 20.2 & 4.5 \\
\hline $\mathrm{TAA}^{4}$ & 90.1 & 24.1 & 39.0 & 8.6 \\
\hline TEAA:TAA & 53.2 & 53.2 & 51.9 & 51.9 \\
\hline
\end{tabular}

${ }^{1}$ Values are rounded for clarity. Mean and standard deviation for hydroxylated amino acids, ornithine and taurine are presented to the hundredths place because they comprise only a small fraction of total amino acids yet are detectable in some samples.

${ }^{2}$ Essential amino acids.

${ }^{3}$ Total essential amino acids.

${ }^{4}$ Total amino acids (hydroxylysine, hydroxyproline, lanthionine, ornithine and taurine are omitted because they are not included in the 20 most common amino acids). 
Figure 1. Flowchart for recovery of muscle proteins from whole trout using isoelectric solubilization/precipitation.

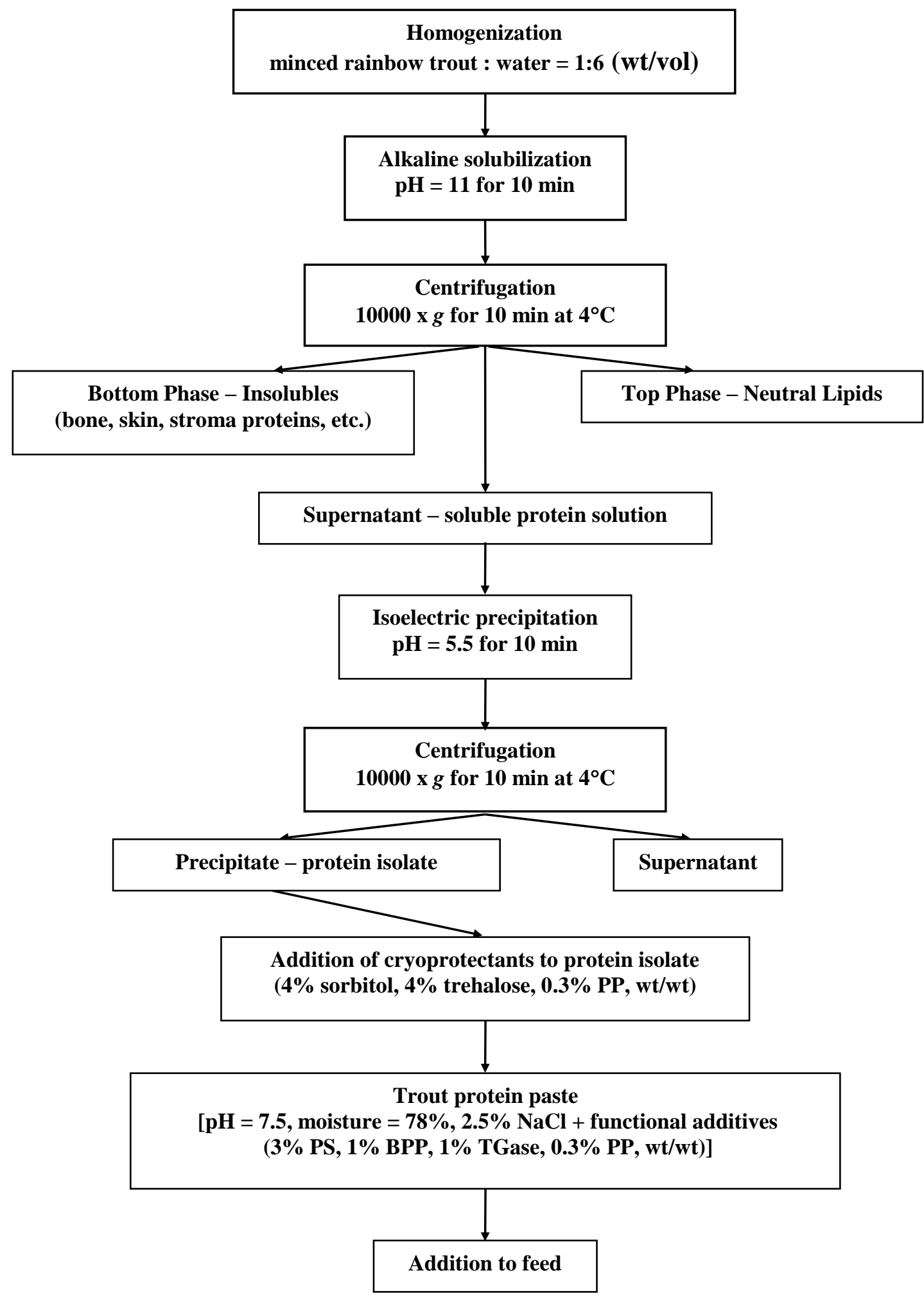


Table 4. Effect of trout protein paste on manufacturing variables.

\begin{tabular}{|c|c|c|c|c|c|c|c|}
\hline Item & $\begin{array}{l}\text { P-Rate, }{ }^{1} \\
\text { metric tons } / \mathrm{h}\end{array}$ & $\begin{array}{c}\text { REEU }-\mathrm{P}^{2} \\
(\mathrm{~kW} \cdot \mathrm{h} / \text { metric ton })\end{array}$ & $\begin{array}{c}\text { REEU }-\mathrm{C},^{3} \\
\mathrm{~kW} \cdot \mathrm{h} / \text { metric ton }\end{array}$ & $\begin{array}{l}\text { Bulk Density, } \\
\mathrm{lb} / \mathrm{ft}^{3}\left(\mathrm{~kg} / \mathrm{m}^{3}\right)\end{array}$ & $\begin{array}{c}\text { Total } \\
\text { fines }^{4}, \%\end{array}$ & $\begin{array}{l}\mathrm{PDI},{ }^{5} \\
\%\end{array}$ & $\underset{\%}{\mathrm{MPDI},{ }^{6}}$ \\
\hline \multicolumn{8}{|c|}{ Treatment $^{7}$} \\
\hline $\mathrm{CON}$ & $0.95^{\mathrm{a}}$ & $5.51^{\mathrm{b}}$ & $0.35^{\mathrm{b}}$ & $\begin{array}{c}40.38^{\mathrm{a}} \\
(646.83)\end{array}$ & 36.09 & $65.49^{c}$ & $37.02^{\mathrm{d}}$ \\
\hline LTPP & $0.91^{\mathrm{b}}$ & $4.92^{\mathrm{bc}}$ & $0.34^{\mathrm{b}}$ & $\begin{array}{c}39.78^{\mathrm{b}} \\
(637.21)\end{array}$ & 28.59 & $78.37^{\mathrm{b}}$ & $54.46^{\mathrm{b}}$ \\
\hline НTPP & $0.89^{\mathrm{b}}$ & $6.45^{\mathrm{a}}$ & $0.41^{\mathrm{a}}$ & $\begin{array}{c}39.15^{\mathrm{c}} \\
(627.12)\end{array}$ & 26.45 & $87.19^{\mathrm{a}}$ & $70.94^{\mathrm{a}}$ \\
\hline MOIS & $0.91^{\mathrm{b}}$ & $4.48^{\mathrm{c}}$ & $0.35^{\mathrm{b}}$ & $\begin{array}{c}39.20^{c} \\
(627.92)\end{array}$ & 26.17 & $75.58^{\mathrm{b}}$ & $47.15^{\mathrm{c}}$ \\
\hline $\mathrm{P}$-value & 0.0413 & 0.0090 & 0.0303 & 0.0018 & 0.2682 & $<0.0001$ & $<0.0001$ \\
\hline $\mathrm{LSD}^{8}$ & 0.035 & 0.922 & 0.049 & 0.4571 & - & 3.126 & 4.453 \\
\hline SEM $^{9}$ & 0.010 & 0.267 & 0.014 & 0.1321 & 3.571 & 0.9033 & 1.287 \\
\hline
\end{tabular}

${ }^{\mathrm{a}-\mathrm{c}}$ Means within a column with no common superscript differ significantly $(\mathrm{P} \leq 0.05)$.

${ }^{1}$ Pellet mill production rate; $\mathrm{kW} \cdot \mathrm{h}=$ kilowatt hour.

${ }^{2}$ Relative electrical energy usage (pellet mill).

${ }^{3}$ Relative electrical energy usage (conditioner).

${ }^{4}$ Total fines were calculated as [(\% of bagged fines $\mathrm{x} \mathrm{kg}$ of bagged feed $)+(\%$ of cooler fines $\mathrm{x} \mathrm{kg}$ of cooler feed $\left.)\right] / \mathrm{kg}$ of feed produced. Bagged fines were determined with feed from the same bag that was used for pellet durability index and modified pellet durability index determinations. Cooler feed is designated as feed collected below the cooler. Fines were determined by weighing $500 \mathrm{~g}$ of feed, sifting through a no. 6 American Society for Testing and Materials screen, weighing the sifted pellets, and determining the percentage of fines.

${ }^{5}$ Pellet durability index.

${ }^{6}$ Modified pellet durability index (utilizing five 13-mm hex nuts for added pressure on pellets).

${ }^{7} \mathrm{LTPP}=$ low trout protein paste $(2.5 \%)$; HTPP $=$ high trout protein paste $(5 \%)$; MOIS $=$ moisture

${ }^{8}$ Fisher's LSD.

${ }^{9}$ Pooled SEM. 


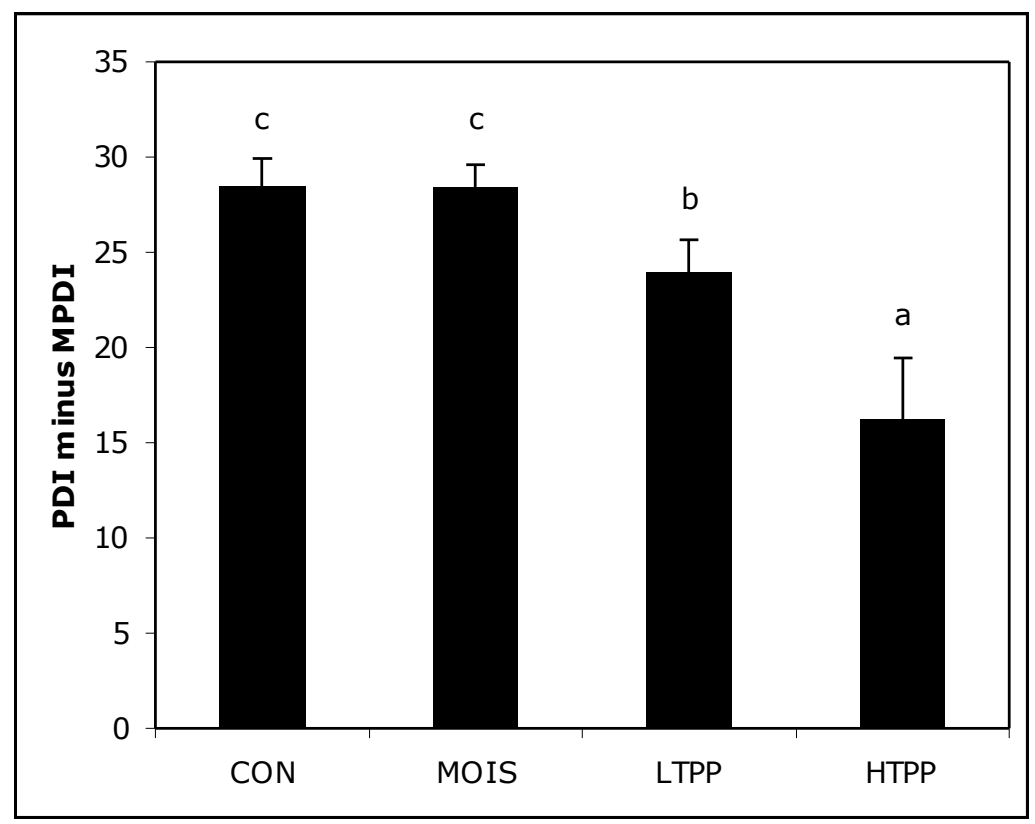

Figure 2. Protective effect of TPP against pellet degredation. ${ }^{\mathrm{a}-\mathrm{c}}$ Bars with no common letter differ significantly $(P \leq 0.05)$. CON $=$ control; LTPP $=$ low trout protein paste $(2.5 \%)$; $\mathrm{HTPP}=$ high trout protein paste $(5 \%)$; MOIS $=$ moisture 
Table 5. Pellet and mash moisture

\begin{tabular}{lcccc}
\hline Item & Mash & Hot Pellet $^{1}$ & Cool Pellet $^{2}$ & Day-3 Pellet $^{3}$ \\
\hline Treatment & & & & \\
Control & $10.68^{\mathrm{b}}$ & 14.93 & $13.44^{\mathrm{c}}$ & $12.25^{\mathrm{b}}$ \\
LTTP & $12.58^{\mathrm{a}}$ & 16.89 & $14.48^{\mathrm{b}}$ & $13.25^{\mathrm{b}}$ \\
HTTP & $14.22^{\mathrm{a}}$ & 18.41 & $15.96^{\mathrm{a}}$ & $14.56^{\mathrm{a}}$ \\
MOIS & $13.59^{\mathrm{a}}$ & 18.89 & $15.68^{\mathrm{a}}$ & $14.53^{\mathrm{a}}$ \\
$P$ - value & 0.0082 & 0.0595 & $<0.0001$ & 0.0100 \\
LSD $^{5}$ & 1.643 & - & 0.4238 & 1.231 \\
SEM $^{6}$ & 0.4747 & 0.8545 & 0.1225 & 0.3556 \\
\hline
\end{tabular}

\footnotetext{
${ }^{\mathrm{a}-\mathrm{c}}$ Means within a column with no common superscript differ significantly $(\mathrm{P} \leq 0.05)$.

${ }^{1}$ Samples taken as pellets exited the pellet mill.

${ }^{2}$ Samples taken as pellets exited the cooler.

${ }^{3}$ Cool pellets analyzed for moisture after $3 \mathrm{~d}$ of ambient temperature storage.

${ }^{4} \mathrm{LTPP}=$ low trout protein paste $(2.5 \%)$; HTPP $=$ high trout protein paste $(5 \%)$; MOIS = moisture

${ }^{5}$ Fisher's LSD value.

${ }^{6}$ Pooled SEM.
} 
Table 6. True amino acid digestibility of pelleted diets and isoelectrically solubilized-precipitated trout proteins ${ }^{1}$

\begin{tabular}{|c|c|c|c|c|c|c|c|c|c|c|c|c|}
\hline \multirow[b]{2}{*}{ Item } & \multicolumn{11}{|c|}{ Amino acid, $\%$} & \multirow[b]{2}{*}{ Average $^{2}$} \\
\hline & Ala & Asp & Cys & Glu & Ile & Leu & Lys & Met & Pro & Thr & Val & \\
\hline Treatment $^{3}$ & & & & & & & & & & & & \\
\hline Control & $83.66^{\mathrm{bc}}$ & $89.30^{c}$ & $74.71^{\mathrm{bc}}$ & $92.41^{\mathrm{b}}$ & $88.41^{\mathrm{c}}$ & $90.69^{b c}$ & $93.28^{\mathrm{bc}}$ & $93.55^{\mathrm{bc}}$ & $90.86^{\mathrm{ab}}$ & $83.27^{\mathrm{bc}}$ & $86.46^{\mathrm{c}}$ & 87.64 \\
\hline LTPP & $77.17^{\mathrm{d}}$ & $86.57^{\mathrm{cd}}$ & $65.13^{c}$ & $90.11^{\mathrm{bc}}$ & $84.69^{\mathrm{cd}}$ & $88.13^{\mathrm{cd}}$ & $90.13^{\mathrm{c}}$ & $92.17^{\mathrm{c}}$ & $88.25^{\mathrm{bc}}$ & $82.27^{\mathrm{c}}$ & $83.89^{c}$ & 88.13 \\
\hline HTPP & $80.35^{\mathrm{cd}}$ & $84.95^{\mathrm{d}}$ & $65.94^{c}$ & $89.29^{c}$ & $83.47^{\mathrm{d}}$ & $87.20^{\mathrm{d}}$ & $89.96^{\mathrm{c}}$ & $92.09^{c}$ & $84.98^{\mathrm{c}}$ & $80.28^{c}$ & $82.51^{\mathrm{c}}$ & 87.20 \\
\hline MOIS & $80.71^{\mathrm{cd}}$ & $88.46^{\mathrm{cd}}$ & $73.13^{\mathrm{bc}}$ & $91.79^{\mathrm{bc}}$ & $87.73^{c}$ & $90.25^{\mathrm{cd}}$ & $91.42^{c}$ & $93.13^{b c}$ & $91.10^{\mathrm{ab}}$ & $82.48^{\mathrm{c}}$ & $86.51^{\mathrm{c}}$ & 90.25 \\
\hline TPI & $96.30^{\mathrm{a}}$ & $97.86^{\mathrm{a}}$ & $89.75^{\mathrm{a}}$ & $97.87^{\mathrm{a}}$ & $97.86^{\mathrm{a}}$ & $98.13^{\mathrm{a}}$ & $97.18^{\mathrm{a}}$ & $98.40^{\mathrm{a}}$ & $96.08^{\mathrm{a}}$ & $96.74^{\mathrm{a}}$ & $97.54^{\mathrm{a}}$ & 98.13 \\
\hline TPP & $87.99^{\mathrm{b}}$ & $93.44^{\mathrm{b}}$ & $78.86^{\mathrm{b}}$ & $93.13^{b}$ & $92.94^{\mathrm{b}}$ & $93.99^{b}$ & $96.25^{\mathrm{ab}}$ & $94.81^{\mathrm{b}}$ & $88.75^{b c}$ & $90.45^{\mathrm{ab}}$ & $91.79^{\mathrm{b}}$ & 93.99 \\
\hline$P$-value & 0.0001 & $<0.0001$ & 0.0011 & 0.0005 & $<0.0001$ & $<0.0001$ & 0.0035 & 0.0002 & 0.0156 & 0.0021 & $<0.0001$ & - \\
\hline $\mathrm{LSD}^{4}$ & 6.252 & 3.736 & 10.10 & 3.113 & 4.109 & 3.350 & 3.868 & 2.201 & 5.539 & 7.517 & 4.784 & - \\
\hline $\mathrm{SEM}^{5}$ & 2.074 & 1.239 & 3.352 & 1.033 & 1.363 & 1.111 & 1.283 & 0.7303 & 1.838 & 2.494 & 1.587 & - \\
\hline
\end{tabular}

${ }^{\mathrm{a}-\mathrm{d}}$ Means within a column with no common superscript differ significantly $(\mathrm{P} \leq 0.05)$.

${ }^{1}$ Determined with cecectomized SCWL roosters.

${ }^{2}$ Mean digestibility of amino acids assayed within a row.

${ }^{3} \mathrm{LTPP}=$ low trout protein paste $(2.5 \%)$; HTPP $=$ high trout protein paste $(5 \%)$; MOIS $=$ moisture; $\mathrm{TPI}=$ trout protein isolate; TPP $=$ trout protein paste. $\mathrm{TPP}$ contained cryoprotectants ( $4 \%$ sorbitol, $4 \%$ trehalose, $0.3 \%$ polyphosphate, wt/wt), $2.5 \% \mathrm{NaCl}$ and functional additives $(3 \%$ potato starch, $1 \%$ beef plasma protein, $1 \%$ transglutaminase, $0.3 \%$ polyphosphate, wt/wt).

${ }^{4}$ Fisher's LSD value.

${ }^{5}$ Pooled SEM. 


\section{Increasing Mixer-Added Fat Reduces the Energy Required for Pelleting and Improves Exogenous Enzyme Efficacy for Broilers}

C. K. Gehring, K. G. S. Lilly, L. K. Worley-Shires, K. R. Beaman, S. A. Loop and J. S. Moritz ${ }^{1}$ Division of Animal and Nutritional Sciences, West Virginia University, Morgantown 26506

Keywords: Mixer-Added Fat, Pellet Manufacture Variables, Enzyme Activity, Broiler Performance Running Title: Fat Addition and Broiler Performance

Primary Audience: feed manufacturers, nutritionists, researchers

\footnotetext{
${ }^{1}$ Corresponding Author: Joe.Moritz@mail.wvu.edu
} 


\section{SUMMARY}

The price of fat and diet formulation with exogenous enzymes have reduced the amount of fat added to broiler diets. Although diets may be cheaper to produce, there is potential for nutrient and exogenous enzyme destruction with low inclusions of fat (0.5-1\%) because of frictional heat and shear forces produced in the pellet die. Additionally, much of the added fat may be applied using post-pellet spray application and the amount of fat added in the mixer may become negligible. Thermal inactivation of exogenous enzymes and occurrence of unfavorable reactions (e.g., Maillard reaction, protein cross-linking, etc.) may be abated by increased levels of fat included at the mixer prior to pelleting, i.e., mixer-added fat (MAF). This study evaluated the effects of MAF $(1,2.5$ or 4\%) with or without exogenous enzyme addition (carbohydrase, protease and phytase), and at different conditioning temperatures $\left(82\right.$ or $\left.85^{\circ} \mathrm{C}\right)$, on feed manufacture and finisher phase broiler performance variables, and processing yields. Increasing MAF reduced the electrical energy usage required to manufacture broiler feed $(P<0.0001)$. Feed intake and live weight gain were increased with enzyme addition $(P<0.0001)$. Enzyme addition, conditioning temperature and MAF interacted in their effects on feed conversion ratio $(P=0.0093)$. Overall, enzyme addition decreased feed conversion ratio, but the effect was greatest with $1 \% \mathrm{MAF}$ and $82^{\circ} \mathrm{C}$ or $4 \% \mathrm{MAF}$ and $85^{\circ} \mathrm{C}$. Increasing MAF and conditioning temperature reduced abdominal fat pad yield $(P=0.0259$ and 0.0240 , respectively). There was no difference in carcass, breast or leg yield due to any of the factors $(P>0.05)$. It is likely that increased MAF improved exogenous enzyme retention and nutrient utilization by broilers. Subject to current fat prices, increasing MAF may reduce the total cost of broiler production, particularly when reduction of electrical energy usage is considered. 


\section{DESCRIPTION OF PROBLEM}

Factors that enhance pellet quality by increasing feed temperature may also be deleterious to broiler performance by reducing nutrient availability and exogenous enzyme retention. The pelleting process involves raising temperature and moisture by injecting steam into mash feed and further increasing feed temperature during pellet formation due to mechanical friction at the mash-die interface. Exogenous enzymes may denature with sufficiently high feed temperature and moisture, and amino acids may become unavailable because of Maillard reaction or crosslinking.

Least-cost diet formulation does not account for interaction among feed ingredients or the effects of pellet manufacture on nutrient quality and subsequent broiler performance. The assumption that feed ingredient nutrient content is invariably static and additive is a fallacy [1] that may limit the performance of broilers fed least-cost diets. Current industry practice is to reduce the amount of added fat in broiler diets to reduce diet cost and improve pellet quality [2]. Very little fat may be added in the mixer because of the prevalence of exogenous enzymes that spare ME, and post-pellet fat application. The nutritional quality of pelleted broiler diets may be compromised if the amount of fat added in the mixer is below a critical level [2].

Fat added in the mixer may contribute to improved nutrient utilization and enzyme efficacy by coating feed particles $[3,4]$ and lubricating the pellet die $[5,6]$. Die lubrication may also reduce the electrical energy usage required to pellet broiler feed [7]. The effects of fat added in the mixer on feed manufacture, broiler performance, and carcass composition were assessed by conducting feed manufacture and broiler grower and finisher phase performance studies using practical diets conditioned at different temperatures. 


\section{MATERIALS AND METHODS}

\section{Diet Formulations and Pellet Manufacture}

Experiments were conducted to evaluate the effects of mixer-added fat (MAF) on finisher feed manufacture variables and broiler performance during 11-22 d grower and 22-38 d finisher production cycles. Broiler grower and finisher diets that contained 1 or $4 \%$ MAF were formulated using 2008 AgriStats, Inc. averages [8] with decreased ME, CP, AA and available P commensurate with producer provided enzyme nutrient matrix values (Tables 1 and 2). Diets that contained 2.5\% MAF, were created by blending the 1 and 4\% MAF diets. Grower and finisher positive control diets were formulated to have a higher plane of nutrition equal to the enzyme nutrient matrix values. The concentration of Trp was allowed to fluctuate to maintain equal or nearly equal inclusions of dried bakery product, corn distillers dried grains with solubles (DDGS), wheat middlings and corn gluten meal in diets differing in MAF. All diets were formulated to be isocaloric and isonitrogenous. Calculated nutrient density was held constant by the addition of washed play sand. All diets were formulated with practical ingredients found in commercial formulations.

Feed was manufactured at the West Virginia University pilot feed mill [9]. The experiments consisted of a $2 \times 3 \times 2$ factorial arrangement of treatments with the addition of a positive control diet. Factors were enzyme inclusion (with or without), MAF (1, 2.5 or 4\%) and conditioning temperature $\left(82\right.$ or $\left.85^{\circ} \mathrm{C}\right)$. Factor levels were constant between grower and finisher phases, except grower feed was conditioned at a high temperature of 93 , rather than $85^{\circ} \mathrm{C}$. The levels of MAF were chosen because previous research from the authors' lab indicates that nutrient availability may be compromised at industry levels (approximately 1\%) but not at higher 
levels (>3\%) [2]. Enzymes were included to provide the following minimum activities: $300 \mathrm{U}$ xylanase, $400 \mathrm{U} \alpha$-amylase, and $4000 \mathrm{U}$ subtilisin protease/kg of feed from a commercial enzyme cocktail [10] and 1,000 FTU phytase/kg of feed from a commercial E. coli phytase [11]. Diets were top-dressed with either $0.05 \%$ enzyme-cocktail and $0.0125 \%$ phytase, or an equal amount of sand.

Finisher feed was manufactured using $168 \mathrm{~kg}$ batches in a randomized complete block design. The blocking factor was day of manufacture and pelleting was conducted over four replicate days. Mixing was accomplished using a single-screw vertical mixer [9]. Each $168 \mathrm{~kg}$ batch represented the experimental unit to be steam conditioned and pelleted. Pellets were formed in a California Pellet Mill [9], fitted with a $30.48 \mathrm{~cm}$ (12 in), $4.76 \mathrm{~mm}$ (3/16 in) x 38.1 $\mathrm{mm}$ (1.5 in) die. Feed screw rate was adjusted to achieve an approximate production rate of 1.37 metric tons/hr. Speed of the conditioner [9] was constant (429 rpm) and mash feed was conditioned to a constant temperature of 82 or $85^{\circ} \mathrm{C}$. Finisher feed was not able to be pelleted at $93^{\circ} \mathrm{C}$, because the pellet die began to slip above $85^{\circ} \mathrm{C}$. Prior to the start of each days pelleting, the die was warmed up with approximately $90 \mathrm{~kg}$ of feed. The first $45 \mathrm{~kg}$ of each batch used to reach conditioning temperature was discarded so that all feed used to assess broiler performance was manufactured at either 82 or $85^{\circ} \mathrm{C}$.

Grower diets were mixed in a horizontal ribbon mixer [9] in $54.43 \mathrm{~kg}$ batches and combined to create $163.29 \mathrm{~kg}$ batches of feed to be pelleted. Each $163.29 \mathrm{~kg}$ batch was remixed for $5 \mathrm{~min}$ in the vertical screw mixer and conditioned and pelleted in an identical manner as finisher feed, with the exception of being steam conditioned at $93^{\circ} \mathrm{C}$. However, due to a lower feed volume need pelleting was not replicated.

All pellets were reground to mash form using a roller mill to eliminate feed form effects on 
broiler performance. Lilly et al. [12] demonstrated that pellet quality affects live weight gain and carcass weight of broilers when nutritional quality is maintained. The current study was designed to specifically evaluate the effects of MAF on exogenous enzyme efficacy at different conditioning temperatures without confounding from differences in pellet quality.

\section{Variables Measured}

Relative electrical energy usage of the pellet mill (PREEU) and conditioner (CREEU) [13], pellet mill motor load, and production rate were determined. Samples of mash, conditioned mash and cool pellets (pellets sampled immediately after exiting the cooler) were obtained for moisture analysis. Proximate analysis was conducted on cool pellet samples. Cool pellets were subsequently analyzed for crude protein, crude fat, and ash (\% of DM) [14].

\section{Separation of Sand and MAF Effects on Feed Manufacture}

Sand inclusion increased with MAF inclusion because the diets were formulated to be isocaloric. To separate the effects of sand and MAF on pellet manufacture variables, a supplemental feed manufacture experiment was conducted utilizing a completely randomized design with a $2 \times 2$ factorial arrangement of treatments and 4 replications. Treatment combinations consisting of the low and high levels of sand and MAF used in the previous feed manufacture and performance studies (1.5 or $6 \%$ sand and 1 or $4 \%$ MAF), were manufactured during $1 \mathrm{~d}$ using a conditioning temperature of $85^{\circ} \mathrm{C}$, and a die and feed screw rate identical to the previous feed manufacture experiments. Treatments were 1) $1 \%$ MAF and $1.5 \%$ sand, 2) $1 \%$ MAF and 6\% sand, 3) 4\% MAF and 1.5\% sand, and 4) 4\% MAF and 6\% sand. Two 2,100 lb (953 kg) batches of a basal corn-soybean meal-based diet (treatment 1) [15] were mixed and allocated evenly into 4 sub-batches. A portion of the basal diet was removed from 3 sub-batches and replaced with the appropriate amounts of MAF and washed, play sand to create treatments 2- 
4. In addition to PREEU and CREEU, bulk density, percentage of fines, and standard (PDI) and modified (MPDI) pellet durability [16] were determined.

\section{Broiler Management}

Feather-sexed Cobb 500 broiler chicks were obtained from a commercial hatchery. Chicks were placed in alternating, gender specific, $1.68 \mathrm{~m}^{2}$ floor pens containing 22 chicks each. The research facility was a solid-sided negative pressure house with 3 mesh curtain-separated rooms. Temperature was regulated using thermostatically controlled forced air heaters in each room. Each pen had one hanging feeder, one drinker line with 3 nipples, and built-up litter top-dressed with clean pine shavings. During the initial $5 \mathrm{~d}$, feed pans were added to each pen to ensure that chicks had sufficient access to feed. Brooding temperature was maintained initially at $33^{\circ} \mathrm{C}$ and decreased by $\sim 3^{\circ} \mathrm{C}$ each week to achieve a final set point of $21^{\circ} \mathrm{C}$. Broilers' thermal neutral zone was assessed by visual inspection and temperature was adjusted accordingly. The lighting regimen consisted of continuous light from d 1-3, 23L:1D from d 4-7, 20L:4D from d 8-24, and 23L:1D for the remainder of the study. Broilers were provided an industry-style corn-soybean meal-based starter diet in mash form for the initial $10 \mathrm{~d}$ post-hatch that met or exceeded 2008 AgriStats averages [8]. The starter diets were formulated to be as similar as possible to the $2.5 \%$ MAF diets of either the grower or finisher phase formulations. Feed and water were provided $a d$ libitum.

On d 11, broilers were weighed individually by gender and placed in groups of 10 that did not differ significantly in weight. A total of 1,638 broilers ( 819 cockerels and 819 pullets) were used for the experiment. The experimental unit was a pen and each pen consisted of 9 male and 9 female broilers. Prior research conducted using the same facility has indicated blocking by location was ineffective with 12 or more treatments, because of blocks spanning rooms. 
Therefore, a completely randomized design was implemented.

\section{Performance and Carcass Measurements}

On d 22 and 38, broilers were weighed and feed consumption was calculated. Mortalities were collected and recorded daily. Performance variables calculated included live weight gain (LWG), feed intake (FI), FCR (adjusted for mortality), and mortality. On d 38, one male and one female bird from each pen, whose weights were within $\pm 100 \mathrm{~g}$ of the mean weight of their respective genders, were selected for processing. Approximately $11 \%$ of each experimental unit was processed and used to determine carcass variables. On d 39, selected birds were placed in crates and transported to the West Virginia University pilot processing facility. Birds were stunned electrically, exsanguinated by cutting the jugular vein, scalded, plucked and eviscerated manually. Hot carcass, abdominal fat pad and bone-in leg quarter weights were recorded. The front half of each carcass was chilled in ice overnight and breasts were deboned manually and weighed. All carcass traits were calculated as weight relative to live weight. This was done to center the data so that the weights of carcass components were not confounded by live weight.

\section{Statistical Analysis}

Finisher phase and sand x MAF feed manufacture data was analyzed using three- or twoway factor effects ANOVA models with interaction terms, respectively. For broiler performance and carcass measurements, data was analyzed by analysis of covariance, with room as a covariate. Significance was determined by $\alpha \leq 0.05$. Multiple comparisons of means were made using Tukey's honestly significant difference test. The statistical analyses were conducted using the R statistical software package [17].

\section{Animal Care and Use}

All animals and facilities were maintained in compliance with guidelines established by the 
West Virginia University Animal Care and Use Committee.

\section{RESULTS AND DISCUSSION}

\section{Feed Manufacture}

Increasing the level of MAF or conditioning temperature (TEMP) had a marked effect on the electrical energy required to pellet broiler feed (Table 3). Increasing MAF caused a concurrent decrease in PREEU $(P<0.0001)$. On average, increasing MAF from 1 to $4 \%$ of the diet reduced PREUU by $2.97 \mathrm{~kW} \cdot \mathrm{h} /$ metric ton. Contrary to the effect of MAF, increasing TEMP from 82 to $85^{\circ} \mathrm{C}$ increased PREEU ( $\left.P=0.0512\right)$. Mixer-added fat also affected CREEU and pellet mill motor load. Increasing MAF increased CREEU $(P=0.0181)$ but decreased motor load $(P<0.0001)$. Because of the relatively minor effect of CREEU on total energy usage compared to PREEU, overall, increasing MAF from 1 to $4 \%$, decreased total electrical energy usage (PREEU minus CREEU) by $42 \%$. Added fat lubricates the pellet die $[5,6,18]$, decreasing the coefficient of friction between the interior of the die ports and conditioned mash. Lubrication of the mash-die interface reduces the amount of energy necessary to overcome the opposing frictional force and extrude conditioned feed. In addition to decreasing relative electrical energy usage and loss of heat-labile nutrients, die lubrication by MAF may reduce wear on the pellet die and motor [18]. Pellet mill motor load $(P<0.0001)$ was reduced by approximately $12 \%$ by increasing MAF from 1 to $4 \%$. It is unclear why relative electrical energy usage increased when feed was conditioned at 85 compared to $82^{\circ} \mathrm{C}$. Several authors have reported reduced pellet mill electrical energy usage for steam conditioned and pelleted diets compared to dry pelleted diets $[19,20]$. Skoch et al. [20] proposed that because steam acts a lubricant, mechanical friction is reduced. Cowieson et al. [21] reported increased diet viscosity when wheat-based diets were conditioned at temperatures above $80^{\circ} \mathrm{C}$. They attributed the occurrence to release of previously 
encapsulated non-starch polysaccharides (NSP). In the current study, the finisher diet formulations had nearly $7 \%$ wheat middlings and DDGS, although it is the difference in free NSP following conditioning at 82 compared to $85^{\circ} \mathrm{C}$ was not assessed in the current study. The effect of mixer-added fat on conditioner relative electrical energy usage may be related to the ability of fat to coat feed particles $[3,4]$ and reduce their interaction with heat and moisture. Thus, slightly reduced plasticization and mobility of conditioned feed ingredients may be responsible for marginally increasing the energy required for the conditioner picks to move through the feed mass.

Mash and cool pellet moisture (Table 3) were only slightly affected by treatments (range of $<1$ percentage point). Increasing MAF decreased mash and cool pellet moisture $(P \leq 0.05)$; however, the effect was small enough that no differences were detected by the mildly conservative HSD test. Moisture added by steam conditioning increased mash moisture by approximately 4 percentage points. No differences were detected $(P>0.05)$ due to any of the treatments.

Sand is often used as an inert filler or diluent in nutrition studies. However, little is known about the effects of sand on pellet manufacture variables, especially electrical energy usage and pellet quality. Sand has a coarse, grainy texture, similar to feed phosphates, and may affect pellet manufacture variables by die scouring. Die scouring may be dependent on particle size and density. For example, tricalcium phosphate has been reported to improve feed production rate [22] and reduce pellet mill electrical energy usage [23] compared to other feed phosphates in corn-soybean meal-based diets. In the current study, diets were made to be isocaloric and have similar ingredient compositions by adding washed play sand. The effects of sand and MAF were confounded, and therefore, a second feed manufacture experiment was 
conducted to separate their effects (Table 4). Increasing sand or MAF increased production rate by 1 and $2 \%$, respectively $(P<0.05)$. The effect of sand on production rate is likely due to the die scouring effect attributed to some feed phosphate sources [22]. The level of MAF significantly affected pellet mill motor load $(P<0.0001)$. From 1 to $4 \%$ MAF, motor load decreased by more than 6\% $(P \leq 0.05)$. Sand inclusion numerically increased pellet mill motor load $(P=0.0878)$. Increased electrical energy usage indicates greater frictional force at the mash-die interface. Conversion of mechanical energy to heat in the die affects pellet formation by increasing starch gelatinization and protein denaturation in the conditioned feed and this may have offset the physical effect of sand on pellet quality. Sand inclusion did not affect the production of fines $(P$ $>0.05)$. The level of MAF significantly increased all pellet manufacture variables associated with fines production, including the amount of feed that fell through the cooler, cooler fines, bagged fines, and total fines $(P \leq 0.05)$.

Sand and MAF inclusion affected PDI, MPDI, and bulk density of pelleted feed $(P \leq$ 0.05). Increasing MAF significantly decreased PDI and MPDI, by 23 and 42 percentage points, respectively. The disparity between the PDI and MPDI at both levels of MAF indicate that increasing MAF reduces pellet elasticity, likely by coating feed particles and disrupting starch and protein reactions that are requisite for agglomeration. The difference between PDI and MPDI with 1\% MAF and 1.5\% sand was 6.25 percentage points and with 4\% MAF and $1.5 \%$ sand was 24 percentage points. Other ingredients, such as water, impart a shift from control treatments in PDI and MPDI, without changing the difference [24], indicating a change in hardness but not elasticity. Pellets formed with greater amounts of fat would be less able to withstand transportation and handling stress than those formed by current industry practices. However, despite reduced pellet quality, increasing MAF up to $4 \%$ in corn-soybean meal-based 
diets may not affect FCR or carcass yield, based solely on feed form, of broilers [12]. Lilly et al. [12] reported no difference in carcass weight or FCR of broilers fed diets with 30 or $60 \%$ pellets. Significant improvement of carcass weight was only achieved by increasing the percentage of pellets in the feed pan to $90 \%$. Based on past surveys, this level of pellet quality is not typical of the broiler industry $[25,26]$.

Increasing sand up to $6 \%$ of the diet only slightly decreased PDI and MPDI $(P \leq 0.05)$. Feed particles are primarily agglomerated by starch gelatinization and protein denaturationaggregation. Feed constituents that disrupt the interaction of feed polymers reduce pellet quality, e.g., pellets often break along the outside of a corn particle. Sand would likely disrupt pellet formation in the same manner, although the effect was small, even at $6 \%$ of the diet. The effect may also be related to increased production rate and thus, reduced retention time in the pellet die. Bulk density increased as the level of sand or MAF was increased $(P \leq 0.05)$. Sand likely improved bulk density because of its density, rather than by a change in feed form. In contrast, increasing MAF likely increased bulk density because of the greater percentage of fines associated with 4 versus 1\% MAF. Moritz et al. [7] attributed decreased bulk density with greater pellet durability to the air space between high quality pellets. In the current study, the difference in bagged fines between 1 and 4\% MAF treatments (7.99 compared to $26.08 \%$, respectively) likely affected bulk density, because fines were able to fill in gaps between whole pellets.

\section{Grower Phase Broiler Performance}

Broiler performance variables are presented in Tables 5 and 6 . Initial pen weight at $11 \mathrm{~d}$ of age did not differ significantly among treatments $(P>0.05)$. Factorial analysis (without the positive control $)$ yielded a MAF x TEMP interaction $(P=0.0248)$. The interaction occurred 
because on average, $2.5 \% \mathrm{MAF}$ had a $10 \mathrm{~g}$ lower initial pen weight at $82^{\circ} \mathrm{C}$, and a $15 \mathrm{~g}$ higher initial pen weight at $93^{\circ} \mathrm{C}$, compared to 1 and $4 \%$ MAF. The difference equals less than $1 \mathrm{~g}$ per bird and is probably why there was no difference detected on a treatment basis (Table 5.).

Exogenous enzyme addition (ENZ) and MAF interacted in their effects on feed intake $(P=$ 0.0299). The addition of exogenous enzymes increased feed consumption of broilers fed 1 or 2.5\% MAF diets compared to the same diets without ENZ. In contrast, broilers fed 4\% MAF diets consumed less feed with ENZ compared to without. When the data was combined with the PC, there were no differences between individual treatments $(P>0.05)$. The interaction may have occurred because of an increase in transit time of ingesta. Mateos et al. [27] reported a linear increase in transit time when graded levels of yellow grease were included in diets fed to White Leghorn hens. Increased transit time may improve the digestibility of all diet components by providing digesta increased exposure to endogenous and exogenous enzymes.

There was an ENZ $x$ MAF interaction on 11-22 d live weight gain (LWG) $(P=0.0538)$. On average, ENZ improved LWG by 200 g per bird; however, LWG of broilers increased when the level of MAF was increased in diets without ENZ but there was no effect of MAF on LWG in diets with ENZ. Past research conducted during a similar growth phase (8-21d), demonstrated that addition of $\alpha$-amylase, xylanase and protease did not affect LWG [28]. However, Café $e t$ al. [29] demonstrated improved 16 and 35d LWG, using the same strain of broiler as the current study, when the same enzyme cocktail was fed. It is likely that phytase also improved LWG, although the individual effects of the different enzymatic activities on broiler performance variables cannot be elucidated in the current study. The PC diet elicited greater LWG than diets without ENZ formulated to a lower plane of nutrition $(P=0.0399)$. The addition of exogenous enzymes brought LWG back to the level of the PC (P > 0.05). Thus, nutrient matrix values for 
the enzymes were appropriate for the grower phase. Steam conditioning feed at $93^{\circ} \mathrm{C}$ reduced live weight gain by $10 \mathrm{~g}$ per bird on average compared to conditioning at $82^{\circ} \mathrm{C}$. Moreover, conditioning at $93^{\circ} \mathrm{C}$ decreased LWG compared to the PC $(P=0.0508)$. Pelleting improves broiler performance compared to mash $[30,31]$ primarily by reducing time and energy for prehension, improving palatability and thermal modification of starch and protein [32]. The beneficial effects of pelleting on starch and protein availability have been attributed to destruction of cell walls, destruction of heat-labile anti-nutrients and starch gelatinization [33]. Although the benefits of pelleting are numerous, over-processing may reduce broiler performance. Results of the current study are in agreement with prior research [21], demonstrating reduced LWG when feed is conditioned above approximately $80^{\circ} \mathrm{C}$. Reduction of LWG may have occurred due to reduced protein solubility [34, 35], Maillard reaction product formation [33, 35] and/or release of previously encapsulated non-starch polysaccharides [21].

During the 11-22 d grower phase there were no differences $(P>0.05)$ in FCR or mortality. Feed conversion ratio followed similar trends as live weight gain (Table 4.) although the differences were not detectable with $95 \%$ confidence. Failure to detect differences in FCR may be related to the degree of feed consumption in the grower phase. The strain of broilers used in the current study typically only consume between 23 and $33 \%$ of their total feed intake from hatch to $21 \mathrm{~d}$, when marketed at 35 to $42 \mathrm{~d}$ of age [37]. Thus, differences in performance due to dietary treatment are more likely to be realized during the finisher phase when the majority of feed is consumed.

\section{Finisher Phase Broiler Performance}

Initial body weights reflected differences in live weight gain during the grower phase (Table 5). Exogenous enzyme addition and higher conditioning temperature increased and 
decreased initial ( $22 \mathrm{~d}$ ) body weight, respectively. Use of $22 \mathrm{~d}$ body weight as a covariate was not significant for any of the variables tested. Feed intake and live weight gain were not affected by TEMP or MAF $(P>0.05)$. However, ENZ increased feed intake by $7.7 \%$ (179 g per bird) and live weight gain by $10.1 \%$ (120 g per bird) compared to feeding diets without exogenous enzymes $(P \leq 0.05)$. Feeding the PC diet yielded the lowest LWG $(P \leq 0.05)$. This likely occurred because there was not a great enough difference between the PC diet and experimental diets without ENZ, to yield improved broiler performance due to the PC.

Mixer-added fat, TEMP and ENZ interacted in their effects on 22-38 d FCR $(P=0.0293)$. On average, ENZ decreased FCR by 3 points (Table $4 ; P \leq 0.05$ ) but the magnitude of the FCR response to ENZ depended on the level of TEMP and MAF. Exogenous enzyme addition to diets with $4 \% \mathrm{MAF}$, conditioned at $85^{\circ} \mathrm{C}$, reduced FCR by 9 points compared to the same diet without ENZ. Diets with ENZ at 2.5 or $1 \% \mathrm{MAF}$, conditioned at $82^{\circ} \mathrm{C}$, yielded reduced FCR of 6 and 4 points, respectively, compared to their non-ENZ counterparts. The primary substrate for carbohydrases is the portion of the digesta that becomes the ileal undigested fraction. Exogenous enzymes typically act upon a fixed percentage of the undigested fraction and therefore, their response is dependent on diet composition and digestibility [38]. A diet with lower basal digestibility will generally be improved more by ENZ than a diet that is more inherently digestible. Some of the reduction in nutritional quality that is attributed to overprocessing is not likely to be overcome by ENZ, specifically loss of amino acids due to cross-linking or Maillard reaction. The ileal undigested fraction may become larger, but rather than increasing the pool of substrate, the increase would likely be associated with the dietary enzyme-resistant fraction (typically $80-85 \%$ of the ileal undigested fraction). Thus, increased MAF in diets processed at high conditioning temperatures maximized enzyme substrate, that in part, improved enzyme 
efficacy.

Increasing the inclusion of MAF to 3\% or more may prevent reduced nutrient availability [2]. Cutlip et al [6] observed a 20 point reduction in FCR when broilers were fed diets conditioned at 93 versus $82^{\circ} \mathrm{C}$ with $3.09 \%$ MAF. The increase in temperature corresponded to increased pellet durability. Subsequent studies $[2,12]$ were designed to evaluate feed form effects on broiler performance. When MAF was included at $1.26 \%$ there were no differences in FCR even with a range in PDI from 71-96\%. However, in a following study, when 3.09\% MAF diets were used, there were significant feed form benefits on live weight gain, carcass weight and breast weight. In the current study, feed manufactured with $4 \% \mathrm{MAF}$ and conditioned at $85^{\circ} \mathrm{C}$ was most responsive to ENZ. Prevention of exogenous enzyme denaturation and reduction of nutrient availability because of die lubrication may have also increased enzyme activity and subsequent release of previously unavailable nutrients.

One or 4\% MAF reduced FCR compared to the PC $(P \leq 0.05)$; however, individual factor level (marginal) means are confounded by ENZ, as indicated by the significant three-way interaction $(P=0.0293)$ on FCR and the overall large response to ENZ in the present study. The difference between the grower and finisher phase data may be related to conditioning temperature and the enzyme nutrient matrix values. A high conditioning temperature of $93^{\circ} \mathrm{C}$ was reached during grower feed manufacture and this may have exacerbated the lower nutrient density of the experimental treatments. Finisher feed could not be conditioned at $93^{\circ} \mathrm{C}$ because the pellet die began to slip near $85^{\circ} \mathrm{C}$. Thus, the high conditioning temperature used for finisher feed was the highest temperature that could be reached for all diet formulations. In the finisher phase, experimental treatments yield LWG and FCR equal to or better than the PC. Only an available P matrix value was used for the exogenous phytase (1\%) and amino acid values for the 
enzyme cocktail were marginal $(\sim 0.01 \%)$. The data indicates that nutrient matrix values used for diet formulation may have been too conservative. It is likely that reduction of the ileal undigested fraction and thus, improved energy and protein utilization with the phytase addition, elicited performance above the positive control.

The addition of exogenous enzymes decreased mortality by nearly a full percentage point (0.92). The effect of exogenous enzymes on broiler mortality is equivocal. Some researchers have reported reduced mortality with enzyme supplementation [29, 39] and others have reported no effect on mortality $[40,41,42]$. In the current study late period mortality due to leg problems, began to increase marginally in non-ENZ birds. However, in general, the response to enzyme addition on mortality may be related to dietary or environmental stressors, such that exogenous enzymes only reduce mortality when basal mortality is sufficiently high.

\section{9 d Broiler Processing Yields}

Carcass and leg yields were not affected by any of the treatments (Table $6 ; P>0.05)$. The author's feel that there was a strong trend $(P=0.0683)$ for a MAF $x$ ENZ interaction on breast yield. The trend for an interaction occurred because, on average, ENZ to 1 and $2.5 \%$ MAF diets increased breast yield and ENZ to 4\% MAF diets decreased breast yield compared to 1, 2.5 and 4\% MAF diets without exogenous enzymes, respectively. Phytase addition to mash diets marginal in available $\mathrm{P}$ has been reported to improve carcass yield of broilers at $42 \mathrm{~d}$ of age [43]. It is likely that the trend for an interaction in the current study was associated with differences in enzyme or substrate concentrations due to pelleting. Although the conditioning temperature in the current study was not particularly high, other factors, such as mash moisture may have contributed to enzyme denaturation. It is estimated that steam conditioning causes a $1 \%$ increase in moisture for every $20-30^{\circ} \mathrm{F}$ increase in mash temperature [44]. In the current study, feed was 
manufactured in January when ambient temperature was below freezing. Exogenous enzymes may be denatured to a greater extent in the winter months compared to summer because of increased moisture added during steam conditioning [45]. The increase in moisture in the current study may have promoted enzyme denaturation and provided opportunity for MAF to improve retention of the thermostable phytase.

The abdominal fat pad is the most apparent adipose depot in the broiler chick. The amount of adipose tissue deposition in the abdominal fat pad is correlated $\left(\mathrm{R}^{2}>0.5\right)$ to body and carcass fat [46]. In the current study, increasing MAF from 1 to $4 \%$ decreased abdominal fat pad yield $(P \leq 0.05)$. Steam conditioning at $85^{\circ} \mathrm{C}$ decreased abdominal fat pad yield compared to conditioning at $82^{\circ} \mathrm{C}(P \leq 0.05)$. The main effect occurred because the data was pooled across levels of ENZ and MAF and the lowest abdominal fat pad yields occurred when broilers were fed diets that were steam conditioned at $85^{\circ} \mathrm{C}$ with $4 \% \mathrm{MAF}$. This data along with the previous FCR data indicate that broilers fed diets conditioned at $85^{\circ} \mathrm{C}$ with $4 \% \mathrm{MAF}$ and ENZ, converted nutrients into saleable carcass more efficiently than all other broilers. Increasing MAF likely prevented the loss of amino acids during pelleting and improved protein utilization by promoting phytase, xylanase, and protease retention. Diets were formulated to have equal protein:calorie ratios, and a reduction of the protein:calorie ratio caused by reduced protein digestibility may increase whole body adipose tissue deposition $[47,48]$. These results indicate that mixer-added fat lubricates the mash-die interface and at a minimum inclusion, improves exogenous enzyme efficacy and subsequent broiler performance by maximizing substrate and enzyme concentrations, and limiting the loss of amino acids that may occur during pelleting. 


\section{CONCLUSIONS AND APPLICATIONS}

1. Increasing mixer-added fat improves exogenous enzyme efficacy and subsequent broiler performance by three possible mechanisms; 1) maximizing substrate and 2) exogenous enzyme concentrations, and 3) reducing the loss of amino acids associated with feed manufacture at high conditioning temperatures or with high mash moisture.

2. Increasing mixer-added fat reduces the electrical energy required for pelleting.

3. Broilers fed diets that were conditioned at $85^{\circ} \mathrm{C}$ with exogenous enzymes and $4 \%$ mixer-added fat demonstrated the most efficient conversion of nutrients to saleable carcass.

4. Sand included below $6 \%$ of the diet has little effect on pellet manufacture variables, and thus, can be used as an inert filler in both broiler performance and feed manufacture research. 


\section{REFERENCES AND NOTES}

1. Bedford, M. R. 1996. The effect of enzymes on digestion. J. Appl. Poult. Res. 5:370-378.

2. Gehring, C. K., K. G. S. Lilly, and J. S. Moritz. 2009. Maximizing the performance of broilers fed pelleted diets. Multi-State Poultry Feeding and Nutrition Conference. May 19-21, Indianapolis, IN.

3. Eliasson, A. -C., K. Larsson, and Y. Miezis. 1981. On the possibility of modifying the gelatinization properties of starch by lipid surface coating. Starch. 33:231-235.

4. Zimonja, O., A. Stevnebø, and B. Svihus. 2007. Nutritional value of diets for broiler chickens as affected by fat source, amylose level and diet processing. Can. J. Anim. Sci. 87:553-562.

5. Jones, F. T., K. E. Anderson, and P. R. Ferket. 1995. Effect of extrusion on feed characteristics and broiler chicken performance. J. Appl. Poult. Res. 4:300-309.

6. Cutlip, S. E., J. M. Hott, N. P. Buchanan, A. L. Rack, J. D. Latshaw, and J. S. Moritz. 2008. The effect of steam-conditioning practices on pellet quality and growing broiler nutritional value. J. Appl. Poult. Res. 17:249-261.

7. Moritz, J. S., K. R. Cramer, K. J. Wilson, and R. S. Beyer. 2003. Feed manufacture and feeding of rations with graded levels of added moisture formulated to different energy densities. J. Appl. Poult. Res. 12:371-381.

8. AgriStats, Inc. 2008. Fort Wayne, IN

9. Weigh-tronix stationary feed mill SFM-2000 (integrated hammer mill, scale, micro ingredient mixer); 15-horse power horizontal shaft hammer mill (4 screens: 1/8, 3/16, 1/4, and 5/16 in.); 2,000-lb capacity single-screw vertical mixer in series with a pellet mill; 250-lb horizontal ribbon mixer; A $4.25 \mathrm{ft}$ length, $1.02 \mathrm{ft}$ diameter short term California Pellet Mill conditioner (3 steam 
inlet ports), 429 rpm shaft speed; 21 picks; 10-s feed retention time; California Pellet Mill 2288A master model pellet mill; 40-HP main drive motor; 12 in. diameter, 3/16 in. x 1.77 in. die.

10. Avizyme 1502, Danisco Animal Nutrition, St. Louis, MO.

11. Optiphos 2000 PF, JBS United, Sheridan, IN.

12. Lilly, K. G. S., C. K. Gehring, K. R. Beaman, and J. S. Moritz. 2009. Examining the relationship between pellet quality, broiler performance and bird sex. Poult. Sci. 88(Suppl. 1):(Accepted Abstr.)

13. Powerlogic power meters attached to the 3-phase leads of the pellet mill main drive and conditioner motor (Square D, Palatine, IL).

14. Association of Official Analytical Chemists. 1990. Official Methods of Analysis (15th ed.) Association of Official Analytical Chemists, Arlington, VA. Dry matter determinations were completed by weighing two 0.5 -g samples of each treatment into aluminum weighing pans and drying them in an oven at $105^{\circ} \mathrm{F}$ for $16 \mathrm{~h}$. Ash content was measured by first grinding each diet using a laboratory bench top blender. Approximately $1 \mathrm{~g}$ samples of each treatment were weighed out in aluminum pans and placed into an ashing oven overnight, cooled to room temperature, and then reweighed. The Kjeldahl method was used to determine crude protein: 0.5 g ground samples of each treatment were used for this analysis. Fat extractions were completed on the ground samples of each diet with petroleum ether in a Soxhlet apparatus. All samples analyzed were replicated for statistical purposes.

15. The basal diet was composed of: Yellow corn (62.02\%), $48 \%$ soybean meal (31.74\%), washed, play sand (1.5\%), limestone (1.20\%), animal-vegetable blended fat (1\%), deflourinated phosphate $(0.72 \%)$, Poultry vitamin-mineral pre-mix $(0.25 \%)$, salt $(0.39 \%)$, L-lysine- $\mathrm{HCl}(0.11 \%)$ and DL-methionine (0.03\%). 
16. American Society of Agricultural Engineers. 1997. ASAE S269.4: Cubes, pellets, and crumblesDefinitions and methods for determining density, durability, and moisture. ASAE Standards 1997. Am. Soc. Agric. Eng., St. Joseph, MI. Due to the use of a 3/16 in. x 1.77 in. die, pellets were sifted in a No. 6 American Society for Testing and Materials (ASTM) screen. Five hundred grams of sifted pellets were placed in a dust-tight enclosure and tumbled for $10 \mathrm{~min}$ at $50 \mathrm{rpm}$. The enclosure was of the dimensions $12 \times 12$ in., with a $2 \times 9$ in. plate affixed diagonally along one of the 12 x 12 in. sides. The tumbled samples were then sifted again (No. 6 ASTM) and weighed. The PDI was calculated by dividing the weight of pellets after tumbling by the weight of pellets before tumbling, and then multiplying by 100. The MPDI was determined in a similar manner, with the exception of adding five 13-mm hex nuts to the pretumbled sample to obtain added pellet agitation.

17. Ihaka, R. and R. Gentleman. 1996. R: A language for data analysis and graphics. J. Comput. Graph. Stat. 5:299-314.

18. Briggs, J. L., D. E. Maier, B. A. Watkins, and K. C. Behnke. 1999. Effect of ingredients and processing parameters on pellet quality. Poult. Sci. 78:1464-1471.

19. Skoch, E. R., K. C. Behnke, C. W. Deyoe, and S. F. Binder. 1981. The effect of steamconditioning rate on the pelleting process. Anim. Feed Sci. Tech. 6:83-90.

20. Skoch, E. R., S. F. Binder, C. W. Deyoe, G. L. Allee, and K. C. Behnke. 1983. Effects of pelleting conditions on pigs fed corn-soybean meal diet. J. Anim. Sci. 57:922-928.

21. Cowieson, A. J., M. Hruby, and M. Faurschou Isaksen. 2005. The effect of conditioning temperature and exogenous xylanase addition on the viscosity of wheat-based diets and the performance of broiler chickens. Br. Poult. Sci. 46:717-724.

22. Behnke, K.C. 1981. Pellet mill performance as affected by mineral source. Feedstuffs 53:34-36. 
23. Gehring, C. K., K. G. S. Lilly, E. A. Fontana, and J. S. Moritz. 2009. Effect of feed phosphate source and manufacture technique on pellet manufacture variables in simple and practical diet formulations. Unpublished Data.

24. Gehring, C. K., J. Jaczynski, and J. S. Moritz. 2009. Improvement of pellet quality with proteins recovered from whole fish using isoelectric solubilization-precipitation. J. Appl. Poult. Res. doi: 10.3382/JAPR.2008-00054.

25. Scheideler, S. E. 1991. Pelleting is important for broilers. Pages 1-7 in Proc. 18th Annu. Carolina Poult. Nutr. Conf., Charlotte, NC. North Carolina State Univ., Raleigh.

26. Moritz, J.S. 2007. Impact of the pelleting process on dietary nutrients and supplemental enzymes. Proc. Arkansas Nutr. Conf., Rogers, AR.

27. Mateos, G. G., J. L. Sell, and J. A. Eastwood. 1982. Rate of food passage (transit time) as influenced by level of supplemental fat. Poult. Sci. 61:94-100.

28. Douglas, M. W., C. M. Parsons, and M. R. Bedford. 2000. J. Appl. Poult. Res.9:74-80.

29. Café, M. B., C. A. Borges, C. A. Fritts, and P. W. Waldroup. 2002. Avizyme improves performance of broilers fed corn-soybean meal-based diets. J. Appl. Poult. Res. 11:29-33.

30. Heywang, B. W., and R. B. Morgan. 1944. A comparison of a pelleted and unpelleted all-mash diet for growing chickens. Poult. Sci. 23:16-20.

31. Runnels, T. D. 1976. The influence of feed texture on broiler performance. Poult. Sci. 55:19581961.

32. Behnke, K.C. 1994. Factors affecting pellet quality. Proc. Maryland Nutrition Conference. Dept. of Poultry Science and Animal Science, College of Agriculture, Univ. of Maryland, College Park.

33. Pickford, J. R., 1992. Effects of processing on the stability of heat labile nutrients in animal 
feeds. Pages 177-192 in: Recent Advances in Animal Nutrition. P. C. Garnsworthy, W. Haresign, D.J.A. Cole, ed. Butterworth-Heinemann, Oxford, U.K.

34. Araba, M., and N. M. Dale. 1990a. Evaluation of KOH solubility as an indicator of overprocessing soybean meal. Poult. Sci. 69:76-83.

35. Araba, M., and N. M. Dale. 1990b. Evaluation of protein solubility as an indicator of underprocessing of soybean meal. Poult. Sci. 69:1749-1752.

36. Donoso, G., O. A. M. Lewis, D. S. Miller, and P. R. Payne. 1962. Effect of heat treatment on the nutritive value of proteins: Chemical and balance studies. J. Sci. Food Agric. 12:192.

37. Cobb 500 Broiler Performance and Nutrition Supplement. Cobb-Vantress Inc., Siloam Springs, AR.

38. Cowieson, A. J. 2009. Strategic selection of exogenous enzymes (i.e., xylanase and phytase) for poultry diets: Characterizing the substrate. Multi-State Poultry Feeding and Nutrition Conference. May 19-21, Indianapolis, IN.

39. Kidd, M. T., G. W. Morgan, Jr., C. J. Price, P. A. Welch, and E. A. Fontana. 2001. Enzyme supplementation to corn and soybean meal diets for broilers. J. Appl. Poult. Res. 10:65-70.

40. Silversides, F. G., and M. R. Bedford. 1999. Effect of pelleting temperature on the recovery and efficacy of a xylanase enzyme in wheat-based diets. Poult. Sci. 78:1184-1190.

41. Waldroup, P. W., C. A. Fritts, C. A. Keen, and F. Yan. 2005. The effect of alpha-galactosidase enzyme with and without avizyme 1502 on performance of broilers fed diets based on corn and soybean meal. 4:920-927.

42. Cowieson, A. J., and V. Ravindran. 2008. Effect of exogenous enzymes in maize-based dietsvarying in nutrient density for young broilers: growth performance and digestibility of energy, minerals and amino acids. Br. Poult. Sci. 49:37-44. 
43. Pillai, P. B., T. O’Connor-Dennie, C. M. Owens, and J. L. Emmert. 2006. Efficacy of an Escherichia coli phytasein broilers fed adequate or reduced phosphorus diets and its effect on carcass characteristics. Poult. Sci. 85:1737-1745.

44. Reimer, L. 1992. Conditioning. Page 7 in Proc. Northern Crops Institute Feed Mill Management and Feed Manufacturing Technol. Short Course. p.7. California Pellet Mill Co. Crawfordsville, IN.

45. Wyatt, C. L. 2009. Technical tools for supporting next generation thermo-tolerant enzymes in poultry diets. Multi-State Poultry Feeding and Nutrition Conference. May 19-21, Indianapolis, IN.

46. Crespo, N., and E. Esteve-Garcia. 2002. Dietary polyunsaturated fatty acids decrease fat deposition in separable fat depots but not in the remainder carcass. Poult. Sci. 81:512-518.

47. Donaldson, W. E., G. F. Combs, and G. L. Romoser. 1956. The effect of calorie:protein ratio of the ration on the growth, nutrient utilization, and body composition of chicks. Poultry Sci. 35:1100-1105.

48. Velu, J. G., D. H. Baker and H. M. Scott. 1971. Protein and energy utilization by chicks fed graded levels of a balanced mixture of crystalline amino acids. J. Nutr. 101:1249-1256. 
Table 1. Grower diet formulations and compositions.

\begin{tabular}{|c|c|c|c|c|}
\hline Item & $\begin{array}{l}\text { Positive } \\
\text { Control }\end{array}$ & $1 \% \mathrm{MAF}$ & $2.5 \% \mathrm{MAF}$ & $4 \% \mathrm{MAF}$ \\
\hline \multicolumn{5}{|l|}{ Ingredients, $\%$} \\
\hline Corn & 46.81 & 50.66 & 45.22 & 39.78 \\
\hline Soybean Meal (44\%) & 16.52 & 10.94 & 15.97 & 21.0 \\
\hline Dried Bakery Product & 9.0 & 9.0 & 9.0 & 9.0 \\
\hline Extruded Soybean Meal & 11.05 & 13.5 & 11.05 & 8.59 \\
\hline Corn Gluten Meal (60\%) & 1.09 & 2.0 & 1.71 & 1.41 \\
\hline Wheat Middlings & 1.84 & 1.98 & 1.98 & 1.98 \\
\hline Corn DDGS & 1.98 & 4.0 & 4.12 & 4.24 \\
\hline Sand & 4.32 & 1.5 & 3.75 & 6.0 \\
\hline Poultry By-product Meal & 0.71 & 1.01 & 0.71 & 0.40 \\
\hline Hydrolyzed Feather Meal & 0.48 & 0.69 & 0.48 & 0.27 \\
\hline Porcine Meat and Bone Meal & 0.60 & 0.87 & 0.60 & 0.34 \\
\hline Limestone & 1.07 & 1.36 & 1.38 & 1.39 \\
\hline Animal/Vegetable Fat Blend & 2.5 & 1.0 & 2.5 & 4.0 \\
\hline Trical Phosphate & 1.09 & 0.48 & 0.57 & 0.66 \\
\hline NB3000 ${ }^{1}$ & 0.25 & 0.25 & 0.25 & 0.25 \\
\hline DL-Methionine & 0.24 & 0.23 & 0.25 & 0.26 \\
\hline L-Lysine $\mathrm{HCl}$ & 0.17 & 0.23 & 0.18 & 0.13 \\
\hline Salt & 0.18 & 0.17 & 0.18 & 0.19 \\
\hline Coban- $90^{2}$ & 0.05 & 0.05 & 0.05 & 0.05 \\
\hline BMD- $60^{3}$ & 0.04 & 0.04 & 0.04 & 0.04 \\
\hline L-Threonine & 0.02 & 0.03 & 0.03 & 0.02 \\
\hline \multicolumn{5}{|l|}{ Calculated Analysis } \\
\hline $\mathrm{ME}$ (kcal/lb) & 1415 & 1380.6 & 1380.6 & 1380.6 \\
\hline $\mathrm{CP}(\%)$ & 21.0 & 20.5 & 20.5 & 20.5 \\
\hline TSAA $(\%)$ & 0.91 & 0.90 & 0.90 & 0.90 \\
\hline Lys (\%) & 1.19 & 1.18 & 1.18 & 1.18 \\
\hline Thr (\%) & 0.80 & 0.79 & 0.79 & 0.79 \\
\hline $\operatorname{Trp}(\%)$ & 0.24 & 0.22 & 0.23 & 0.24 \\
\hline $\mathrm{Ca}(\%)$ & 0.85 & 0.85 & 0.85 & 0.85 \\
\hline $\mathrm{P}_{\mathrm{av}}(\%)$ & 0.40 & 0.30 & 0.30 & 0.30 \\
\hline $\mathrm{Na}(\%)$ & 0.22 & 0.22 & 0.22 & 0.22 \\
\hline \multicolumn{5}{|l|}{ Analyzed Value } \\
\hline Crude Protein \pm SD, $\%$ of DM & $22.25 \pm 0.05$ & $20.79 \pm 0.52$ & $21.11 \pm 0.51$ & $21.84 \pm 0.79$ \\
\hline
\end{tabular}




\begin{tabular}{|c|c|c|c|c|}
\hline Crude Fat $\pm \mathrm{SD}, \%$ of $\mathrm{DM}$ & $10.29 \pm 0.37$ & $8.42 \pm 0.22$ & $10.04 \pm 0.57$ & $10.75 \pm 0.58$ \\
\hline Ash $\pm \mathrm{SD}, \%$ of $\mathrm{DM}$ & $7.37 \pm 0.58$ & $6.63 \pm 0.50$ & $8.34 \pm 2.05$ & $10.66 \pm 0.67$ \\
\hline $\begin{array}{l}{ }^{1} \text { Supplied per kg of diet: ma } \\
0.0003 \% \text {; selenium, } 0.00003 \\
0.03 \mathrm{mg} \text {; vitamin B } 6,1.38 \mathrm{~m} \\
\text { manadione, } 0.83 \mathrm{mg} \text {; vitamir } \\
7716 \mathrm{IU} \text {. } \\
{ }^{2} \text { Active drug ingredient Mor } \\
\text { Indianapolis, IN. As an aid i } \\
\text { tenella, Eimeria acervulina, } \\
{ }^{3} \text { Bacitracin Methylene Disal }\end{array}$ & $\begin{array}{l}0.02 \% \text {; zinc } 0 \\
\text { acid, } 0.69 \mathrm{mg} \text {; } \\
27.56 \mathrm{mg} \text {; par } \\
1 \mathrm{mg} \text {; vitamin } \\
\text { dium } 90 \mathrm{~g} / \mathrm{lb} \text { ( } \\
\text { vention of coc } \\
\text { brunette, Eim } \\
\text { Og/lb }(60 \mathrm{~g} / \mathrm{ton} \\
\text { roved feed ef }\end{array}$ & $\begin{array}{l}\% \text {; iron, } 0.01 \\
\text { line, } 386 \mathrm{mg} \\
\text { henic acid, } 6 \\
16.53 \mathrm{IU} \text {; vit } \\
\text { g/ton inclusi } \\
\text { iosis caused } \\
\text { mivati, and } \\
\text { lusion)- Alp } \\
\text { ency. }\end{array}$ & $\begin{array}{l}\text { copper, } 0.002 \\
\text { oflavin, } 6.61 \mathrm{r} \\
\mathrm{ng} \text {; thiamine, } \\
\mathrm{n}_{3}, 2133 \mathrm{IC} \\
\text { - Elanco Anir } \\
\text { imeria necar } \\
\text { na, Fort Lee, }\end{array}$ & $\begin{array}{l}\text {; iodine, } \\
\text {; biotin, } \\
\text { 20mg; } \\
\text {; vitamin A, } \\
1 \text { Health, } \\
\text { Eimeria } \\
\text { For }\end{array}$ \\
\hline
\end{tabular}


Table 2. Finisher diet formulations and compositions.

\begin{tabular}{|c|c|c|c|c|}
\hline Item & $\begin{array}{l}\text { Positive } \\
\text { Control }\end{array}$ & $1 \% \mathrm{MAF}$ & $2.5 \% \mathrm{MAF}$ & $4 \% \mathrm{MAF}$ \\
\hline \multicolumn{5}{|l|}{ Ingredients, $\%$} \\
\hline Corn & 53.60 & 57.36 & 51.77 & 46.17 \\
\hline Soybean Meal (44\%) & 19.44 & 16.93 & 19.89 & 22.85 \\
\hline Dried Bakery Product & 9.0 & 9.0 & 9.0 & 9.0 \\
\hline Corn Gluten Meal (60\%) & 1.51 & 2.37 & 1.94 & 1.5 \\
\hline Corn DDGS & 2.10 & 3.0 & 3.0 & 3.0 \\
\hline Wheat Middlings & 3.81 & 3.81 & 3.81 & 3.81 \\
\hline Washed, Play Sand & 2.87 & 1.5 & 3.75 & 6.0 \\
\hline Poultry By-product Meal & 0.98 & 0.98 & 0.69 & 0.39 \\
\hline Hydrolyzed Feather Meal & 0.67 & 0.68 & 0.47 & 0.27 \\
\hline Porcine Meat and Bone Meal & 0.84 & 0.84 & 0.59 & 0.34 \\
\hline Limestone & 1.05 & 1.37 & 1.39 & 1.4 \\
\hline Animal/Vegetable Fat Blend & 2.5 & 1.0 & 2.5 & 4.0 \\
\hline Deflourinated Phosphate & 0.75 & 0.21 & 0.3 & 0.39 \\
\hline NB3000 & 0.25 & 0.25 & 0.25 & 0.25 \\
\hline DL-Methionine & 0.18 & 0.18 & 0.20 & 0.21 \\
\hline L-Lysine $\mathrm{HCl}$ & 0.17 & 0.23 & 0.17 & 0.11 \\
\hline Salt & 0.17 & 0.17 & 0.18 & 0.19 \\
\hline Coban-60 & 0.05 & 0.05 & 0.05 & 0.05 \\
\hline BMD & 0.04 & 0.04 & 0.04 & 0.04 \\
\hline L-Threonine & 0.03 & 0.04 & 0.04 & 0.03 \\
\hline \multicolumn{5}{|l|}{ Calculated Analysis } \\
\hline $\mathrm{ME}, \mathrm{kcal} / \mathrm{lb}$ & 1441 & 1406.6 & 1406.6 & 1406.6 \\
\hline $\mathrm{CP}, \%$ & 18.69 & 18.19 & 18.19 & 18.19 \\
\hline TSAA, $\%$ & 0.80 & 0.79 & 0.79 & 0.79 \\
\hline Lys, \% & 1.02 & 1.01 & 1.01 & 1.01 \\
\hline Thr, $\%$ & 0.71 & 0.70 & 0.70 & 0.70 \\
\hline $\operatorname{Trp}, \%$ & 0.20 & 0.19 & 0.20 & 0.21 \\
\hline $\mathrm{Ca}, \%$ & 0.79 & 0.79 & 0.79 & 0.79 \\
\hline Available Phosphorus, \% & 0.35 & 0.25 & 0.25 & 0.25 \\
\hline $\mathrm{Na}, \%$ & 0.22 & 0.22 & 0.22 & 0.22 \\
\hline \multicolumn{5}{|l|}{ Analyzed Value } \\
\hline Crude Protein \pm SD, \% of DM & $20.41 \pm 0.08$ & $19.74 \pm 0.48$ & $19.49 \pm 0.57$ & $20.09 \pm 0.76$ \\
\hline Crude Fat $\pm \mathrm{SD}, \%$ of $\mathrm{DM}$ & $7.89 \pm 0.77$ & $6.99 \pm 0.77$ & $8.70 \pm 0.77$ & $8.50 \pm 0.37$ \\
\hline $\mathrm{Ash} \pm \mathrm{SD}, \%$ of $\mathrm{DM}$ & $6.31 \pm 0.08$ & $6.42 \pm 0.23$ & $8.50 \pm 0.37$ & $10.30 \pm 0.54$ \\
\hline
\end{tabular}


${ }^{\mathrm{I}}$ Supplied per kg of diet: manganese, $0.02 \%$; zinc $0.02 \%$; iron, $0.01 \%$; copper, $0.0025 \%$; iodine, $0.0003 \%$; selenium, $0.00003 \%$; folic acid, $0.69 \mathrm{mg}$; choline, $386 \mathrm{mg}$; riboflavin, $6.61 \mathrm{mg}$; biotin, $0.03 \mathrm{mg}$; vitamin B 6, 1.38mg; niacin, 27.56mg; pantothenic acid, $6.61 \mathrm{mg}$; thiamine, $2.20 \mathrm{mg}$; manadione, $0.83 \mathrm{mg}$; vitamin B12, $0.01 \mathrm{mg}$; vitamin E, $16.53 \mathrm{IU}$; vitamin $\mathrm{D}_{3}, 2133 \mathrm{ICU}$; vitamin A, 7716 IU.

${ }^{2}$ Active drug ingredient Monensin Sodium 90g/lb (120g/ton inclusion).- Elanco Animal Health, Indianapolis, IN. As an aid in the prevention of coccidiosis caused by Eimeria necarix, Eimeria tenella, Eimeria acervulina, Eimeria brunette, Eimeria mivati, and Eimeria maxima ${ }^{3}$ Bacitracin Methylene Disalicylate 60g/lb (60g/ton inclusion)- Alpharma,- Fort Lee, NJ. For increased rate of weight gain and improved feed efficiency. 


\begin{tabular}{|c|c|c|c|c|c|c|c|}
\hline Item & $\begin{array}{c}\text { Pro Rate, } \\
\text { Metric } \\
\text { Ton/hr } \\
\end{array}$ & $\begin{array}{c}\text { PREEU, } \\
\mathrm{kW} \cdot \mathrm{h} / \\
\text { Metric Ton }\end{array}$ & $\begin{array}{c}\text { CREEU, } \\
\mathrm{kW} \cdot \mathrm{h} / \\
\text { Metric Ton }\end{array}$ & $\begin{array}{l}\text { Motor } \\
\text { Load, } \\
\text { A }\end{array}$ & $\begin{array}{c}\text { Mash } \\
\text { Moisture, } \\
\%\end{array}$ & $\begin{array}{c}\text { Conditioned } \\
\text { Mash } \\
\text { Moisture, } \\
\% \\
\end{array}$ & $\begin{array}{c}\text { Cool Pellet } \\
\text { Moisture }^{2}, \\
\%\end{array}$ \\
\hline \multicolumn{8}{|l|}{ Treatments $^{3}$} \\
\hline NE, low, $1 \%$ & 0.80 & $6.72^{\mathrm{abc}}$ & 0.15 & $16.70^{\mathrm{abc}}$ & 10.42 & 14.61 & 10.57 \\
\hline NE, high, $1 \%$ & 0.81 & $8.59^{\mathrm{a}}$ & 0.13 & $18.15^{\mathrm{a}}$ & 10.11 & 15.00 & 10.39 \\
\hline NE, low, $2.5 \%$ & 0.79 & $4.61^{\mathrm{bc}}$ & 0.16 & $15.18^{\mathrm{bc}}$ & 9.92 & 15.20 & 10.29 \\
\hline $\begin{array}{l}\text { NE, high, } \\
2.5 \%\end{array}$ & 0.80 & $6.14^{\mathrm{abc}}$ & 0.15 & $15.68^{b c}$ & 9.95 & 14.66 & 10.45 \\
\hline NE, low, $4 \%$ & 0.80 & $3.99^{c}$ & 0.12 & $14.75^{\mathrm{c}}$ & 9.46 & 14.30 & 9.96 \\
\hline NE, high, $4 \%$ & 0.81 & $5.04^{\mathrm{bc}}$ & 0.15 & $14.98^{\mathrm{bc}}$ & 9.31 & 14.07 & 9.53 \\
\hline E, low, $1 \%$ & 0.81 & $6.34^{\mathrm{abc}}$ & 0.15 & $16.08^{\mathrm{abc}}$ & 10.27 & 14.60 & 10.64 \\
\hline E, high, $1 \%$ & 0.78 & $7.56^{\mathrm{ab}}$ & 0.14 & $17.00^{\mathrm{ab}}$ & 10.34 & 15.02 & 10.33 \\
\hline $\mathrm{E}$, low, $2.5 \%$ & 0.81 & $4.74^{\mathrm{bc}}$ & 0.16 & $15.20^{\mathrm{bc}}$ & 9.87 & 13.95 & 10.26 \\
\hline E, high, $2.5 \%$ & 0.79 & $6.30^{\mathrm{abc}}$ & 0.16 & $15.68^{b c}$ & 10.01 & 14.22 & 9.86 \\
\hline $\mathrm{E}$, low, $4 \%$ & 0.78 & $4.44^{\mathrm{bc}}$ & 0.16 & $15.30^{\mathrm{bc}}$ & 9.62 & 14.27 & 10.30 \\
\hline E, high, $4 \%$ & 0.78 & $3.86^{\mathrm{c}}$ & 0.16 & $14.75^{\mathrm{c}}$ & 9.92 & 14.22 & 9.52 \\
\hline Positive & 0.79 & $5.06^{\mathrm{bc}}$ & 0.16 & $15.55^{\mathrm{bc}}$ & 10.22 & 14.56 & 10.65 \\
\hline \multicolumn{8}{|l|}{ Control $^{4}$} \\
\hline Tukey’s HSD ${ }^{5}$ & - & 3.47 & - & 2.12 & - & - & 一 \\
\hline SEM $^{6}$ & 0.013 & 0.691 & 0.004 & 0.423 & 0.228 & 0.440 & 0.270 \\
\hline \multicolumn{8}{|l|}{ Marginal Means } \\
\hline No Enzyme & 0.80 & 5.85 & 0.14 & 15.90 & 9.86 & 14.63 & 10.20 \\
\hline Enzyme & 0.79 & 5.54 & 0.16 & 15.65 & 10.01 & 14.36 & 10.15 \\
\hline $82^{\circ} \mathrm{C}$ & 0.80 & 5.14 & 0.15 & 15.53 & 9.93 & 14.49 & 10.34 \\
\hline $85^{\circ} \mathrm{C}$ & 0.80 & 6.25 & 0.15 & 15.96 & 9.94 & 14.50 & 10.01 \\
\hline $1 \% \mathrm{MAF}$ & 0.80 & 7.30 & 0.15 & 16.98 & 10.29 & 14.79 & 10.48 \\
\hline $2.5 \% \mathrm{MAF}$ & 0.79 & 5.45 & 0.16 & 15.31 & 9.94 & 14.51 & 10.21 \\
\hline $4 \% \mathrm{MAF}$ & 0.79 & 4.33 & 0.16 & 14.94 & 9.58 & 14.21 & 9.83 \\
\hline \multicolumn{8}{|c|}{ Probability $(>F)^{7}$} \\
\hline Treatment & 0.7361 & 0.0003 & 0.3046 & 0.0015 & 0.0377 & 0.7303 & 0.0532 \\
\hline Enzyme & 0.6730 & 0.9026 & 0.3419 & 0.9809 & 0.2911 & 0.2828 & 0.7542 \\
\hline Temperature & 0.8151 & 0.0512 & 0.5660 & 0.3077 & 0.9255 & 0.9893 & 0.0428 \\
\hline Fat inclusion & 0.9536 & $<0.0001$ & 0.0181 & $<0.0001$ & 0.0006 & 0.2418 & 0.0058 \\
\hline E X T & 0.4089 & 0.7819 & 0.5660 & 0.9285 & 0.2482 & 0.4353 & 0.2597 \\
\hline E X F & 0.6370 & 0.2735 & 0.4741 & 0.5409 & 0.4510 & 0.4028 & 0.4574 \\
\hline $\mathrm{T} X \mathrm{~F}$ & 0.1961 & 0.4419 & 0.7790 & 0.3959 & 0.7781 & 0.9307 & 0.4220 \\
\hline E X T X F & 0.2037 & 0.3047 & 0.2034 & 0.5159 & 0.8585 & 0.8479 & 0.8498 \\
\hline
\end{tabular}


${ }^{\mathrm{I}}$ Pro Rate $=$ production rate; PREEU $=$ relative electrical energy usage $($ pellet mill); CREEU $=$ relative electrical energy usage (conditioner).

${ }^{2}$ Pellets sampled immediately after exiting the cooler.

${ }^{3} \mathrm{NE}=$ No Enzyme; $\mathrm{E}=$ Enzyme; low $=82^{\circ} \mathrm{C}$; high $=85^{\circ} \mathrm{C} ; 1 \%, 2.5 \%$ or $4 \%$ Mixer-added Fat (MAF).

${ }^{42} \mathrm{NE}$, low, $2.5 \%$ formulated without enzyme matrix values

${ }^{5}$ Honestly significant difference.

${ }^{6}$ Pooled standard error of the mean $(n=4)$.

${ }^{7} \mathrm{E}=$ Enzyme, $\mathrm{T}=$ Conditioning Temperature, $\mathrm{F}=\mathrm{MAF}$. 
Table 4. Effects of Washed Play Sand and Mixer-Added Fat on Pellet Manufacture Variables. ${ }^{1}$

\begin{tabular}{|c|c|c|c|c|c|c|c|c|c|}
\hline Item & & $\begin{array}{c}\text { Pro } \\
\text { Rate, } \\
\text { Metric } \\
\text { Ton/hr }\end{array}$ & $\begin{array}{c}\text { PREEU, } \\
\mathrm{kW} \cdot \mathrm{h} / \\
\text { Metric } \\
\text { Ton }\end{array}$ & $\begin{array}{c}\text { CREEU, } \\
\mathrm{kW} \cdot \mathrm{h} / \\
\text { Metric } \\
\text { Ton }\end{array}$ & $\begin{array}{c}\text { Motor } \\
\text { Load, } \\
\text { A }\end{array}$ & $\begin{array}{c}\text { Total } \\
\text { Fines, } \\
\%\end{array}$ & $\begin{array}{c}\text { PDI, } \\
\%\end{array}$ & $\begin{array}{c}\text { MPDI, } \\
\%\end{array}$ & $\begin{array}{c}\mathrm{BD}, \\
\mathrm{kg} / \mathrm{m}^{3}\end{array}$ \\
\hline \multicolumn{10}{|c|}{ Treatments } \\
\hline \multicolumn{10}{|c|}{$\begin{array}{cc}\text { Fat, } & \text { Sand, } \\
\% & \%\end{array}$} \\
\hline 1 & 1.5 & $0.95^{\mathrm{b}}$ & $7.79^{\mathrm{a}}$ & 0.69 & $20.36^{\mathrm{a}}$ & $12.42^{b}$ & $90.20^{\mathrm{a}}$ & $83.95^{\mathrm{a}}$ & $637.45^{\mathrm{c}}$ \\
\hline 1 & 6 & $0.96^{\mathrm{ab}}$ & $7.78^{a}$ & 0.76 & $20.45^{\mathrm{a}}$ & $11.75^{\mathrm{b}}$ & $89.04^{\mathrm{a}}$ & $82.02^{\mathrm{a}}$ & $648.27^{\mathrm{ab}}$ \\
\hline 4 & 1.5 & $0.96^{\mathrm{ab}}$ & $6.36^{\mathrm{b}}$ & 0.76 & $18.95^{\mathrm{b}}$ & $29.89^{\mathrm{a}}$ & $68.47^{\mathrm{b}}$ & $44.47^{\mathrm{b}}$ & $645.22^{\mathrm{b}}$ \\
\hline 4 & 6 & $0.98^{\mathrm{a}}$ & $6.34^{b}$ & 0.75 & $19.18^{\mathrm{b}}$ & $31.78^{\mathrm{a}}$ & $64.75^{\mathrm{c}}$ & $37.97^{\mathrm{c}}$ & $654.11^{\mathrm{a}}$ \\
\hline $\begin{array}{l}\text { Tuke } \\
\text { HSD }\end{array}$ & & 0.023 & 1.009 & - & 0.353 & 4.082 & 3.100 & 6.298 & 6.886 \\
\hline SEM & & 0.006 & 0.240 & 0.021 & 0.084 & 0.972 & 0.738 & 1.500 & 1.64 \\
\hline \multicolumn{10}{|c|}{ Probability $(>F)$} \\
\hline Fat & & 0.0072 & $<0.0001$ & 0.1925 & $<0.0001$ & $<0.0001$ & $<0.0001$ & $<0.0001$ & 0.0013 \\
\hline Sand & & 0.0188 & 0.9372 & 0.1957 & 0.0878 & 0.5451 & 0.0062 & 0.0159 & $<0.0001$ \\
\hline Fat $x$ & Sand & 0.6393 & 0.9835 & 0.0658 & 0.4295 & 0.2127 & 0.1084 & 0.1547 & 0.5688 \\
\hline \multicolumn{10}{|c|}{ Marginal Means } \\
\hline $1 \% \mathrm{I}$ & & 0.95 & 7.79 & 0.73 & 20.41 & 12.08 & 89.62 & 82.98 & 642.86 \\
\hline $4 \% \mathrm{I}$ & & 0.97 & 6.35 & 0.75 & 19.06 & 30.83 & 66.61 & 41.22 & 649.67 \\
\hline $1.5 \%$ & Sand & 0.96 & 7.08 & 0.73 & 19.66 & 21.16 & 79.34 & 64.21 & 641.34 \\
\hline $6 \%$ & and & 0.97 & 7.06 & 0.75 & 19.81 & 21.76 & 76.89 & 59.99 & 651.19 \\
\hline
\end{tabular}

${ }^{1}$ Fat $=$ animal/vegetable blended fat; Sand = washed play sand. Factorial design consisting of low and high levels of fat and sand used in grower-finisher feed manufacture.

Means without a common superscript differ significantly $(P<0.05)$.

${ }^{2} \mathrm{MT}=$ tonne; $\mathrm{kWh}=$ kilo watt hour; Pro Rate =production rate; PREEU = relative electrical energy usage (pellet mill); CREEU = relative electrical energy usage (conditioner); Motor Load $=$ pellet mill motor load.

${ }^{3}$ Cooler Fines $=$ Percent of feed that fell through the cooler during production; Cooler Fines Fines $=$ Percentage of Fines that passed through a \#6 U.S. standard sieve; Bagged Fines were determined from the fourth bag of feed from each batch and are the percentage of the bagged feed that passed through a \#6 U.S. standard sieve.

${ }^{4} \mathrm{PDI}=$ pellet durability index; MPDI = modified pellet durability index. Bulk density (BD) was determined from the fourth bag of feed from each batch.

${ }^{5}$ Honestly significant difference.

${ }^{6}$ Pooled standard error of the mean $(n=4)$. 
Table 5. Broiler performance variables.

\begin{tabular}{|c|c|c|c|c|c|c|c|c|c|c|}
\hline \multirow{2}{*}{$\frac{\text { Item }}{\text { Broiler Age }}$} & \multicolumn{2}{|c|}{$\begin{array}{c}\text { Initial } \\
\text { Body Weight } \\
\text { (kg per pen) }\end{array}$} & \multicolumn{2}{|c|}{$\begin{array}{l}\text { Feed Intake } \\
\text { (kg per pen) }\end{array}$} & \multicolumn{2}{|c|}{$\begin{array}{c}\text { LWG } \\
\text { (kg per bird) }\end{array}$} & \multicolumn{2}{|c|}{$\begin{array}{c}\text { FCR } \\
(\mathrm{kg}: \mathrm{kg})\end{array}$} & \multicolumn{2}{|c|}{$\begin{array}{c}\text { Mortality } \\
(\%)\end{array}$} \\
\hline & $11-22 \mathrm{~d}$ & $22-38 d$ & $11-22 \mathrm{~d}$ & $22-38 d$ & $11-22 \mathrm{~d}$ & $22-38 d$ & $11-22 \mathrm{~d}$ & $22-38 d$ & $11-22 \mathrm{~d}$ & $22-38 d$ \\
\hline \multicolumn{11}{|l|}{ Treatments $^{1}$} \\
\hline NE, low, $1 \%$ & 3.18 & $12.94^{\mathrm{ab}}$ & 14.87 & $41.34^{\text {abcde }}$ & $0.54^{\mathrm{abc}}$ & $1.22^{\mathrm{abc}}$ & 1.52 & $1.92 \mathrm{a}^{\mathrm{b}}$ & 0.00 & 2.38 \\
\hline NE, high, $1 \%$ & 3.15 & $12.55^{\mathrm{b}}$ & 14.59 & $44.16^{\mathrm{abc}}$ & $0.52^{\mathrm{c}}$ & $1.33^{\mathrm{a}}$ & 1.55 & $1.89^{\mathrm{b}}$ & 0.00 & 0.00 \\
\hline NE, low, $2.5 \%$ & 3.17 & $13.06^{\mathrm{ab}}$ & 15.29 & $43.46^{\text {abcde }}$ & $0.55^{\mathrm{abc}}$ & $1.17^{\mathrm{c}}$ & 1.54 & $1.98^{\mathrm{a}}$ & 0.00 & 0.00 \\
\hline NE, high, $2.5 \%$ & 3.18 & $12.66^{\mathrm{ab}}$ & 15.04 & $44.91^{\mathrm{a}}$ & $0.53^{\mathrm{bc}}$ & $1.30^{\mathrm{a}}$ & 1.59 & $1.94^{\mathrm{ab}}$ & 0.00 & 0.79 \\
\hline NE, low, $4 \%$ & 3.18 & $13.05^{\mathrm{ab}}$ & 15.21 & $40.44^{\mathrm{de}}$ & $0.55^{\mathrm{ab}}$ & $1.18^{\mathrm{c}}$ & 1.54 & $1.92 \mathrm{a}^{\mathrm{b}}$ & 0.79 & 2.38 \\
\hline NE, high, $4 \%$ & 3.18 & $13.00^{\mathrm{ab}}$ & 15.29 & $44.61^{\mathrm{ab}}$ & $0.55^{\mathrm{abc}}$ & $1.30^{\mathrm{a}}$ & 1.54 & $1.95 \mathrm{a}^{\mathrm{b}}$ & 0.79 & 0.79 \\
\hline E, low, $1 \%$ & 3.17 & $13.02^{\mathrm{ab}}$ & 15.22 & $40.14^{\mathrm{e}}$ & $0.56^{\mathrm{a}}$ & $1.20^{\mathrm{bc}}$ & 1.52 & $1.88^{\mathrm{b}}$ & 1.59 & 3.17 \\
\hline E, high, $1 \%$ & 3.17 & $13.09^{\mathrm{ab}}$ & 15.28 & $44.31^{\mathrm{ab}}$ & $0.55^{\mathrm{ab}}$ & $1.32^{\mathrm{a}}$ & 1.54 & $1.86^{\mathrm{b}}$ & 0.00 & 0.79 \\
\hline E, low, $2.5 \%$ & 3.16 & $13.20^{\mathrm{a}}$ & 15.57 & $41.17^{\text {bcde }}$ & $0.56^{\mathrm{a}}$ & $1.17^{\mathrm{c}}$ & 1.55 & $1.88^{\mathrm{b}}$ & 0.00 & 1.59 \\
\hline E, high, $2.5 \%$ & 3.18 & $13.06^{\mathrm{ab}}$ & 15.17 & $44.25^{\mathrm{ab}}$ & $0.55^{\mathrm{abc}}$ & $1.29^{\mathrm{ab}}$ & 1.54 & $1.91 \mathrm{a}^{\mathrm{b}}$ & 0.00 & 1.59 \\
\hline E, low, $4 \%$ & 3.18 & $13.12^{\mathrm{ab}}$ & 15.28 & $40.54^{\text {cde }}$ & $0.56^{\mathrm{a}}$ & $1.18^{\mathrm{c}}$ & 1.54 & $1.93^{\mathrm{ab}}$ & 0.79 & 0.79 \\
\hline E, high, $4 \%$ & 3.16 & $12.97^{\mathrm{ab}}$ & 15.00 & $43.80^{\mathrm{abcd}}$ & $0.55^{\mathrm{abc}}$ & $1.32^{\mathrm{a}}$ & 1.51 & $1.86^{\mathrm{b}}$ & 0.79 & 0.00 \\
\hline Positive Control $^{2}$ & 3.17 & $13.07^{\mathrm{ab}}$ & 15.30 & $41.19^{\text {bcde }}$ & $0.55^{\mathrm{ab}}$ & $1.17^{\mathrm{c}}$ & 1.54 & $1.96^{\mathrm{ab}}$ & 0.79 & 0.00 \\
\hline Tukey's HSD ${ }^{3}$ & - & 0.6055 & - & 3.646 & 0.028 & 0.104 & - & 0.09 & - & - \\
\hline SEM $^{4}$ & 0.009 & 0.126 & 0.187 & 0.753 & 0.132 & 0.021 & 0.017 & 0.019 & 0.055 & 1.05 \\
\hline \multicolumn{11}{|l|}{ Marginal Means } \\
\hline No Enzyme & 3.17 & 12.88 & 15.04 & 41.18 & 0.54 & 1.19 & 1.55 & 1.93 & 0.34 & 1.85 \\
\hline Enzyme & 3.17 & 13.08 & 15.25 & 44.34 & 0.55 & 1.31 & 1.53 & 1.90 & 0.53 & 0.66 \\
\hline $82^{\circ} \mathrm{C}$ & 3.17 & 13.06 & 15.24 & 43.15 & 0.55 & 1.25 & 1.54 & 1.92 & 0.57 & 1.06 \\
\hline High Temp & 3.17 & 12.89 & 15.06 & 42.37 & 0.54 & 1.25 & 1.55 & 1.90 & 0.26 & 1.46 \\
\hline $1 \% \mathrm{MAF}$ & 3.17 & 12.90 & 14.99 & 42.49 & 0.54 & 1.27 & 1.54 & 1.89 & 0.40 & 1.59 \\
\hline $2.5 \% \mathrm{MAF}$ & 3.17 & 12.99 & 15.26 & 43.45 & 0.55 & 1.23 & 1.55 & 1.93 & 0.16 & 1.19 \\
\hline $4 \% \mathrm{MAF}$ & 3.18 & 13.04 & 15.20 & 42.35 & 0.55 & 1.25 & 1.53 & 1.91 & 0.79 & 0.99 \\
\hline \multicolumn{11}{|l|}{ Probability $(>\mathrm{F})^{5}$} \\
\hline Treatment & 0.2801 & 0.0263 & 0.2362 & $<0.0001$ & 0.0003 & $<0.0001$ & 0.2693 & 0.0037 & 0.8131 & 0.3646 \\
\hline Enzyme & 0.6092 & 0.0081 & 0.8734 & $<0.0001$ & 0.0003 & $<0.0001$ & 0.1132 & 0.0018 & 0.4776 & 0.0295 \\
\hline Temperature & 0.2567 & 0.0172 & 0.4748 & 0.2538 & 0.0019 & 0.3872 & 0.2516 & 0.0800 & 0.4776 & 0.4175 \\
\hline Fat inclusion & 0.5928 & 0.3562 & 0.1090 & 0.3451 & 0.0785 & 0.1602 & 0.1075 & 0.0099 & 0.2237 & 0.7604 \\
\hline $\mathrm{E} \times \mathrm{T}$ & 0.8305 & 0.1040 & 0.3487 & 0.8101 & 0.1729 & 0.5502 & 0.1175 & 0.5568 & 0.3733 & 0.9812 \\
\hline Ex F & 0.6109 & 0.2105 & 0.0299 & 0.6203 & 0.0538 & 0.6742 & 0.5852 & 0.7776 & 0.7202 & 0.4073 \\
\hline $\mathrm{T} \times \mathrm{F}$ & 0.0248 & 0.5957 & 0.7529 & 0.9725 & 0.3896 & 0.8573 & 0.4721 & 0.9968 & 0.6154 & 0.2283 \\
\hline Ex T x F & 0.2718 & 0.2324 & 0.3577 & 0.4750 & 0.3377 & 0.8361 & 0.4598 & 0.0093 & 0.6484 & 0.8660 \\
\hline
\end{tabular}


${ }^{1} \mathrm{NE}=$ No Enzyme; $\mathrm{E}=$ Enzyme; low $=82^{\circ} \mathrm{C}$; high $=85^{\circ} \mathrm{C} ; 1 \%, 2.5 \%$ or $4 \%$ Mixer-added Fat $(\mathrm{MAF})$.

${ }^{2} \mathrm{NE}$, low, $2.5 \%$ formulated without enzyme matrix values.

${ }^{3}$ Honestly Significant Difference.

${ }^{4}$ Pooled standard error of the mean $(n=7)$.

${ }^{5} \mathrm{E}=$ Enzyme, $\mathrm{T}=$ Conditioning Temperature, $\mathrm{F}=\mathrm{MAF}$. 
Table 6. $38 \mathrm{~d}$ Broiler processing variables.

\begin{tabular}{|c|c|c|c|c|c|}
\hline Item & $\begin{array}{c}\text { Body } \\
\text { Weight, } \\
\text { kg }\end{array}$ & $\begin{array}{c}\text { Carcass } \\
\text { Yield, } \\
\%\end{array}$ & $\begin{array}{c}\text { Breast } \\
\text { Yield, } \\
\%\end{array}$ & $\begin{array}{c}\text { Leg } \\
\text { Yield, } \\
\%\end{array}$ & $\begin{array}{c}\text { Fat Pad } \\
\text { Yield, } \\
\%\end{array}$ \\
\hline \multicolumn{6}{|l|}{ Treatments $^{1}$} \\
\hline NE, low, $1 \%$ & 2.03 & 67.25 & 20.13 & 24.63 & $1.57^{\mathrm{ab}}$ \\
\hline NE, high, $1 \%$ & 2.01 & 65.78 & 20.34 & 23.57 & $1.52^{\mathrm{ab}}$ \\
\hline NE, low, $2.5 \%$ & 2.01 & 67.53 & 20.13 & 24.02 & $1.58^{\mathrm{ab}}$ \\
\hline NE, high, $2.5 \%$ & 1.99 & 66.49 & 20.31 & 22.93 & $1.55^{\mathrm{ab}}$ \\
\hline NE, low, $4 \%$ & 2.03 & 66.72 & 20.64 & 24.05 & $1.64^{\mathrm{ab}}$ \\
\hline NE, high, $4 \%$ & 2.02 & 67.49 & 21.05 & 24.38 & $1.26^{\mathrm{b}}$ \\
\hline E, low, $1 \%$ & 2.15 & 68.16 & 20.65 & 23.78 & $1.79^{\mathrm{a}}$ \\
\hline $\mathrm{E}$, high, $1 \%$ & 2.18 & 67.62 & 20.87 & 24.03 & $1.67^{\mathrm{ab}}$ \\
\hline E, low, $2.5 \%$ & 2.13 & 68.16 & 20.44 & 24.68 & $1.60^{\mathrm{ab}}$ \\
\hline E, high, $2.5 \%$ & 2.08 & 66.82 & 20.30 & 23.79 & $1.52^{\mathrm{ab}}$ \\
\hline $\mathrm{E}$, low, $4 \%$ & 2.13 & 67.54 & 20.22 & 23.90 & $1.49^{\mathrm{ab}}$ \\
\hline $\mathrm{E}$, high, $4 \%$ & 2.14 & 68.45 & 20.46 & 24.75 & $1.39^{\mathrm{ab}}$ \\
\hline $\begin{array}{l}\text { Positive } \\
\text { Control }^{2}\end{array}$ & 2.04 & 67.16 & 20.96 & 22.93 & $1.47^{\mathrm{ab}}$ \\
\hline Tukey's HSD ${ }^{3}$ & - & - & - & - & 0.463 \\
\hline $\mathrm{SEM}^{4}$ & - & 0.625 & 0.350 & 0.457 & 0.097 \\
\hline \multicolumn{6}{|l|}{ Marginal Means } \\
\hline No Enzyme & 2.02 & 67.07 & 20.43 & 23.93 & 1.52 \\
\hline Enzyme & 2.13 & 67.62 & 20.49 & 24.15 & 1.58 \\
\hline $82^{\circ} \mathrm{C}$ & 2.08 & 67.39 & 20.37 & 24.18 & 1.61 \\
\hline High Temp & 2.07 & 67.30 & 20.56 & 23.91 & 1.48 \\
\hline $1 \% \mathrm{MAF}$ & 2.09 & 66.94 & 20.50 & 24.01 & 1.64 \\
\hline $2.5 \% \mathrm{MAF}$ & 2.05 & 67.25 & 20.29 & 23.85 & 1.56 \\
\hline $4 \% \mathrm{MAF}$ & 2.08 & 67.84 & 20.59 & 24.27 & 1.45 \\
\hline
\end{tabular}




\begin{tabular}{llllll}
\cline { 1 - 1 } Treatment & - & 0.3961 & 0.4059 & 0.1000 & 0.0536 \\
Enzyme & - & 0.0425 & 0.4797 & 0.4005 & 0.3209 \\
Temperature & - & 0.4304 & 0.1843 & 0.3176 & 0.0260 \\
Fat inclusion & - & 0.3993 & 0.3882 & 0.4382 & 0.0282 \\
Ex T & - & 0.5256 & 0.8855 & 0.6000 & 0.6550 \\
Ex F & - & 0.5096 & 0.0683 & 0.8130 & 0.2456 \\
Tx F & - & 0.1872 & 0.8564 & 0.4531 & 0.3422 \\
Ex T x F & - & 0.1786 & 0.9304 & 0.0791 & 0.3952 \\
\hline
\end{tabular}

${ }^{\mathrm{T}} \mathrm{NE}=$ No Enzyme; $\mathrm{E}=$ Enzyme; low $=82^{\circ} \mathrm{C}$; high $=85^{\circ} \mathrm{C} ; 1 \%, 2.5 \%$ or $4 \%$

Mixer-added Fat (MAF).

${ }^{2} \mathrm{NE}$, low, $2.5 \%$ formulated without enzyme matrix values.

${ }^{3}$ Honestly Significant Difference.

${ }^{4}$ Pooled standard error of the mean $(n=7)$.

${ }^{5} \mathrm{E}=$ Enzyme, $\mathrm{T}=$ Conditioning Temperature, $\mathrm{F}=\mathrm{MAF}$.

John

$\mathrm{H}$.

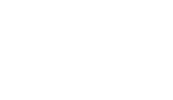

Hagen 